\title{
Costs and Cost Effectiveness of Additive Manufacturing
}

\author{
A Literature Review and Discussion
}

Douglas S. Thomas and Stanley W. Gilbert
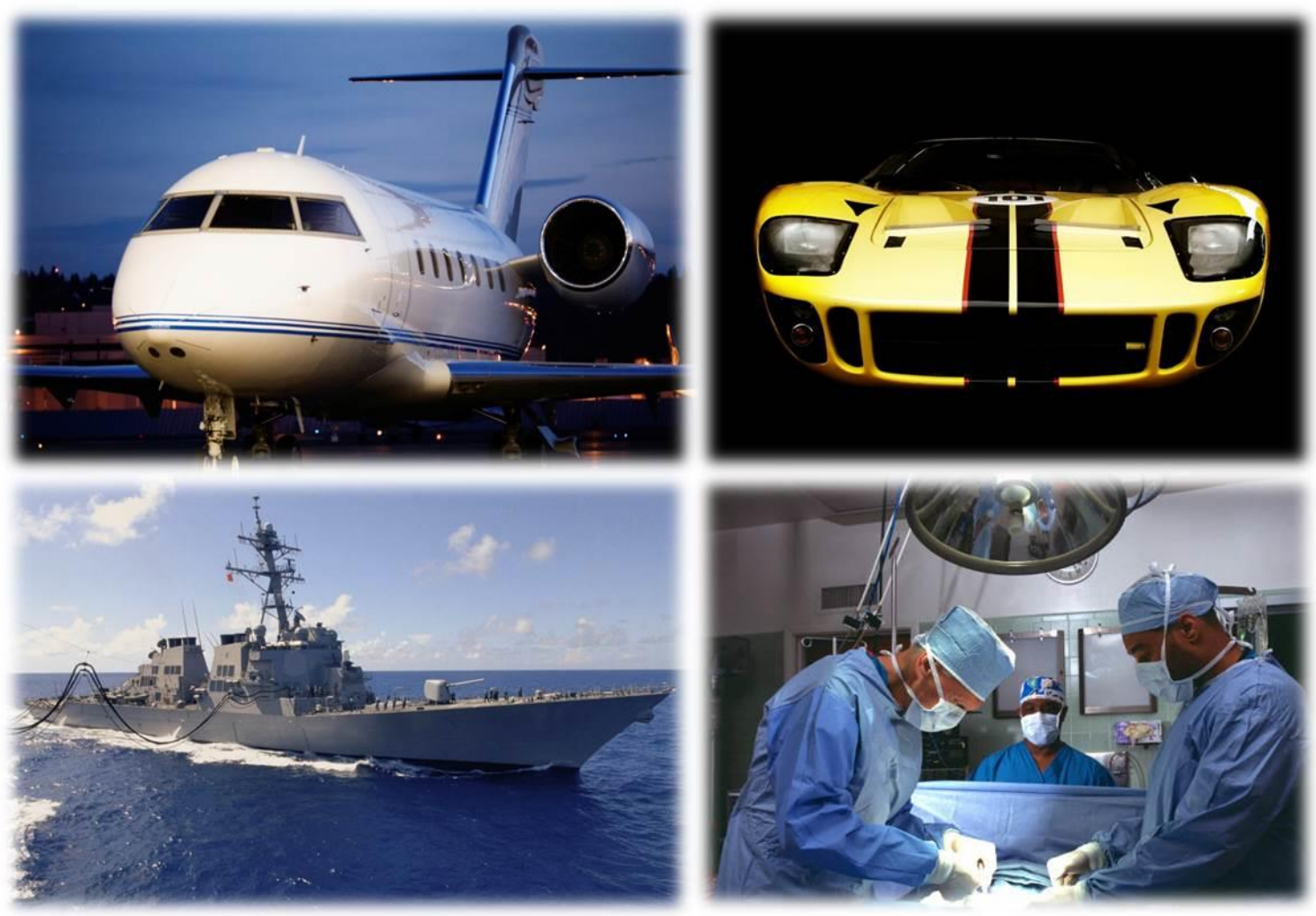

This publication is available free of charge from: http://dx.doi.org/10.6028/NIST.SP.1176

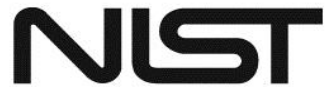

National Institute of Standards and Technology U.S. Department of Commerce 

NIST Special Publication 1176

\title{
Costs and Cost Effectiveness of Additive Manufacturing
}

\section{A Literature Review and Discussion}

\author{
Douglas S. Thomas \\ Stanley W. Gilbert \\ Applied Economics Office \\ Engineering Laboratory
}

This publication is available free of charge from: http://dx.doi.org/10.6028/NIST.SP.1176

December 2014

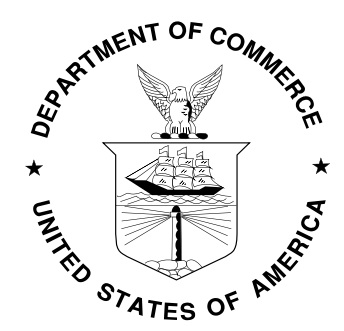

U.S. Department of Commerce

Penny Pritzker, Secretary

National Institute of Standards and Technology Willie May, Acting Under Secretary of Commerce for Standards and Technology and Acting Director 



\section{Abstract}

The use of additive manufacturing has increased significantly in previous years. Additive manufacturing is used by multiple industry subsectors, including motor vehicles, aerospace, machinery, electronics, and medical products. Currently, however, additive manufactured products represent less than one percent of all manufactured products in the U.S. As the costs of additive manufacturing systems decrease, this technology may change the way that consumers interact with producers. Additive manufacturing technology opens up new opportunities for the economy and society. It can facilitate the customized production of strong light-weight products and it allows designs that were not possible with previous manufacturing techniques. Various challenges, however, can impede and slow the adoption of this technology. In many instances, the cost of producing a product using additive manufacturing processes exceeds that of traditional methods. This report examines literature on the costs of additive manufacturing and seeks to identify those instances where additive manufacturing might be cost effective and also identify potential means for reducing costs when using this technology. Current research on additive manufacturing costs reveals that this technology is cost effective for manufacturing small batches with continued centralized manufacturing; however, with increased automation distributed production may become cost effective. Due to the complexities of measuring additive manufacturing costs, current studies are limited in their scope. Many of the current studies examine the production of single parts. Those that examine assemblies tend not to examine supply chain effects such as inventory and transportation costs along with decreased risk to supply disruption. Currently, research also reveals that material costs constitute a major proportion of the cost of a product produced using additive manufacturing. However, technologies can often be complementary, where two technologies are adopted alongside each other and the benefits are greater than if they were adopted individually. Increasing adoption of additive manufacturing may lead to a reduction in raw material cost through economies of scale. The reduced cost in raw material might then propagate further adoption of additive manufacturing. There may also be economies of scale in raw material costs if particular materials become more common rather than a plethora of different materials. The additive manufacturing system is also a significant cost factor; however, this cost has continually decreased. Between 2001 and 2011 the average price decreased $51 \%$ after adjusting for inflation.

Keywords: Additive manufacturing; manufacturing; 3D printing; supply chain; technology diffusion 


\section{Preface}

This study was conducted by the Applied Economics Office in the Engineering Laboratory at the National Institute of Standards and Technology. The study provides aggregate manufacturing industry data and industry subsector data to develop a quantitative depiction of the U.S. additive manufacturing industry.

\section{Disclaimer}

Certain trade names and company products are mentioned in the text in order to adequately specify the technical procedures and equipment used. In no case does such identification imply recommendation or endorsement by the National Institute of Standards and Technology, nor does it imply that the products are necessarily the best available for the purpose.

\section{Cover Photographs Credits}

Microsoft Clip Art Gallery Images used in compliance with Microsoft Corporation's non-commercial use policy. 


\section{Acknowledgements}

The author wishes to thank all those who contributed so many excellent ideas and suggestions for this report. Special appreciation is extended to Kevin Jurrens of the Engineering Laboratory's Intelligent Systems Division for his technical guidance, suggestions, and support. Special appreciation is also extended to Dr. David Butry and Dr. Robert Chapman of the Engineering Laboratory's Applied Economics Office for their thorough reviews and many insights and to Ms. Shannon Takach for her assistance in preparing the manuscript for review and publication. The author also wishes to thank Dr. Nicos Martys, Materials and Structural Systems Division, for his review. 


\section{Table of Contents}

ABSTRACT PREFACE

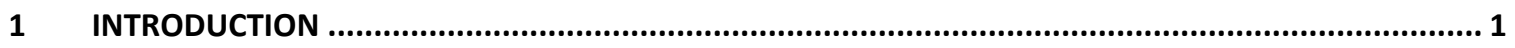

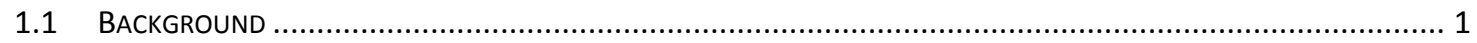

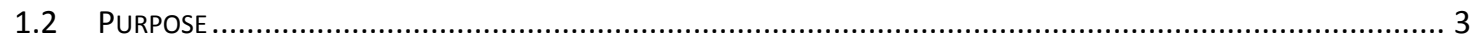

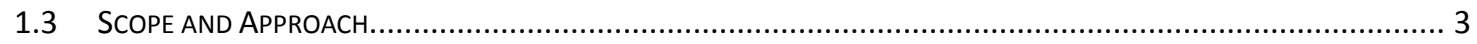

2 ADDITIVE MANUFACTURING PROCESSES, MATERIALS, AND LITERATURE..................................... 5

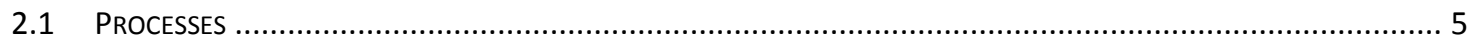

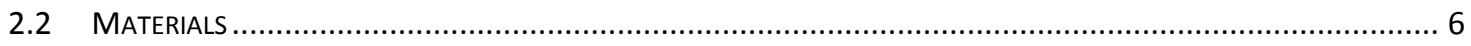

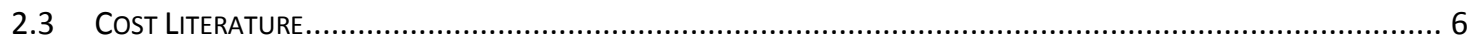

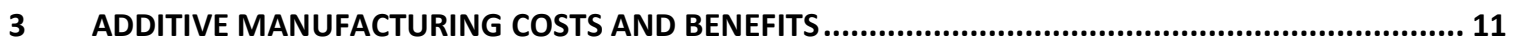

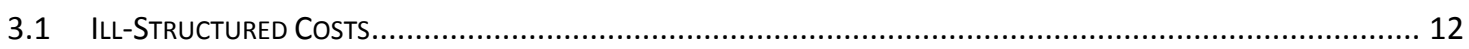

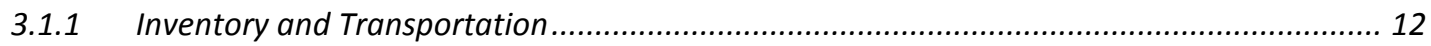

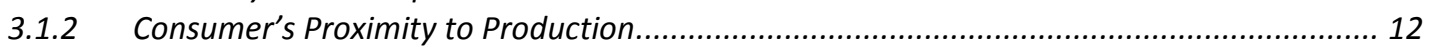

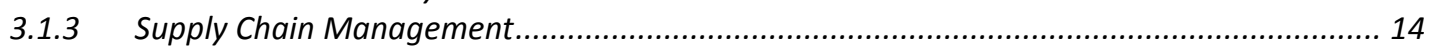

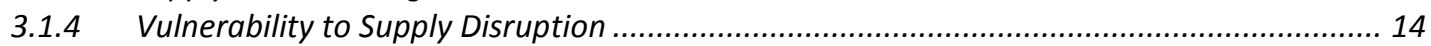

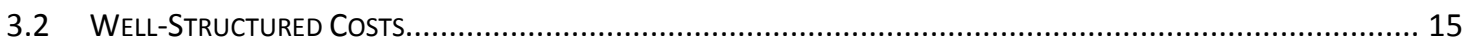

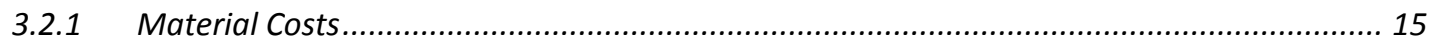

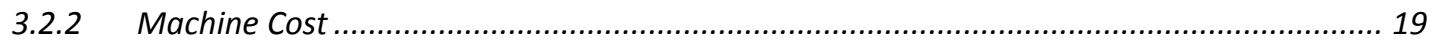

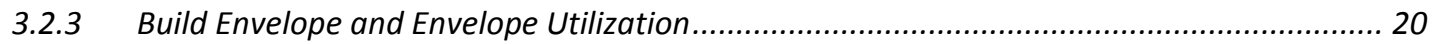

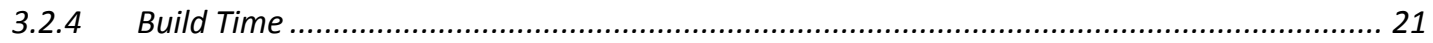

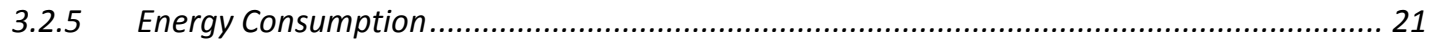

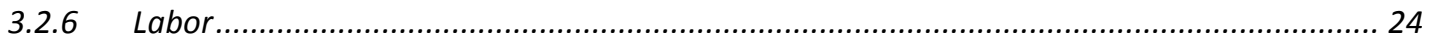

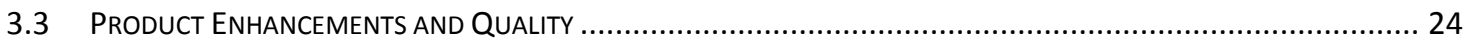

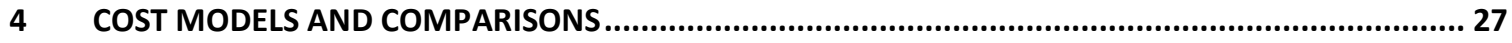

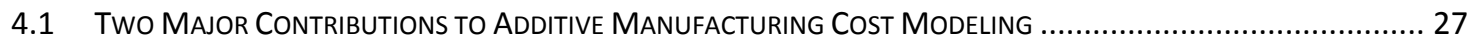

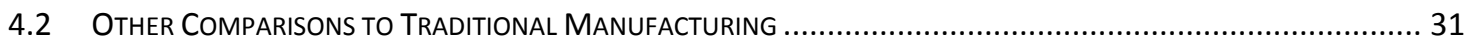

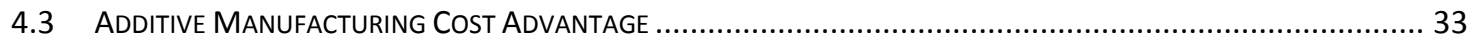

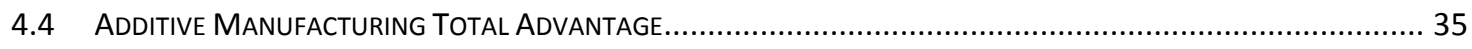

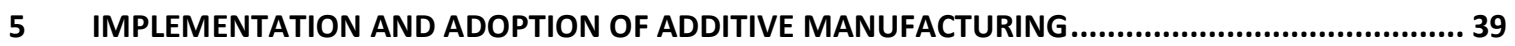

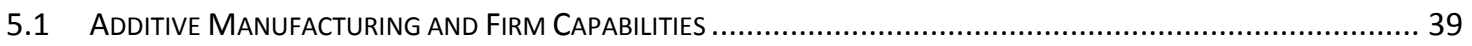

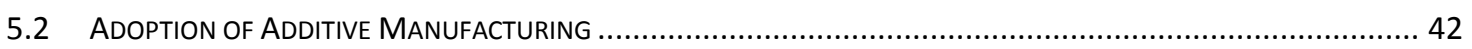

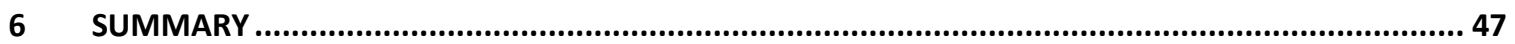




\section{List of Figures}

Figure 3.1: Example of Traditional Manufacturing Flow....

Figure 3.2: Example of Traditional Supply Chain Compared to the Supply Chain for

Additive Manufacturing with Localized Production .......................................... 15

Figure 3.3: Cost Distribution of Additive Manufacturing of Metal Parts by varying

Factors

Figure 3.4: Cost Comparison of Injection Molding and Additive Manufacturing for a

Selected Product, Atzeni et al. (2010) .................................................................. 18

Figure 3.5: Cost Breakout, Hopkinson and Dickens (2003) .......................................... 20

Figure 3.6: Cost Comparison for Selective Laser Sintering ........................................ 21

Figure 3.7: Energy Consumption per kg Deposited (Baumers et al. 2011) ..................... 23

Figure 3.8: Energy Consumption, Magnol, Lepicart, and Perry (2006) ......................... 23

Figure 3.9: Energy Efficiency of Selective Laser Sintering, Cassandra and Seepersad

(2012), megajoules......................................................................................... 25

Figure 4.1: Hopkinson and Dickens (2003) Cost Model Compared to Injection Molding

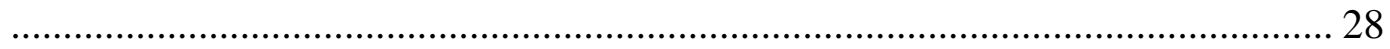

Figure 4.2: Ruffo, Tuck, and Hague Cost Model ..................................................... 29

Figure 4.3: Cost Model Comparison (Ruffo, Tuck, and Hague vs. Hopkinson and

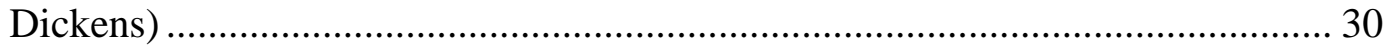

Figure 4.4: Breakeven Point for High-Pressure Die-Casting and Selective Laser Sintering, Atzeni and Salmi (2011) ...................................................................................... 32

Figure 4.5: Time and Labor Needed to Produce a Manufactured Product ....................... 36

Figure 4.6: Time, Labor, and Natural Resources Needed to Produce a Manufactured

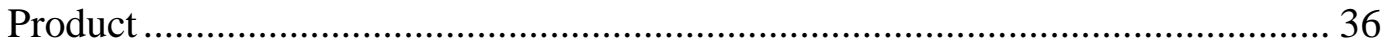

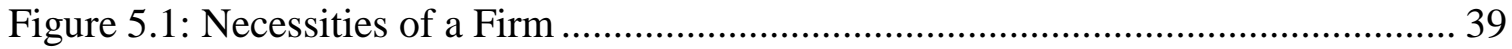

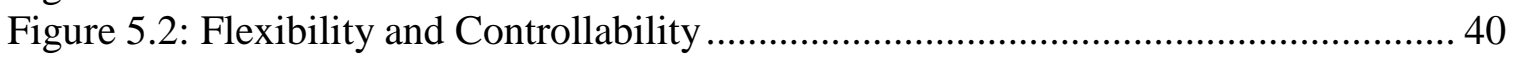

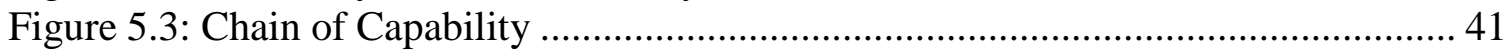

Figure 5.4: Forecasts of U.S. Additive Manufacturing Shipments, by Varying Market

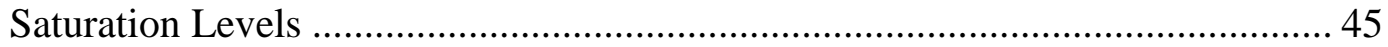

\section{List of Tables}

Table 1.1: Additive Manufacturing Shipments, 2011 .................................................... 2

Table 2.1: Additive Manufacturing Process and Material Combinations........................... 6

Table 2.2: Literature on the Costs of Additive Manufacturing ....................................... 8

Table 2.3: Literature on the Build Time of Additive Manufacturing ............................... 9

Table 2.4: Literature on the Energy Consumption of Additive Manufacturing ............... 10

Table 3.1: Cost Breakout, Hopkinson and Dickens (2003) ........................................... 19

Table 4.1: Indirect Cost Activities (Ruffo, Tuck, and Hague 2006a)............................ 29

Table 4.2: Production Costs Compared, Atzeni and Salmi (2011) ................................. 32

Table 5.1: Forecasts of U.S. Additive Manufacturing Shipments by Varying Market

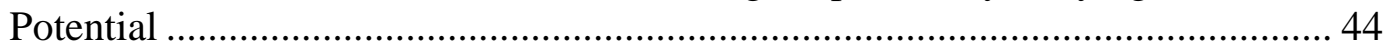




\section{Introduction}

\subsection{Background}

In 2011, the world produced approximately \$11.3 trillion in manufacturing value added, according to United Nations Statistics Division (UNSD) data. The U.S. produced approximately $17 \%$ of these goods, making it the second largest manufacturing nation in the world, down from being the largest in 2009. Many products and parts made by the industry are produced by taking pieces of raw material and cutting away sections to create the desired part or by injecting material into a mold; however, a relatively new process called additive manufacturing is beginning to take hold where material is aggregated together rather than formed in a mold or cut away. Additive manufacturing is the process of joining materials to make objects from three-dimensional (3D) models layer by layer as opposed to subtractive methods that remove material. The terms additive manufacturing and 3D printing tend to be used interchangeably to describe the same approach to fabricating parts. This technology is used to produce models, prototypes, patterns, components, and parts using a variety of materials including plastic, metal, ceramics, glass, and composites. Products with moving parts can be printed such that the pieces are already assembled. Technological advances have even resulted in a 3D-Bioprinter that one day might create body parts on demand. ${ }^{1,2}$

Additive manufacturing is used by multiple industry subsectors, including motor vehicles, aerospace, machinery, electronics, and medical products. ${ }^{3}$ This technology dates back to the 1980's with the development of stereolithography, which is a process that solidifies layers of liquid polymer using a laser. The first additive manufacturing system available was the SLA-1 by 3D Systems. Technologies that enabled the advancement of additive manufacturing were the desktop computer and the availability of industrial lasers.

Although additive manufacturing allows the manufacture of customized and increasingly complex parts, the slow print speed of additive manufacturing systems limits their use for mass production. Additionally, 3D scanning technologies have enabled the replication of real objects without using expensive molds. As the costs of additive manufacturing systems decrease, this technology may change the way that consumers interact with producers. The customization of products will require increased data collection from the end user. Additionally, an inexpensive 3D printer allows the end user to produce polymer-based products in their own home or office. Currently, there are a number of polymer systems that are within the budget of the average consumer.

\footnotetext{
${ }^{1}$ Economist. "Printing Body Parts: Making a Bit of Me." <http://www.economist.com/node/15543683>

${ }^{2}$ Quick 2009.. "3D Bio-printer to Create Arteries and Organs." $<$ http://www.gizmag.com/3d-bioprinter/13609/>

${ }^{3}$ Wohlers, Terry. "Wohlers Report 2012: Additive Manufacturing and 3D Printing State of the Industry." Wohlers Associates, Inc. 2012.
} 
Globally, an estimated $\$ 967$ million in revenue was collected for additive manufactured goods ${ }^{4}$ with the U.S. accounting for an estimated $\$ 367$ million or $38 \%$ of global production in 2013. ${ }^{5}$ Table 1.1 provides a comparison of additive manufactured products and total industry production for 2011. Additive manufactured products are categorized as being in the following sectors: motor vehicles; aerospace; industrial/business machines; medical/dental; government/military; architectural; and consumer products/electronics, academic institutions, and other. The consensus among wellrespected industry experts is that the penetration of the additive manufacturing market was $8 \%$ in $2011 ;^{6}$ however, as seen in Table 1.1 , goods produced using additive manufacturing methods represent between $0.01 \%$ and $0.05 \%$ of their relevant industry subsectors. Thus, additive manufacturing has sufficient room to grow.

Table 1.1: Additive Manufacturing Shipments, 2011

\begin{tabular}{|c|c|c|c|c|c|}
\hline Category & Relevant NAICS Codes & $\begin{array}{l}\text { Percent of } \\
\text { Total AM Made } \\
\text { Products }\end{array}$ & $\begin{array}{l}\text { Shipments of } \\
\text { US Made AM } \\
\text { Products } \\
\text { (\$millions, } \\
2011)^{*}\end{array}$ & $\begin{array}{l}\text { Total } \\
\text { Shipments } \\
\text { (\$millions, } \\
\text { 2011) }\end{array}$ & $\begin{array}{l}\text { AM Share } \\
\text { of Industry } \\
\text { Shipments }\end{array}$ \\
\hline Motor vehicles & NAICS 3361, 3362, 3363 & $19.5 \%$ & 48.0 & 445289.4 & $0.01 \%$ \\
\hline Aerospace & $\begin{array}{l}\text { NAICS } 336411,336412 \\
\quad 336413\end{array}$ & $12.1 \%$ & 29.8 & 157700.7 & $0.02 \%$ \\
\hline Industrial/business machines & NAICS 333 & $10.8 \%$ & 26.6 & 365734.8 & $0.01 \%$ \\
\hline Medical/dental & NAICS 3391 & $15.1 \%$ & 37.2 & 89519.5 & $0.04 \%$ \\
\hline Government/military & $\begin{array}{c}\text { NAICS } 336414,336415 \\
336419,336992\end{array}$ & $6.0 \%$ & 14.8 & 32784.4 & $0.05 \%$ \\
\hline Architectural & NAICS 3323 & $3.0 \%$ & 7.4 & 72186.9 & $0.01 \%$ \\
\hline $\begin{array}{l}\text { Consumer products/electronics, } \\
\text { academic institutions, and other }\end{array}$ & $\begin{array}{c}\text { All other within NAICS } \\
332 \text { through } 339 \\
\end{array}$ & $33.6 \%$ & 82.7 & 895709.8 & $0.01 \%$ \\
\hline $\begin{array}{l}\text { TOTAL } \\
* \text { These values are calculated assuming } \\
\text { for the U.S. as it is globally. It is also as } \\
\text { products }\end{array}$ & $\begin{array}{l}\text { NAICS } 332 \text { through } 339 \\
\text { nat the percent of total ad } \\
\text { ned that the U.S. share of }\end{array}$ & $\begin{array}{l}100.0 \% \\
\text { ive manufacturin } \\
\text { M systems sold is }\end{array}$ & $\begin{array}{l}246.1 \\
\text { nade products } \\
\text { ual to the sha }\end{array}$ & $\begin{array}{l}2058925.5 \\
\text { r each industry } \\
\text { of revenue for }\end{array}$ & $\begin{array}{l}0.01 \% \\
\text { is the same } \\
\text { a }\end{array}$ \\
\hline
\end{tabular}

There have been three proposed alternatives for the diffusion of additive manufacturing. The first is considered by many to be the most extreme where a significant proportion of consumers purchase additive manufacturing systems or 3D printers and produce products themselves. ${ }^{7}$ The second is a copy shop scenario, where individuals submit their designs to a service provider that produces it. ${ }^{8}$ Both of these scenarios are considered by many to

\footnotetext{
${ }^{4}$ Wohlers, Terry. "Wohlers Report 2014: Additive Manufacturing and 3D Printing State of the Industry." Wohlers Associates, Inc. 2014: 129.

5 This value is calculated with the assumption that the U.S. share of additive manufacturing systems sold equates to the share of products produced using additive manufacturing systems. The share of additive manufacturing systems is available in Wohlers, Terry. "Wohlers Report 2012: Additive Manufacturing and 3D Printing State of the Industry." Wohlers Associates, Inc. 2012: 134.

${ }^{6}$ Wohlers, Terry. "Wohlers Report 2012: Additive Manufacturing and 3D Printing State of the Industry." Wohlers Associates, Inc. 2012: 130.

${ }^{7}$ Neef, Andreas, Klaus Burmeister, Stefan Krempl. 2005. Vom Personal Computer zum Personal Fabricator (From Personal Computer to Personal Fabricator). Hamburg: Murmann Verlag.

${ }^{8}$ Neef, Andreas, Klaus Burmeister, Stefan Krempl. 2005. Vom Personal Computer zum Personal

Fabricator (From Personal Computer to Personal Fabricator). Hamburg: Murmann Verlag.
} 
be somewhat less likely. ${ }^{9}$ The third scenario involves additive manufacturing being adopted by the commercial manufacturing industry, changing the technology of design and production. Additive manufacturing is seen as a practical alternative for commercial manufacturing in high wage economies, making it an opportunity for advancing U.S. manufacturing while maintaining and advancing U.S. innovation.

The U.S. is currently a major user of additive manufacturing technology and the primary producer of additive manufacturing systems. Approximately $62.8 \%$ of all commercial/industrial units sold in 2011 were made by the top three producers of additive manufacturing systems: Stratasys, Z Corporation, and 3D Systems based out of the United States. ${ }^{10}$ Approximately $64.4 \%$ of all systems were made by companies based in the United States. If additive manufacturing has a saturation level between $5 \%$ and $35 \%$ of the relevant sectors, it is forecasted that it might reach $50 \%$ of market potential between 2031 and 2038, while reaching near $100 \%$ between 2058 and 2065. The industry would reach $\$ 50$ billion between 2029 and 2031, while reaching $\$ 100$ billion between 2031 and 2044. ${ }^{11}$

\subsection{Purpose}

Additive manufacturing technology opens up new opportunities for the economy and society. It can facilitate the production of strong light-weight products for the aerospace industry and it allows designs that were not possible with previous manufacturing techniques. It may revolutionize medicine with biomanufacturing. This technology has the potential to increase the well-being of U.S. citizens and improve energy efficiency in ground and air transportation. However, the adoption and diffusion of this new technology is not instantaneous. With any new technology, new standards, knowledge, and infrastructure are required to facilitate its use. Organizations such as the National Institute of Standards and Technology can enable the development of these items; thus, it is important to understand the costs and benefits of the additive manufacturing industry. This report examines literature on the costs of additive manufacturing and seeks to identify areas where it maintains a cost advantage and identify potential areas for cost reductions.

\subsection{Scope and Approach}

This report focuses on the costs of additive manufacturing; however, many of the advantages of additive manufacturing may lie in improvements of the finished good. Therefore, there is some discussion on the product improvements that result from additive manufacturing technologies. Section 2 provides an overview of the processes

\footnotetext{
${ }^{9}$ Baumers, Martin. "Economic Aspects of Additive Manufacturing: Benefits, Costs, and Energy Consumption." 2012. Doctoral Thesis. Loughborough University.

${ }^{10}$ 3D Systems purchased Z Corporation in 2012. Stratasys merged with Objet in 2012 and is now incorporated in Israel.

${ }^{11}$ Thomas, Douglas S. Economics of the U.S. Additive Manufacturing Industry. NIST Special Publication 1163. 2013. <http://www.nist.gov/manuscript-publication-search.cfm?pub_id=913515>
} 
and materials used in additive manufacturing. It also discusses the literature on additive manufacturing costs and categorizes them by their process and material combination. Section 3 provides a discussion and examination of the costs and benefits of additive manufacturing. It is broken into ill-structured costs, well-structured costs, and product enhancements and quality. Section 4 provides an examination of the cost models used to examine additive manufacturing. Section 5 provides a discussion on the trends in implementation and adoption of additive manufacturing. 


\section{Additive Manufacturing Processes, Materials, and Literature}

There are a number of additive manufacturing processes; however, at first glance it may appear that there are more types than in actuality. Many companies have created unique system and material names in order to differentiate themselves, which has created some confusion. Fortunately, there has been some effort to categorize the processes and materials using standard methods. The categorization and descriptions of processes and materials below relies heavily on Wohlers (2012) and ASTM International Standards. ${ }^{12}$

\subsection{Processes}

The total global revenue from additive manufacturing system sales was $\$ 502.5$ million with U.S. revenue estimated at $\$ 323.6$ million. These systems are categorized into various different processes. ASTM International Committee F42.91 on Additive Manufacturing Technologies has developed standard terminologies. Provided below are the categories and adapted definitions from the ASTM F2792 standard:

Binder Jetting: This process uses liquid bonding agent deposited using an inkjet-print head to join powder materials in a powder bed.

Directed Energy Deposition: This process utilizes thermal energy, typically from a laser, to fuse materials by melting them as they are deposited.

Material Extrusion: These machines push material, typically a thermoplastic filament, through a nozzle onto a platform that moves in horizontal and vertical directions.

Material Jetting: This process, typically, utilizes a moving inkjet-print head to deposit material across a build area.

Powder Bed Fusion: This process uses thermal energy from a laser or electron beam to selectively fuse powder in a powder bed.

Sheet Lamination: This process uses sheets of material bonded to form a threedimensional object.

Vat Photopolymerization: These machines selectively cure a liquid photopolymer in a vat using light.

\footnotetext{
${ }^{12}$ Wohlers, Terry. "Wohlers Report 2012: Additive Manufacturing and 3D Printing State of the Industry." Wohlers Associates, Inc. 2012.
} 


\subsection{Materials}

Approximately $\$ 327.1$ million was spent globally on materials for additive manufacturing in 2011. ${ }^{13}$ There are two primary types of materials: plastics and metals. There are also ceramics, composites, and other materials that are used as well, but are not as common. Wohlers groups the materials into eight categories:

Polymers and polymer blends

Composites

Metals

Graded/hybrid metals

Ceramics

Investment casting patterns

Sand molds and cores

Paper

Certain processes lend themselves to certain materials. Table 2.1 presents the combinations of additive manufacturing processes and their corresponding materials. The combinations that are left blank are material/process combinations that are not currently utilized.

Table 2.1: Additive Manufacturing Process and Material Combinations

\begin{tabular}{|c|c|c|c|c|c|c|c|}
\hline & $\begin{array}{l}\text { Material } \\
\text { extrusion }\end{array}$ & $\begin{array}{l}\text { Material } \\
\text { jetting }\end{array}$ & $\begin{array}{l}\text { Binder } \\
\text { jetting }\end{array}$ & $\begin{array}{l}\text { Vat } \\
\text { photopoly- } \\
\text { merization }\end{array}$ & $\begin{array}{c}\text { Sheet } \\
\text { lamination }\end{array}$ & $\begin{array}{l}\text { Powder } \\
\text { bed fusion }\end{array}$ & $\begin{array}{c}\text { Directed } \\
\text { energy } \\
\text { deposition }\end{array}$ \\
\hline Polymers and polymer blends & $x$ & $x$ & $x$ & $x$ & $x$ & $x$ & \\
\hline Composites & & $x$ & $x$ & $x$ & & $x$ & \\
\hline Graded/hybrid metals & & & & & $x$ & & $x$ \\
\hline Ceramics & & & $x$ & $x$ & & $x$ & \\
\hline Investment casting patterns & & $x$ & $x$ & $x$ & & $x$ & \\
\hline Sand molds and cores & $\mathrm{x}$ & & $x$ & & & $x$ & \\
\hline Paper & & & & & $x$ & & \\
\hline
\end{tabular}

Source: Wohlers, Terry. "Wohlers Report 2012: Additive Manufacturing and 3D Printing State of the Industry.” Wohlers Associates, Inc. 2012.

\subsection{Cost Literature}

There are two major motivational categories for examining additive manufacturing costs. The first is to compare additive manufacturing processes to other traditional processes such as injection molding and machining. The purpose of these types of examinations is

\footnotetext{
${ }^{13}$ Wohlers, Terry. "Wohlers Report 2012: Additive Manufacturing and 3D Printing State of the Industry." Wohlers Associates, Inc. 2012.
} 
to determine under what circumstances additive manufacturing is cost effective. The second category involves identifying resource use at various steps in the additive manufacturing process. The purpose of this type of analysis is to identify when and where resources are being consumed and whether there can be a reduction in resource use. Table 2.2 provides a literature list for cost studies on additive manufacturing categorized by the combinations of additive manufacturing processes and corresponding materials shown in Table 2.1. The areas in black are those areas that are not possible (i.e., they are the empty cells from Table 2.1) while those with an " $x$ " indicate possible combinations but no cost literature was identified. One column has been added to indicate studies that examine both additive manufacturing and traditional manufacturing. The documents listed in the table are heavily relied on for characterizing the costs of additive manufacturing. Two major components that affect costs are the build time and the energy consumption of additive manufacturing systems. Although these issues will not be discussed at significant length, a selection of literature is categorized in Table 2.3 and Table 2.4. 
Table 2.2: Literature on the Costs of Additive Manufacturing

\begin{tabular}{|c|c|c|c|c|c|c|c|c|}
\hline & $\begin{array}{l}\text { Material } \\
\text { extrusion }\end{array}$ & Material jetting & $\begin{array}{l}\text { Binder } \\
\text { jetting }\end{array}$ & $\begin{array}{l}\text { Vat photopoly- } \\
\text { merization }\end{array}$ & Sheet lamination & Powder bed fusion & $\begin{array}{l}\text { Directed } \\
\text { energy } \\
\text { deposition }\end{array}$ & $\begin{array}{l}\text { Additive Manufacturing } \\
\text { research that includes } \\
\text { Traditional } \\
\text { Manufacturing }\end{array}$ \\
\hline $\begin{array}{l}\text { Polymers, polymer } \\
\text { blends, and } \\
\text { composites }\end{array}$ & $\begin{array}{l}\text { T.A. Grimm } \\
\text { (2010)*; } \\
\text { Hopkinson and } \\
\text { Dickens (2003); } \\
\text { Hopkinson } \\
\text { (2006); Baumers } \\
\text { (2012) }\end{array}$ & $\begin{array}{l}\text { T.A. Grimm } \\
\text { (2010)* }\end{array}$ & $\begin{array}{l}\text { T.A. Grimm } \\
\text { (2010)* }\end{array}$ & $\begin{array}{c}\text { T.A. Grimm } \\
\text { (2010)*; } \\
\text { Hopkinson and } \\
\text { Dickens (2003); } \\
\text { Hopkinson } \\
\text { (2006); Li (2005) }\end{array}$ & T.A. Grimm (2010)* & $\begin{array}{l}\text { Ruffo, Tuck, and Hague } \\
\text { (2006a); Baldinger and } \\
\text { Duchi (2013); Ruffo and } \\
\text { Hague (2007); Hopkinson } \\
\text { and Dickens (2003); } \\
\text { Hopkinson (2006); } \\
\text { Baumers (2012); Zhang } \\
\text { and Bernard (2014); } \\
\text { Atzeni et al. (2010) }\end{array}$ & & $\begin{array}{c}\text { Hopkinson (2006); } \\
\text { Ruffo, Tuck, and Hague } \\
\text { (2006a); Ruffo and } \\
\text { Hague (2007); } \\
\text { Hopkinson and Dickens } \\
\text { (2003); Atzeni et al. } \\
\text { (2010); Li (2005) }\end{array}$ \\
\hline Metals & & $x$ & $x$ & & $x$ & $\begin{array}{l}\text { Rickenbacher (2013)*; } \\
\text { Baumers et al. (2012); } \\
\text { Baumers (2012); Baumers } \\
\text { et al (2013); Atzeni, } \\
\text { luliano and Salmi (2011); } \\
\text { Atzeni and Salmi (2012); } \\
\text { Lindemann et al. (2012); } \\
\text { Lindemann et al. (2013) }\end{array}$ & $x$ & Allen (2006) \\
\hline $\begin{array}{l}\text { Graded/hybrid } \\
\text { metals }\end{array}$ & & & & & $x$ & & $x$ & \\
\hline Ceramics & & & $x$ & $x$ & & $x$ & & \\
\hline $\begin{array}{l}\text { Investment } \\
\text { casting patterns }\end{array}$ & & $x$ & $x$ & $x$ & & $x$ & & \\
\hline $\begin{array}{l}\text { Sand molds and } \\
\text { cores }\end{array}$ & $x$ & & $x$ & & & $x$ & & \\
\hline Paper & & & & & $x$ & & & \\
\hline $\begin{array}{l}\text { Undesignated } \\
\text { Material }\end{array}$ & & & & & & Khajavi et al. (2014) & & \\
\hline
\end{tabular}

*3D Printing 
Table 2.3: Literature on the Build Time of Additive Manufacturing

\begin{tabular}{|c|c|c|c|c|c|c|c|c|c|}
\hline & $\begin{array}{l}\text { Material } \\
\text { extrusion }\end{array}$ & $\begin{array}{c}\text { Material } \\
\text { jetting }\end{array}$ & $\begin{array}{l}\text { Binder } \\
\text { jetting }\end{array}$ & $\begin{array}{l}\text { Vat photopoly- } \\
\text { merization }\end{array}$ & $\begin{array}{c}\text { Sheet } \\
\text { lamination }\end{array}$ & Powder bed fusion & $\begin{array}{l}\text { Directed } \\
\text { energy } \\
\text { deposition }\end{array}$ & $\begin{array}{l}\text { Undesignated } \\
\text { Process }\end{array}$ & $\begin{array}{c}\text { Additive } \\
\text { Manufacturing } \\
\text { research that } \\
\text { includes } \\
\text { Traditional } \\
\text { Manufacturing }\end{array}$ \\
\hline $\begin{array}{l}\text { Polymer, polymer } \\
\text { blend, and } \\
\text { composites }\end{array}$ & $\mathrm{x}$ & $\mathrm{x}$ & $\mathrm{x}$ & $\begin{array}{l}\text { Giannatsis et al. } \\
\text { (2001); Chen and } \\
\text { Sullivan (1996); } \\
\text { Campbell (2008) }\end{array}$ & $\mathrm{x}$ & $\begin{array}{l}\text { Choi and Samavedam } \\
\text { (2002); Ruffo et al. } \\
\text { (2006b); Munguia et al. } \\
\text { (2009); Zhang and } \\
\text { Bernard (2014); Kruth } \\
\text { et al. (2005) }\end{array}$ & & & \\
\hline Metals & & $\mathrm{x}$ & $\mathrm{x}$ & & $\mathrm{x}$ & $\begin{array}{l}\text { Rickenbacher et al. } \\
\text { (2013) }\end{array}$ & $x$ & & \\
\hline $\begin{array}{l}\text { Graded/hybrid } \\
\text { metals }\end{array}$ & & & & & $\mathrm{x}$ & & $x$ & & \\
\hline Ceramics & & & $\mathrm{x}$ & $\mathrm{x}$ & & $\mathrm{x}$ & & & \\
\hline $\begin{array}{l}\text { Investment } \\
\text { casting patterns }\end{array}$ & & $\mathrm{x}$ & $\mathrm{x}$ & $\mathrm{x}$ & & $x$ & & & \\
\hline $\begin{array}{l}\text { Sand molds and } \\
\text { cores }\end{array}$ & $x$ & & $x$ & & & $x$ & & & \\
\hline \multicolumn{10}{|l|}{ Paper } \\
\hline $\begin{array}{l}\text { Undesignated } \\
\text { Material }\end{array}$ & & & & & & & & $\begin{array}{l}\text { Di Angelo } \\
\text { and Di } \\
\text { Stefano } \\
\text { (2011) }\end{array}$ & \\
\hline
\end{tabular}


Table 2.4: Literature on the Energy Consumption of Additive Manufacturing

\begin{tabular}{|c|c|c|c|c|c|c|c|c|c|}
\hline & $\begin{array}{l}\text { Material } \\
\text { extrusion }\end{array}$ & $\begin{array}{c}\text { Material } \\
\text { jetting }\end{array}$ & $\begin{array}{l}\text { Binder } \\
\text { jetting }\end{array}$ & $\begin{array}{l}\text { Vat photopoly- } \\
\text { merization }\end{array}$ & $\begin{array}{c}\text { Sheet } \\
\text { lamination }\end{array}$ & Powder bed fusion & $\begin{array}{l}\text { Directed } \\
\text { energy } \\
\text { deposition }\end{array}$ & $\begin{array}{l}\text { Undesignated } \\
\text { Process }\end{array}$ & $\begin{array}{c}\text { Additive } \\
\text { Manufacturing } \\
\text { research that } \\
\text { includes } \\
\text { Traditional } \\
\text { Manufacturing }\end{array}$ \\
\hline $\begin{array}{l}\text { Polymers, polymer } \\
\text { blends, and } \\
\text { composites }\end{array}$ & $\begin{array}{l}\text { Mognol et al. } \\
\text { (2006); } \\
\text { Baumers } \\
\text { (2011); Luo et } \\
\text { al. (1999) }\end{array}$ & $x$ & $x$ & $\begin{array}{l}\text { Mognol et al. } \\
\text { (2006); Luo et al. } \\
\text { (1999) }\end{array}$ & $x$ & $\begin{array}{c}\text { Sreenivasan et al. (2009); } \\
\text { ATKINS (2007); Telenko } \\
\text { and Seepersad (2010); } \\
\text { Telenko and Seepersad } \\
\text { (2012); Paul and Anand } \\
\text { (2012); Kellens et al. } \\
\text { (2011);Verma and Rai; } \\
\text { Baumers (2011); } \\
\text { Sreenivasan and Bourell } \\
\text { (2009); Baumers et al. } \\
\text { (2010); ; Luo et al. (1999); } \\
\text { Kellens et al. (2010); } \\
\text { Sreenivasan et al. (2010) }\end{array}$ & & & $\begin{array}{l}\text { ATKINS (2007); } \\
\text { Telenko and } \\
\text { Seepersad } \\
\text { (2012) }\end{array}$ \\
\hline Metals & & $x$ & $x$ & & $x$ & $\begin{array}{c}\text { Baumers et al. (2012); } \\
\text { Baumers et al (2013); } \\
\text { Mognol et al. (2006); } \\
\text { Baumers (2011); } \\
\text { Sreenivasan et al. (2010) }\end{array}$ & $\begin{array}{l}\text { Morrow et al. } \\
\quad(2007)\end{array}$ & $\begin{array}{c}\text { ATKINS } \\
\text { Project (2007) }\end{array}$ & $\begin{array}{l}\text { ATKINS Project } \\
\text { (2007); } \\
\text { Morrow et al. } \\
\text { (2007) }\end{array}$ \\
\hline $\begin{array}{l}\text { Graded/hybrid } \\
\text { metals }\end{array}$ & & & & & $x$ & & $x$ & & \\
\hline Ceramics & & & $x$ & $x$ & & $x$ & & & \\
\hline $\begin{array}{l}\text { Investment } \\
\text { casting patterns }\end{array}$ & & $x$ & $x$ & $x$ & & $\mathrm{x}$ & & & \\
\hline $\begin{array}{l}\text { Sand molds and } \\
\text { cores }\end{array}$ & $x$ & & $x$ & & & $x$ & & & \\
\hline Paper & & & & & $x$ & & & & \\
\hline
\end{tabular}




\section{Additive Manufacturing Costs and Benefits}

As discussed by Young (1991), the costs of production can be categorized in two ways. ${ }^{14}$ The first involves those costs that are "well-structured" such as labor, material, and machine costs. The second involves "ill-structured costs" such as those associated with build failure, machine setup, and inventory. In the literature, there tends to be more focus on well-structured costs of additive manufacturing than ill-structured costs; however, some of the more significant benefits and cost savings in additive manufacturing may be hidden in the ill-structured costs. Moreover considering additive manufacturing in the context of lean production might be useful.

A key concept of lean manufacturing is the identification of waste, which is classified into seven categories:

1) Overproduction: occurs when more is produced than is currently required by customers

2) Transportation: transportation does not make any change to the product and is a source of risk to the product

3) Rework/Defects: discarded defects result in wasted resources or extra costs correcting the defect

4) Over-processing: occurs when more work is done than is necessary

5) Motion: unnecessary motion results in unnecessary expenditure of time and resources

6) Inventory: is similar to that of overproduction and results in the need for additional handling, space, people, and paperwork to manage extra product

7) Waiting: when workers and equipment are waiting for material and parts, these resources are being wasted

Additive manufacturing may impact a significant number of these categories. For example, additive manufacturing may significantly reduce the need for large inventory, which is a significant cost in manufacturing. In 2011, there was an average of $\$ 208$ billion or the equivalent of $14 \%$ of annual revenue held in inventory for mediumand high-tech manufacturing ${ }^{15}$ with an estimated cost of $\$ 52$ billion or $3 \%$ of revenue. $^{16}$ Reducing inventory frees up capital and reduces expenses. The following sections will attempt to discuss some of the potential savings and benefits of additive manufacturing as well as its costs.

\footnotetext{
${ }^{14}$ Young, Son K. “A Cost Estimation Model for Advanced Manufacturing Systems.” International Journal of Production Research. 1991. 29(3): 441-452.

${ }^{15}$ For this report, medium- and high-tech manufacturing includes NAICS 333 through 336, which includes machinery, computer, electronic product, electrical equipment, and transportation equipment manufacturing.

${ }^{16}$ It is assumed that the cost of holding inventory is $25 \%$ of the value of the inventory.
} 


\subsection{Ill-Structured Costs}

Many costs are hidden in the supply chain, which is a system that moves products from supplier to customer. Additive manufacturing may, potentially, have significant impacts on the design and size of this system, reducing its associated costs. ${ }^{17}$

\subsubsection{Inventory and Transportation}

Inventory: At the beginning of 2011, there were $\$ 537$ billion in inventories in the manufacturing industry, which was equal to $10 \%$ of that year's revenue. The resources spent producing and storing these products could have been used elsewhere if the need for inventory were reduced. Suppliers often suffer from high inventory and distribution costs. Additive manufacturing provides the ability to manufacture parts on demand. For example, in the spare parts industry, a specific type of part is infrequently ordered; however, when one is ordered, it is needed quite rapidly, as idle machinery and equipment waiting for parts is quite costly. Traditional production technologies make it too costly and require too much time to produce parts on demand. The result is a significant amount of inventory of infrequently ordered parts. ${ }^{18}$ This inventory is tied up capital for products that are unused. They occupy physical space, buildings, and land while requiring rent, utility costs, insurance, and taxes. Meanwhile the products are deteriorating and becoming obsolete. Being able to produce these parts on demand using additive manufacturing reduces the need for maintaining large inventory and eliminates the associated costs.

Transportation: Additive manufacturing allows for the production of multiple parts simultaneously in the same build, making it possible to produce an entire product. Traditional manufacturing often includes production of parts at multiple locations, where an inventory of each part might be stored. The parts are shipped to a facility where they are assembled into a product, as illustrated in Figure 3.1. Additive manufacturing has the potential to replace some of these steps for some products, as this process might allow for the production of the entire assembly. This would reduce the need to maintain large inventories for each part of one product. It also reduces the transportation of parts produced at varying locations and reduces the need for just-in-time delivery.

\subsubsection{Consumer's Proximity to Production}

As previously discussed, three alternatives have been proposed for the diffusion of additive manufacturing. The first is where a significant proportion of consumers purchase additive manufacturing systems or $3 \mathrm{D}$ printers and produce products themselves. ${ }^{19}$ The

\footnotetext{
${ }^{17}$ Reeves P. (2008) "How the Socioeconomic Benefits of Rapid Manufacturing can Offset Technological Limitations.” RAPID 2008 Conference and Exposition. Lake Buena Vista, FL: 1-12.

${ }^{18}$ Walter, Manfred, Jan Holmstrom and Hannu Yrjola. "Rapid Manufacturing and its Impact on Supply Chain Management." Logistics Research Network Annual Conference. September 9-10, 2004. Dublin, Ireland.

${ }^{19}$ Neef, Andreas, Klaus Burmeister, Stefan Krempl. 2005. Vom Personal Computer zum Personal Fabricator (From Personal Computer to Personal Fabricator). Hamburg: Murmann Verlag.
} 
Figure 3.1: Example of Traditional Manufacturing Flow

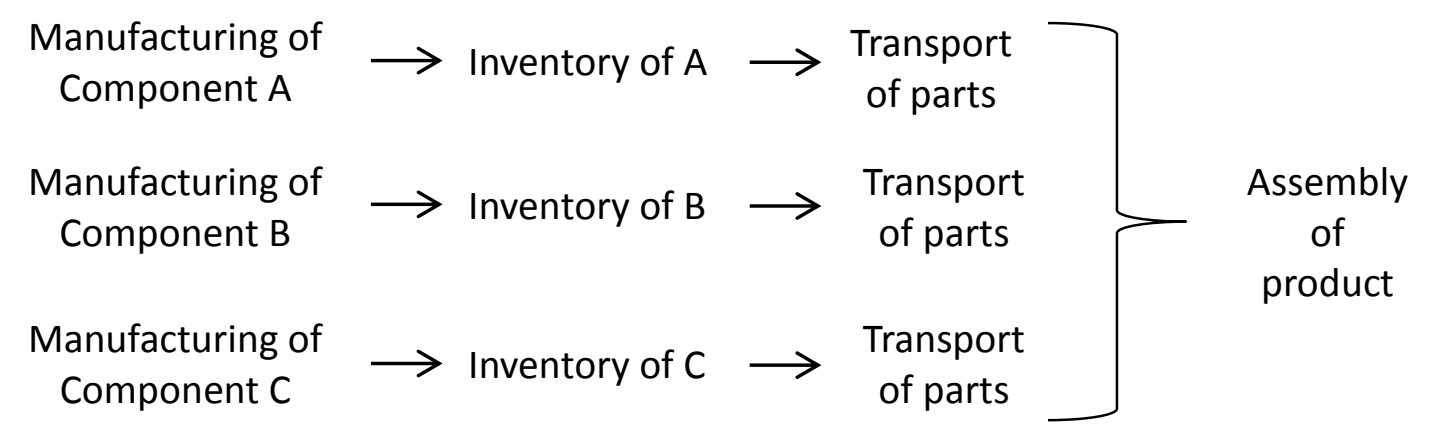

second is a copy shop scenario, where individuals submit their designs to a service provider that produces goods. ${ }^{20}$ The third scenario involves additive manufacturing being adopted by the commercial manufacturing industry, changing the technology of design and production. One might consider a fourth scenario. Because additive manufacturing can produce a final product in one build, there is limited exposure to hazardous conditions, and there is little hazardous waste ${ }^{21}$ there is the potential to bring production closer to the consumer for some products (i.e., distributed manufacture). For example, currently, a more remote geographic area may order automotive parts on demand, which may take multiple days to be delivered. Additive manufacturing might allow some of these parts or products to be produced near the point of use or even onsite. ${ }^{22}$ Further, localized production combined with simplified processes may begin to blur the line between manufacturers, wholesalers, and retailers as each could potentially produce products in their facilities.

Khajavi et al. (2014) compare the operating cost of centralized additive manufacturing production and distributed production, where production is in close proximity to the consumer. ${ }^{23}$ This analysis examined the production of spare parts for the air-cooling ducts of the environmental control system for the F-18 Super Hornet fighter jet, which is a well-documented instance where additive manufacturing has already been implemented. The expected total cost per year for centralized production was $\$ 1.0$ million and $\$ 1.8$ million for distributed production. Inventory obsolescence cost, initial inventory production costs, inventory carrying costs, and spare parts transportation costs are all reduced for distributed production; however, significant increases in personnel costs and the initial investment in additive manufacturing machines make it

\footnotetext{
${ }^{20}$ Neef, Andreas, Klaus Burmeister, Stefan Krempl. 2005. Vom Personal Computer zum Personal Fabricator (From Personal Computer to Personal Fabricator). Hamburg: Murmann Verlag.

${ }^{21}$ Huang, Samuel H., Peng Liu, Abhiram Mokasdar. 2013 "Additive Manufacturing and Its Societal Impact: A Literature Review.” International Journal of Advanced Manufacturing Technology. 67: 11911203.

${ }^{22}$ Holmstrom, Jan, Jouni Partanen, Jukka Tuomi, and Manfred Walter. "Rapid Manufacturing in the Spare Parts Supply Chain: Alternative Approaches to Capacity Deployment." Journal of Manufacturing Technology Management. 2010. 21(6) 687-697.

${ }^{23}$ Khajavi, Siavash H., Jouni Partanen, Jan Holmstrom. 2014 "Additive Manufacturing in the Spare Parts Supply Chain.” Computers in Industry. 65: 50-63.
} 
more expensive than centralized production. Increased automation and reduced machine costs are needed for this scenario to be cost effective. It is also important to note that this analysis examined the manufacture of a relatively simple component with little assembly. One potential benefit of additive manufacturing might be to produce an assembled product rather than individual components. Research by Holmström et al. (2010), which also examines spare parts in the aircraft industry, concurs that, currently, on demand centralized production of spare parts is the most likely approach to succeed; however, if additive manufacturing develops into a widely adopted process, the distributed approach becomes more feasible. ${ }^{24}$

\subsubsection{Supply Chain Management}

The supply chain includes purchasing, operations, distribution, and integration. Purchasing involves sourcing product suppliers. Operations involve demand planning, forecasting, and inventory. Distribution involves the movement of products and integration involves creating an efficient supply chain. ${ }^{25}$ Reducing the need for these activities can result in a reduction in costs. Some large businesses and retailers largely owe their success to the effective management of their supply chain. They have used technology to innovate the way they track inventory and restock shelves resulting in reduced costs. Walmart, for example, cut links in the supply chain, making the link between their stores and the manufacturers more direct. It also began vender managed inventory (VMI), where manufacturers were responsible for managing their products in Walmart's warehouses. It advanced its communication and collaboration network. The management of the supply chain can be the factor that drives a company to market leadership. Additive manufacturing may have significant impacts on the manufacturing supply chain, reducing the need for supply chain management. This technology has the potential to bring manufacturers closer to consumers, reducing the links in the supply chain.

\subsubsection{Vulnerability to Supply Disruption}

If additive manufacturing reduces the number of links in the supply chain and brings production closer to consumers, it will result in a reduction in the vulnerability to disasters and disruptions. Every factory and warehouse in the supply chain for a product is a potential point where a disaster or disruption can stop or hinder the production and delivery of a product. A smaller supply chain with fewer links means there are fewer points for potential disruption. Additionally, if production is brought closer to consumers it will result in more decentralized production where many facilities are producing a few products rather than a few facilities producing many products. Disruptions in the supply chain might result in localized impacts rather than regional or national impacts. Figure 3.2 provides an example that compares traditional manufacturing to additive manufacturing. Under traditional manufacturing, material resource providers deliver to

\footnotetext{
${ }^{24}$ Holmström, Jan, Jouni Partanen, Jukka Tuomi, and Manfred Walter. 2010. "Rapid Manufacturing in the Spare Parts Supply Chain: Alternative Approaches to Capacity Deployment." Journal of Manufacturing Technology. 21(6): 687-697.

${ }^{25}$ University of San Francisco. Walmart: Keys to Successful Supply Chain Management. $<$ http://www.usanfranonline.com/resources/supply-chain-management/walmart-keys-to-successful-supplychain-management/\#.U5IDQfldXzg>
} 
the manufacturers of parts and components, who might deliver parts and components to each other and then to an assembly plant. From there the assembled product is delivered to a retailer or distributer. A disruption at any of the points in manufacturing or assembly may result in a disruption of deliveries to all the retailers or distributers if there is not redundancy in the system. Additive manufacturing with localized production does not have the same vulnerability. First, there may not be any assembly of parts or components. Second, a disruption to manufacturing does not impact all of the retailers and distributers.

Figure 3.2: Example of Traditional Supply Chain Compared to the Supply Chain for Additive Manufacturing with Localized Production

\section{Traditional \\ Manufacturing}

Material Resource
Providers

Manufacturing of

Parts and

Components

Assembly of Parts and Components

Retailer or

Distribution

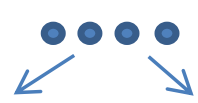

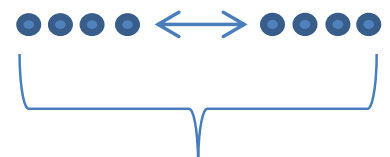

Localized Production

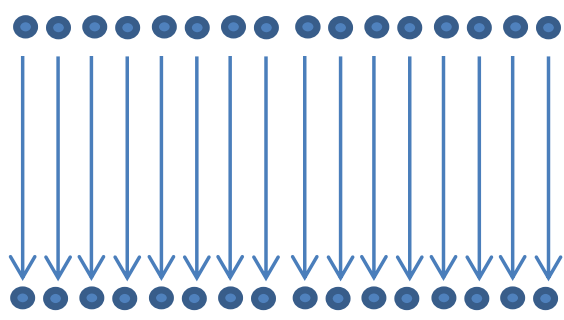

\subsection{Well-Structured Costs}

\subsubsection{Material Costs}

With geometric freedom, additive manufacturing allows products to be produced using less material while maintaining the necessary performance. Products can be produced at the level of performance needed rather than significantly exceeding the necessary performance level because of limitations in traditional manufacturing. Currently, however, the price of materials for additive manufacturing can often exceed those of traditional manufacturing.

Metal Material Costs: As discussed previously, metal and plastic are the primary materials used for this technology. Currently, the cost of material for additive manufacturing can be quite high when compared to traditional manufacturing. Atzeni and Salmi (2011) showed that the material costs for a selected metal part made from aluminum alloys was $€ 2.59$ per part for traditional manufacturing and $€ 25.81$ per part for 
additive manufacturing using selective laser sintering; thus, the additive manufacturing material was nearly ten times more expensive. ${ }^{26}$

Other research on metal parts confirms that material costs are a major cost driver for this technology as seen in Figure 3.3, which presents data for a sample part made of stainless steel. For this example, four cost factors are varied and the production quantity is a little less than 200 for the base case. This analysis provides insight into identifying the largest costs of additive manufacturing. The first cost factor that is varied is the building rate, which is the speed at which the additive manufacturing system operates. In this example, it is measured in cubic centimeters per hour. The second factor that is varied is the machine utilization measured as the number of hours per year that the machine is operated. The third factor is the material cost and the last factor is the machine investment costs, which include items related to housing, using, and maintaining the

Figure 3.3: Cost Distribution of Additive Manufacturing of Metal Parts by varying Factors

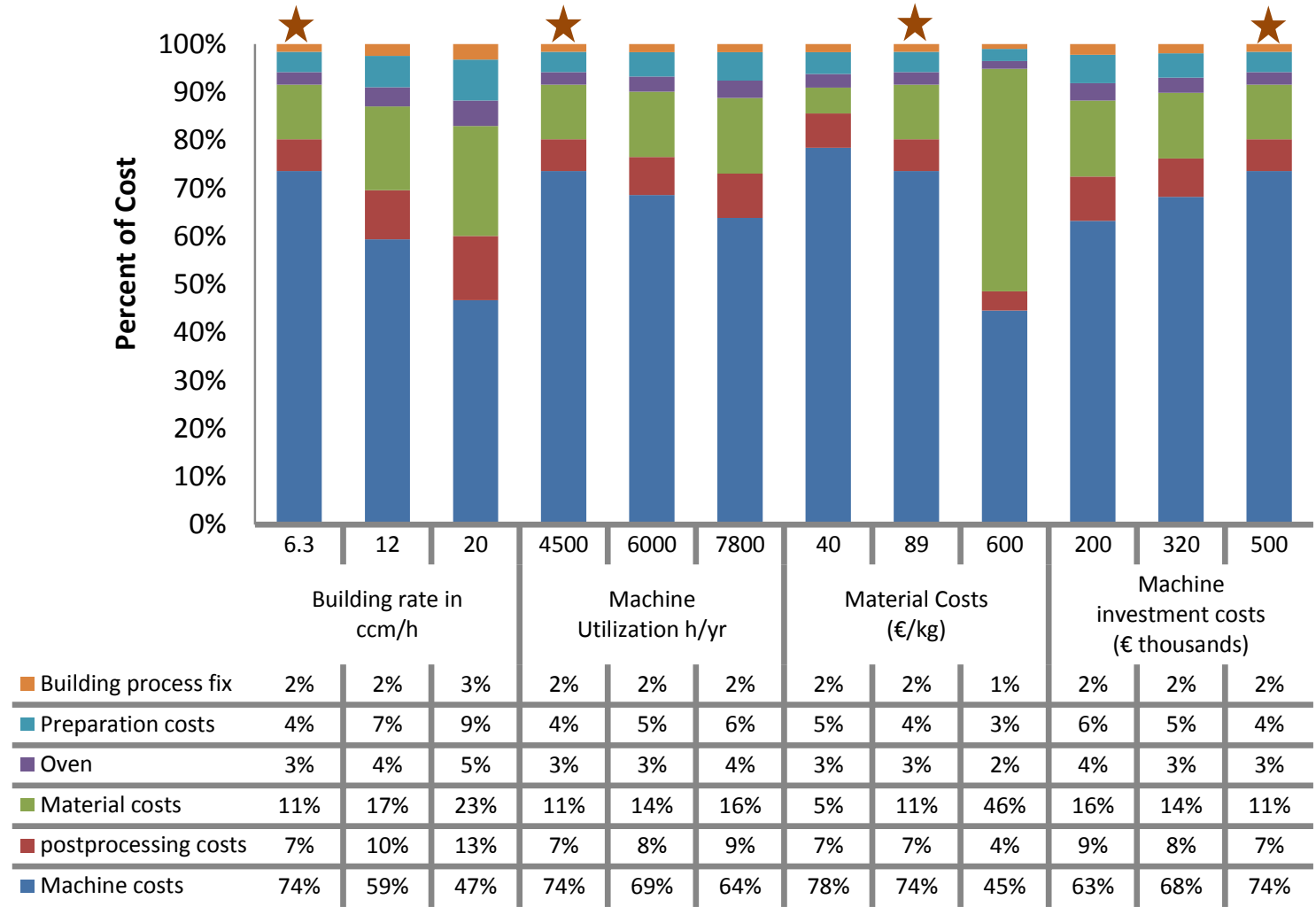

Source: Lindemann C., U. Jahnke, M. Moi, and R. Koch. "Analyzing Product Lifecycle Costs for a Better Understanding of Cost Drivers in Additive Manufacturing." Proceedings of the 2012 Solid Freeform Fabrication Symposium.

$<$ http://utwired.engr.utexas.edu/lff/symposium/proceedingsArchive/pubs/Manuscripts/2012/2012-12Lindemann.pdf>

Note: The orange star indicates the base model.

\footnotetext{
${ }^{26}$ Atzeni, Eleonora and Alessandro Salmi. (2012) "Economics of Additive Manufacturing for End-Usable Metal Parts.” International Journal of Advanced manufacturing Technology. 62: 1147-1155.
} 
additive manufacturing system. Among other things, this includes energy costs, machine purchase, and associated labor costs to operate the system. The base model has a build rate of $6.3 \mathrm{ccm} / \mathrm{hr}$, a utilization of $4500 \mathrm{~h} / \mathrm{yr}$, a material cost of $89 €$, and a machine investment cost of $500000 €$. For comparison, the base case is shown four times in the figure, with each one shown with a star. On average, the machine costs accounted for $62.9 \%$ of the cost estimates in Figure 3.3 (note that the base case is only counted once in the average). This cost was the largest even when building rate was more than tripled and other factors were held constant. This cost was largest in all but one case, where material costs were increased to $600 € / \mathrm{kg}$. The second largest cost is the materials, which, on average, accounted for $18.0 \%$ of the costs; however, it is important to note that this cost is likely to decrease as more suppliers enter the field..$^{27}$ Post processing, preparation, oven heating, and building process fix were approximately $8.4 \%, 5.4 \%, 3.3 \%$, and $1.9 \%$, respectively.

The material costs for additive manufacturing are significant; however, technologies can often be complementary, where two technologies are adopted alongside each other and the benefits are greater than if they were adopted individually. One example is computer aided design and computer aided manufacturing, as both are needed to be utilized for the other to be valuable. Additive manufacturing and the raw materials that are used may be a condition where they are complementary. ${ }^{28}$ All additive manufacturing requires raw materials, and according to Stoneman (2002) this may create a feedback loop. ${ }^{29}$ Increasing adoption of additive manufacturing may lead to a reduction in raw material cost through economies of scale. The reduced cost in raw material might then propagate further adoption of additive manufacturing. There may also be economies of scale in raw material costs if particular materials become more common rather than a plethora of different materials.

Plastic Material Costs: Atzeni et al (2010) compared the costs of manufacturing a lamp holder using injection molding compared to the additive manufacturing process of selective laser sintering using two different machines: EOS SLS P730 and EOS SLS P390. ${ }^{30}$ A significant portion of the cost for injection molding is the mold itself, which accounts for between $84.6 \%$ and $97.7 \%$ of the cost as seen in Figure 3.4. For additive manufacturing, the major costs are the machine cost per part, which is between $58.7 \%$ and $65.9 \%$ of the cost, and the material cost per part, which is between $29.1 \%$ and $30.4 \%$ of the cost. The P730 is cost effective for production volumes of 73000 or less while the P390 is cost effective for 87000 or less.

\footnotetext{
${ }^{27}$ Lindemann C., U. Jahnke, M. Moi, and R. Koch. “Analyzing Product Lifecycle Costs for a Better Understanding of Cost Drivers in Additive Manufacturing." Proceedings of the 2012 Solid Freeform Fabrication Symposium.

<http://utwired.engr.utexas.edu/lff/symposium/proceedingsArchive/pubs/Manuscripts/2012/2012-12Lindemann.pdf>

${ }^{28}$ Baumers, Martin. "Economic Aspects of Additive Manufacturing: Benefits, Costs, and Energy Consumption.” 2012. Doctoral Thesis. Loughborough University.

${ }^{29}$ Stoneman, Paul. The Economics of Technological Diffusion. 2002. Oxford: Blackwell.

${ }^{30}$ Atzeni, Eleonora, Luca Iuliano, Paolo Minetola, and Alessandro Salmi. 2010. "Redesign and Cost Estimation of Rapid Manufactured Plastic Parts.” Rapid Prototyping Journal 16 (5): 308-17.
} 
Hopkinson and Dickens (2003) also investigate the additive manufacturing costs of a polymer part, as discussed in Section $4 .{ }^{31}$ The costs are calculated for two parts, a lever and a cover, using stereolithography, fused deposition modeling, and laser sintering. A cost breakout for the lever is provided in Figure 3.5 and Table 3.1. The material cost represented $25 \%$ of the cost for stereolithography, $39 \%$ for fused deposition modeling, and $74 \%$ for laser sintering. Ruffo et al. (2006a) conduct a similar analysis using the same part. ${ }^{32}$ The cost of additive manufactured parts is calculated by Ruffo et al. using an

Figure 3.4: Cost Comparison of Injection Molding and Additive Manufacturing for a Selected Product, Atzeni et al. (2010)

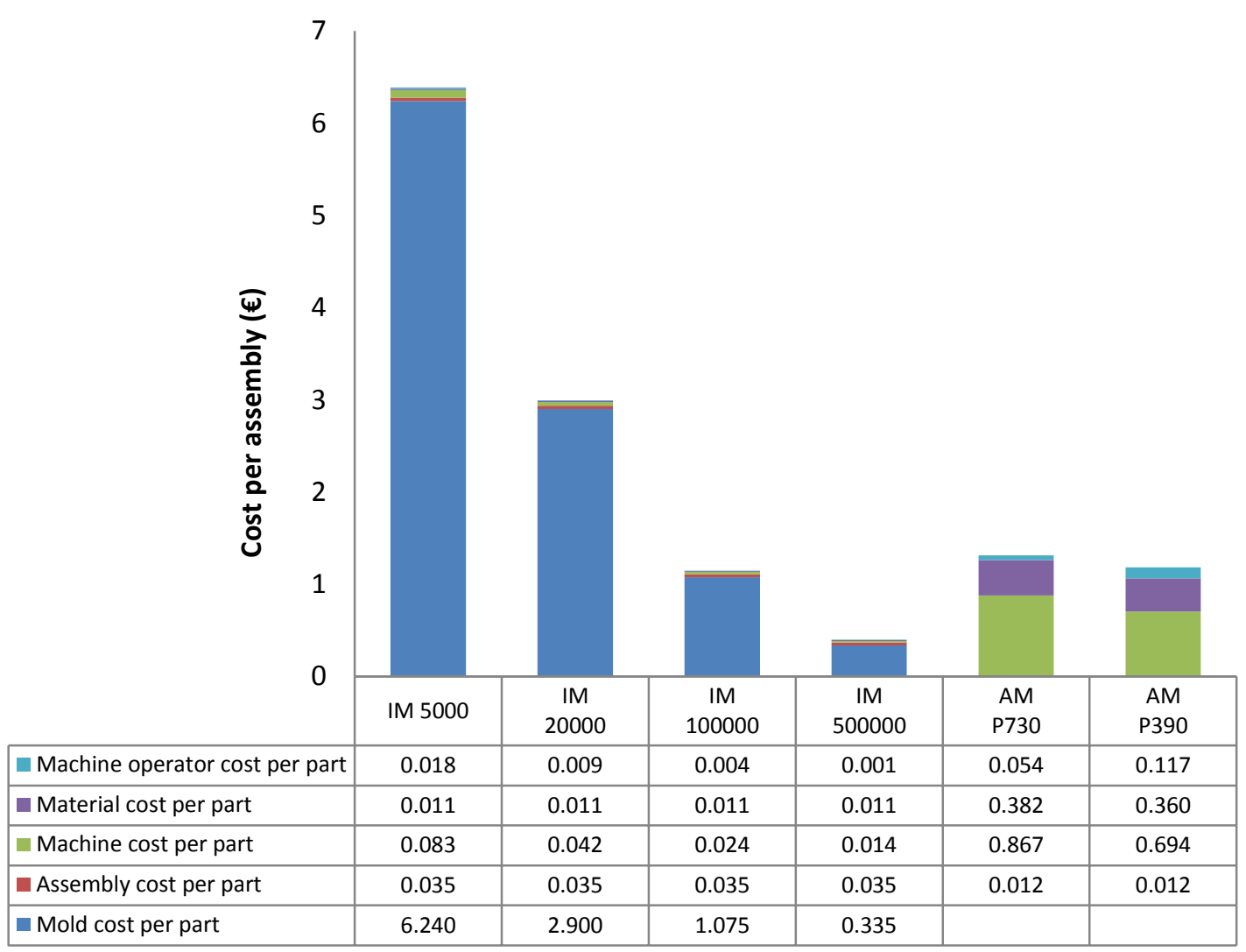

Note: The number following IM is the number of assemblies; thus, IM 5000 is injection molding with 5000 assemblies made. The number following AM is the model of the machine; thus, AM P730 is additive manufacturing machine EOS SLS P730. P390 is the EOS SLS P390.

\footnotetext{
${ }^{31}$ Hopkinson, Neil, and Phill M. Dickens. “Analysis of Rapid Manufacturing - Using Layer Manufacturing Processes for Production." Proceedings of the Institution of Mechanical Engineers, Part C : Journal of Mechanical Engineering Science. 2003. 217(C1): 31-39. <https://dspace.lboro.ac.uk/dspacejspui/handle/2134/3561>

${ }^{32}$ Ruffo, M, Christopher Tuck, Richard J.M. Hague. "Cost Estimation for Rapid Manufacturing - Laser Sintering Production for Low to Medium Volumes.” Proceedings of the Institution of Mechanical Engineers, Part B: Journal of Engineering Manufacture. 2006. 1417-1427.

<https://dspace.lboro.ac.uk/dspace-jspui/handle/2134/4680>
} 
Table 3.1: Cost Breakout, Hopkinson and Dickens (2003)

\begin{tabular}{|c|c|c|c|}
\hline & Stereolithography & $\begin{array}{c}\text { Fused } \\
\text { deposition } \\
\text { modeling }\end{array}$ & $\begin{array}{c}\text { Laser } \\
\text { sintering }\end{array}$ \\
\hline Number per platform & 190 & 75 & 1056 \\
\hline Platform build time & 26.8 & 67.27 & 59.78 \\
\hline Production rate per hour & 7.09 & 1.11 & 17.66 \\
\hline Hours per year in operation & 7884 & 7884 & 7884 \\
\hline production volume total per year & 55894 & 8790 & 139269 \\
\hline Machine and ancillary equipment $(€)$ & 1040000 & 101280 & 340000 \\
\hline Equipment depreciation cost per year $(€)$ & 130000 & 12660 & 42500 \\
\hline Machine maintenance cost per year $(€)$ & 89000 & 10560 & 30450 \\
\hline Total machine cost per year $(€)$ & 219000 & 23220 & 72950 \\
\hline Machine cost per part (€) & 3.92 & 2.64 & 0.52 \\
\hline Machine operator cost per hour $(€)$ & 5.30 & 5.30 & 5.30 \\
\hline Set-up time to control machine ( $\mathrm{min}$ ) & 33 & 10 & 120 \\
\hline Post-processing time per build (min) & 49 & 60 & 360 \\
\hline Labor cost per build $(€)$ & 7.24 & 6.18 & 42.37 \\
\hline Labor cost per part $(€)$ & 0.04 & 0.08 & 0.04 \\
\hline Material per part (kg) & תחת & 0.0035 & \\
\hline Support material per part (kg) & 0.004 & 0.0016 & \\
\hline Build material cost per $\mathrm{kg}(€)$ & 27520 & 400.00 & 54.00 \\
\hline Support material cost per $\mathrm{kg}(€)$ & & 216.00 & 54.00 \\
\hline Cost of material used in one build $(€)$ & & & 1725.72 \\
\hline Material cost per part $(€)$ & 1.29 & 1.75 & 1.63 \\
\hline Total cost per part $(€)$ & 5.25 & 4.47 & 2.20 \\
\hline
\end{tabular}

activity based cost model, where each cost is associated with a particular activity. They make an estimate that compares with Hopkinson and Dickens and another estimate that uses recycling of material. As illustrated in Figure 3.6, material is $69 \%$ of the cost in the first estimate and $55 \%$ in the second estimate.

\subsubsection{Machine Cost}

In addition to material costs, machine cost is one of the most significant costs involved in additive manufacturing. The average selling price of an industrial additive manufacturing system was $\$ 73220$ in $2011 .^{33}$ Although the price is up from $\$ 62570$ in 2010, the price has fallen for most years prior to this point. Between 2001 and 2011, the price decreased $51 \%$ after adjusting for inflation. ${ }^{34}$ While the trends in machine costs are generally downward, large differences remain between the costs for polymer-based systems and metal-based systems, and the tremendous growth in sales of low-cost, polymer-based

\footnotetext{
${ }^{33}$ Wohlers, Terry. "Wohlers Report 2012: Additive Manufacturing and 3D Printing State of the Industry." Wohlers Associates, Inc. 2012.

${ }^{34}$ Ibid
} 
Figure 3.5: Cost Breakout, Hopkinson and Dickens (2003)

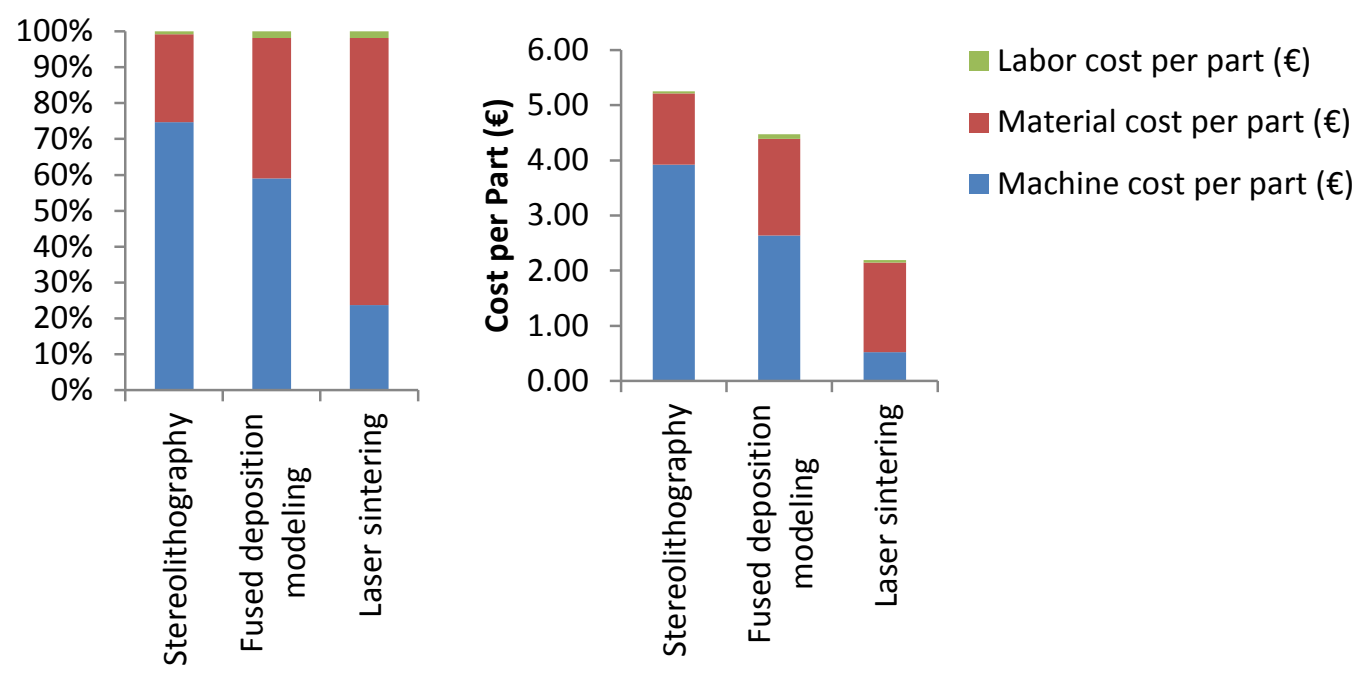

systems during this time has strongly influenced the average selling price of additive manufacturing systems.

For metal material cost studies, Hopkinson and Dickens (2003) showed that machine costs ranged from $23 \%$ to $75 \%$ of a metal part, as seen in Table 3.1. The cost difference between the different types of additive manufacturing machinery was quite significant ranging between $\$ 0.1$ million typically for polymer systems and $\$ 1.0$ million typically for metal systems. One might surmise that the proportion might have decreased over time; however, the machine cost estimates for Lindemann et al. (2012) ranged from $45 \%$ to $78 \%$ of the cost of a metal part, as seen in Figure 3.3. Atzeni et al. (2010) show that machine cost per part was between $59 \%$ and $66 \%$ of the cost of a plastic part, as seen in Figure 3.4.

\subsubsection{Build Envelope and Envelope Utilization}

The size of the build envelope ${ }^{35}$ and the utilization of this envelop both have an impact on the cost of an additive manufactured product. The size of the build envelope has two impacts. First, products can only be built to the size of the build envelope, which means that it might not be possible to build some products using additive manufacturing technologies without enlarging the build envelope. The second impact of the build envelope is related to utilizing the total amount of build capacity. A significant efficiency factor lies in the ability to exhaust the available build space. For example, Baumers et al. (2011) examined the impact of capacity utilization on energy using six different machines (Arcam - A1, MTT Group - SLM 250, EOS GmbH - EOSINT M 270, Concept Laser GmbH - M3 Linear, Stratasys Inc - FDM 400 mc, and EOS GmbH - EOSINT P390) and

\footnotetext{
35 The build envelope is the maximum area for part production in an additive manufacturing system.
} 
Figure 3.6: Cost Comparison for Selective Laser Sintering

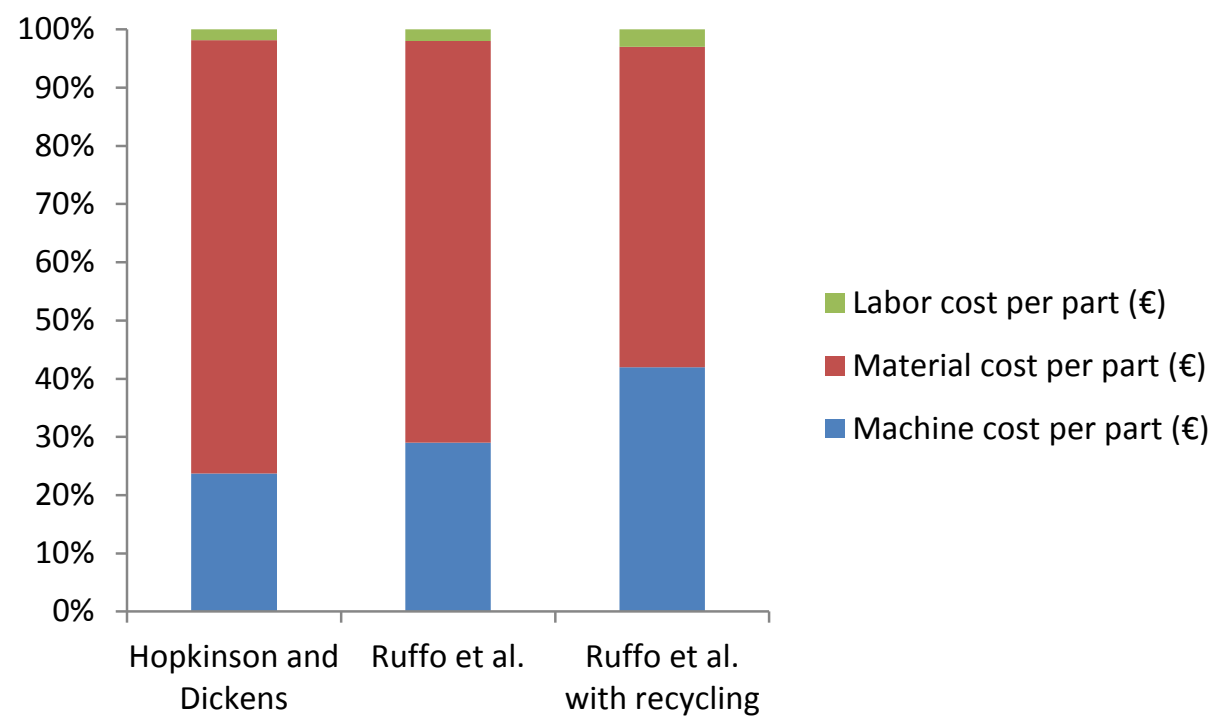

four different materials (titanium, stainless steel, and two kinds of polymers). As seen in Figure 3.7, the full build case, where the build envelope is fully utilized, uses less energy per kilogram deposited than one single part being produced for all six different machines. The EOSINT P 390 has the largest build volume and has the largest difference in energy consumption between a single part and full build.

\subsubsection{Build Time}

Build time is a significant component in regard to estimating the cost of additive manufacturing and a number of software packages are available for estimating build time. ${ }^{36,37}$ There tends to be two approaches to estimating build time: 1 ) detailed analysis and 2) parametric analysis. ${ }^{38}$ Detailed analysis utilizes knowledge about the inner workings of a system, while parametric analysis utilizes information on process time and characteristics such as layer thickness. Build time estimations tend to be specific to the system and material being used. Although this is an important factor in the cost of additive manufacturing, the details of build time are beyond the scope of this report.

\subsubsection{Energy Consumption}

Some cost studies for additive manufacturing, such as Hopkinson and Dickens (2003), included an examination of energy consumption, but they did not include energy in their

\footnotetext{
${ }^{36}$ Ruffo, Massimiliano, Christopher Tuck, and Richard Hague. 2006. "Empirical Laser Sintering Time Estimator for Duraform PA.” International Journal of Production Research 44 (23): 5131-46.

${ }^{37}$ Campbell, I., J. Combrinck, D. De Beer, and L. Barnard. 2008. "Stereolithography Build Time Estimation Based on Volumetric Calculations. Rapid Prototyping Journal. 14(5): 271-279.

${ }^{38}$ Di Angelo, Luca, and Paolo Di Stefano. 2011. "A Neural Network-Based Build Time Estimator for Layer Manufactured Objects." International Journal of Advanced Manufacturing Technology 57 (1-4): 215-24. doi:10.1007/s00170-011-3284-8.
} 
reporting, as it contributed less than one percent to the final cost. ${ }^{39}$ Energy consumption, however, is an important factor in considering the cost of additive manufacturing compared to other methods of manufacturing, especially in terms of examining the costs from cradle to grave. Energy studies on additive manufacturing, however, tend to focus only on the energy used in material refining and by the additive manufacturing system itself. These studies are discussed below.

Metal: As discussed previously, Baumers et al. (2011) examined energy consumption among a number of machines. ${ }^{40}$ The results shown in Figure 3.7 provide the results for energy consumption among these machines. Morrow et al. (2007) compares direct metal deposition to conventional tool and die manufacturing. ${ }^{41}$ This work identifies that energy consumption is driven by the solid-to-cavity volume ratio. At low ratios, the additive manufacturing process of direct metal deposition minimizes energy, while at high ratios computer numeric controlled milling minimizes energy consumption. Other studies tend to focus on accurately predicting energy consumption and minimizing energy consumption for additive manufacturing. Envelope utilization and build orientation are among the issues for reducing energy consumption. Mognol, Lepicart, and Perry (2006) examine the impact of part orientation for three systems: Stratasys FDM 3000, 3D Systems Thermojet, and EOS EOSINT M250 Xtended. ${ }^{42}$ They examined 18 positions for a single part. Due to the change in the position of the part, the energy consumed could increase between $75 \%$ and $160 \%$ depending on the system, as illustrated in Figure 3.8. This figure also illustrates that the position for one system may have low energy consumption, but for another system it might not have a low consumption.

Plastic Material: Telenko and Seepersad (2012) examined energy consumed in the production of nylon parts using selective laser sintering and compared these results to that of injection molding. ${ }^{43}$ This analysis included a small build of 50 parts and a full build of 150 parts. The results are displayed in Figure 3.9 with injection mold values (IM) being shown both with the energy consumed for the production of the mold and without the mold. As seen in the figure, the small build for selective laser sintering used less energy than the small build for injection molding (including the energy for the mold). However, the energy for the full build was approximately $69 \%$ higher. For the full build, approximately $60 \%$ of the energy was used in nylon production and $37 \%$ was used in part manufacture for selective laser sintering.

\footnotetext{
${ }^{39}$ Hopkinson, Neil, and Phill M. Dickens. "Analysis of Rapid Manufacturing - Using Layer Manufacturing Processes for Production." Proceedings of the Institution of Mechanical Engineers, Part C : Journal of Mechanical Engineering Science. 2003. 217(C1): 31-39. <https://dspace.lboro.ac.uk/dspacejspui/handle/2134/3561>

${ }^{40}$ Baumers, Martin. "Economic Aspects of Additive Manufacturing: Benefits, Costs, and Energy Consumption.” 2012. Doctoral Thesis. Loughborough University.

${ }^{41}$ Morrow, W.R., H. Qi, I. Kim, J. Mazumder, and S.J. Skerlos. 2007. "Environmental Aspects of LaserBased and Conventional Tool and Die Manufacturing." Journal of Cleaner Production 15 (10): 932-43. doi:10.1016/j.jclepro.2005.11.030.

42 Mognol, Pascal, Denis Lepicart, and Nicolas Perry. 2006. "Rapid Prototyping: Energy and Environment in the Spotlight." Rapid Prototyping Journal 12 (1): 26-34. doi:10.1108/13552540610637246.

${ }^{43}$ Telenko, Cassandra, and Carolyn Conner Seepersad. 2012. "A Comparison of the Energy Efficiency of Selective Laser Sintering and Injection Molding of Nylon Parts.” Rapid Prototyping Journal 18 (6): 472 81.
} 
Figure 3.7: Energy Consumption per kg Deposited (Baumers et al. 2011)

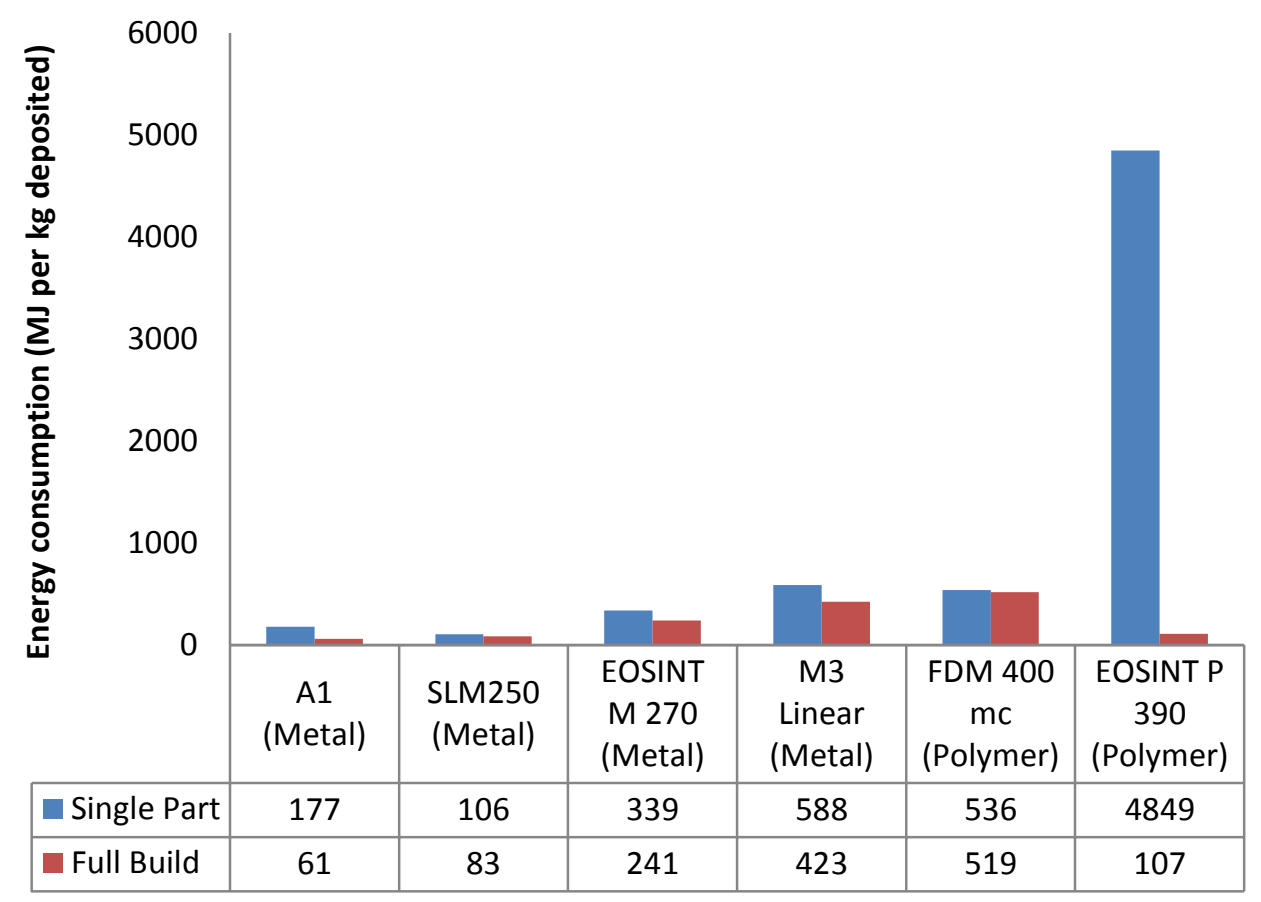

Figure 3.8: Energy Consumption, Magnol, Lepicart, and Perry (2006)

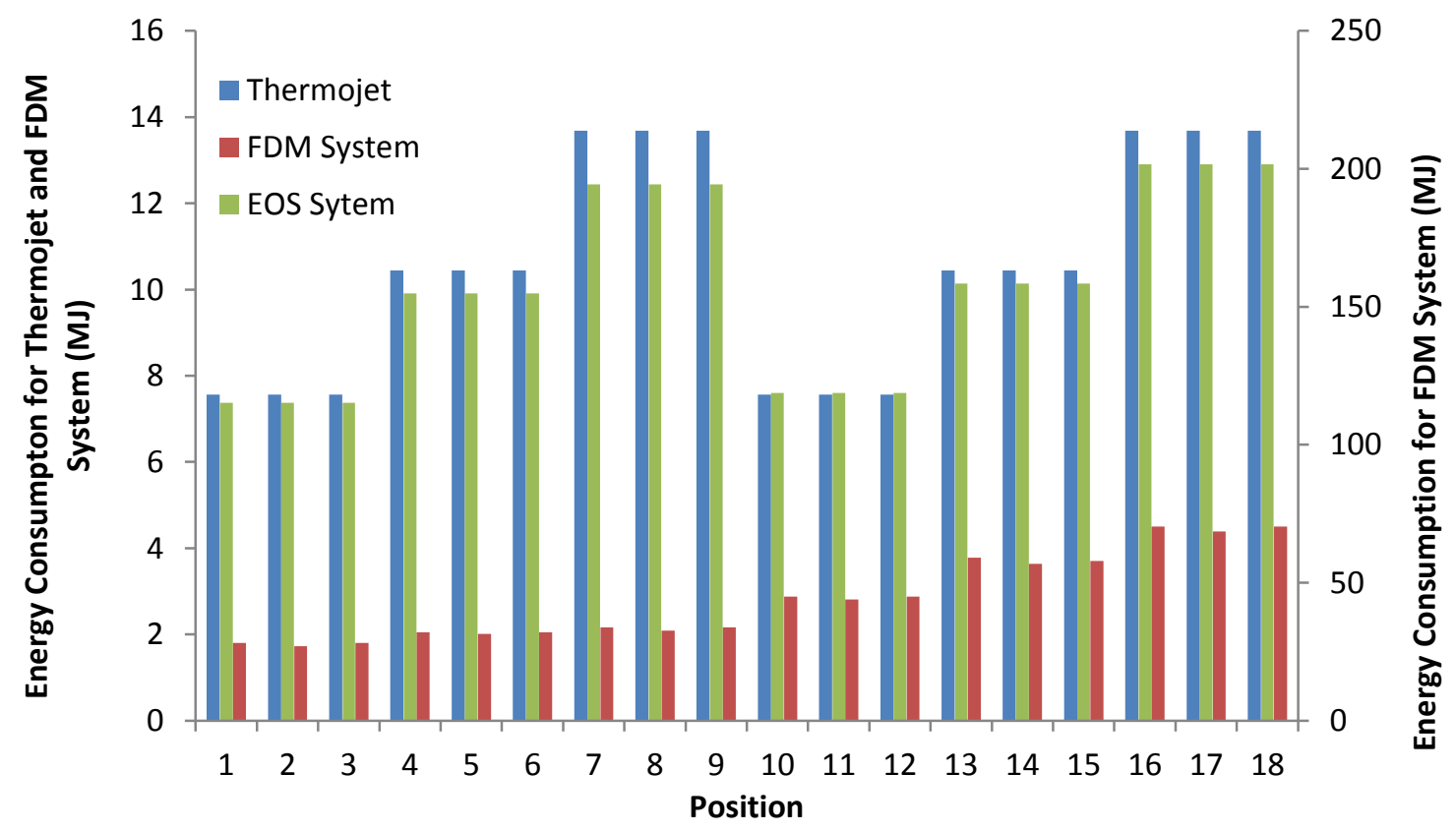


Sreenivasan and Bourell (2009) examined the energy use of selective laser sintering using nylon material, building two "full chamber build[s]" of prosthetic parts. ${ }^{44}$ They identify the components that are major consumers of energy: chamber heaters (37\%), stepper motors for piston control (26\%), roller drives (16\%), and the laser (16\%).

\subsubsection{Labor}

As illustrated in Figure 3.5 and Figure 3.6, labor tends to be a small portion of the additive manufacturing cost. Labor might include removing the finished product or refilling the raw material among other things. From Figure 3.6, Hopkinson and Dickens estimate labor at $2 \%$ of the cost, while Ruffo et al. estimate it at $2 \%$ and $3 \%$. It is important to note that additional labor is built into the other costs such as the material cost and machine cost, as these items also require labor to produce.

\subsection{Product Enhancements and Quality}

Although the focus of this report is the costs of additive manufacturing, it is important to note that there are product enhancements and quality differences due to using this technology. There is more geometric freedom with additive manufacturing and it creates more flexibility; however, there are limitations, as some designs require support structures and means for dissipating heat in production. ${ }^{45}$ However, complexity does not increase the cost of production as it does with traditional methods. With the exception of the design cost, each product produced can be customized at little or no expense. There is significant need for custom products in the medical sector for replacement joint implants, dental work, and hearing aids among other things. ${ }^{46}$ There is also the possibility of customers designing their own products or customizing them. One concern with additive manufacturing, however, is quality assurance. Currently, there is a need for standard methods to evaluate and ensure accuracy, surface finish, and feature detail to achieve desired part quality.

\footnotetext{
44 Sreenivasan, R., and D.L. Bourell. 2009. "Sustainability Study in Selective Laser Sintering - An Energy Perspective." In 20th Annual International Solid Freeform Fabrication Symposium-An Additive Manufacturing Conference, Austin/TX/USA, 3rd-5th August. Austin, TX.

${ }^{45}$ Baumers, Martin. "Economic Aspects of Additive Manufacturing: Benefits, Costs, and Energy Consumption.” 2012. Doctoral Thesis. Loughborough University.

${ }^{46}$ Doubrovski, Zjenja, Jouke C. Verlinden, and Jo M.P. Geraedts. "Optimal Design for Additive Manufacturing: Opportunities and Challenges.” Proceedings of the ASME 2011 International Design Engineering Technical Conferences and Computers and Information in Engineering Conference. August 29-31, 2011. Washington DC.
} 
Figure 3.9: Energy Efficiency of Selective Laser Sintering, Cassandra and Seepersad (2012), megajoules

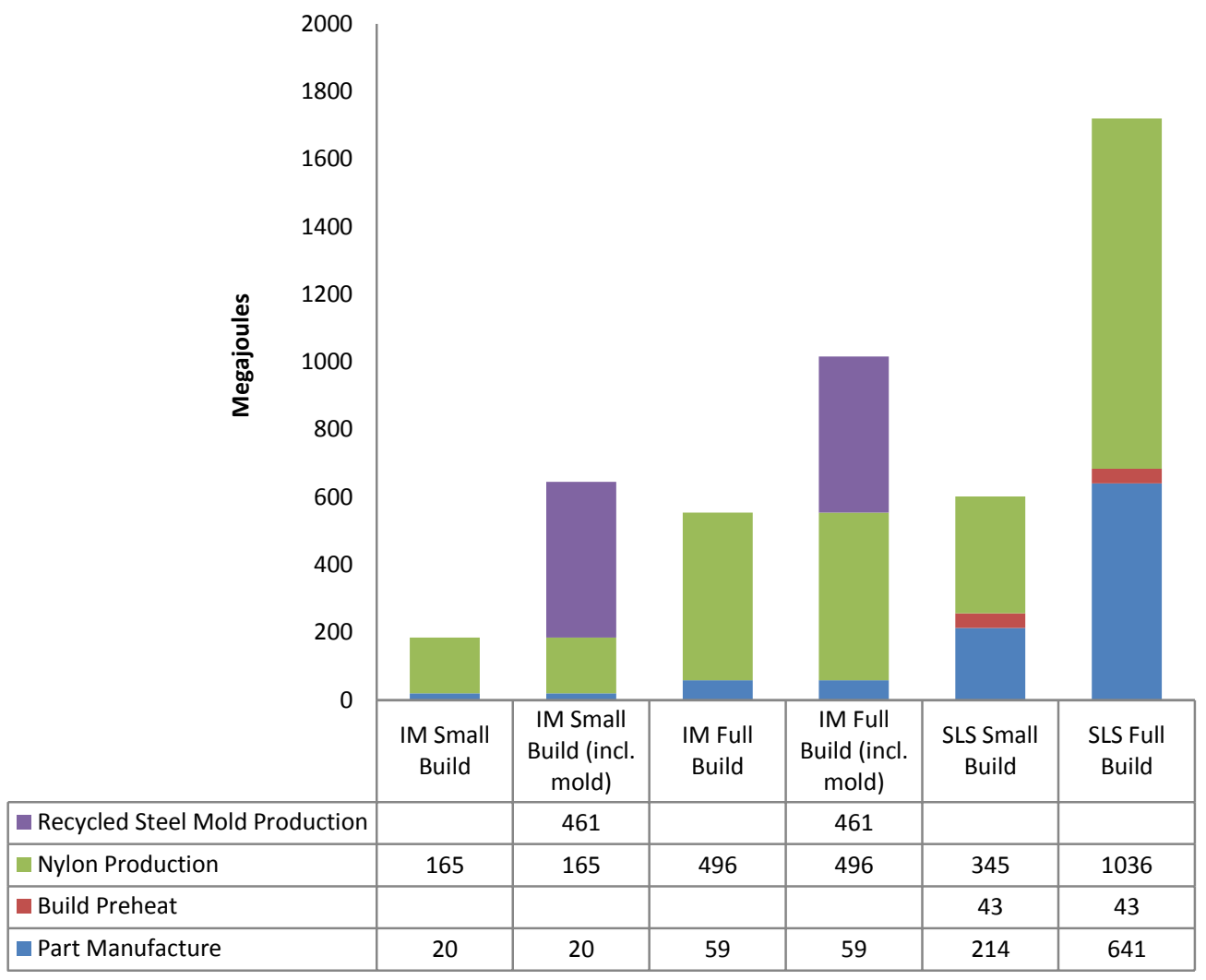




\section{Cost Models and Comparisons}

\subsection{Two Major Contributions to Additive Manufacturing Cost Modeling}

There are two cost models that receive significant attention in additive manufacturing: 1 ) Hopkinson and Dickens (2003) and 2) Ruffo et al. (2006a). ${ }^{47,48,49}$ The cost of additive manufactured parts is calculated by Hopkinson and Dickens based on calculating the average cost per part and three additional assumptions: 1) the system produces a single type of part for one year, 2) it utilizes maximum volumes, and 3) the machine operates for $90 \%$ of the time. The analysis includes labor, material, and machine costs. Other factors such as power consumption and space rental were considered but contributed less than one percent of the costs; therefore, they were not included in the results. The average part cost is calculated by dividing the total cost by the total number of parts manufactured in a year. Costs can be broken into machine costs, labor costs, and material costs. The costs are calculated for two parts, a lever and a cover, using stereolithography, fused deposition modeling, and laser sintering. A cost breakout for the lever is provided in Figure 3.5 and Table 3.1, which shows that in this analysis laser sintering was the cheapest additive manufacturing process for this product. Machine cost was the major contributing cost factor for stereolithography and fused deposition modeling while the material cost was the major contributor for laser sintering.

Hopkinson and Dickens estimate an annual machine cost per part where the machine completely depreciates after eight years; that is, it is the sum of depreciation cost per year (calculated as machine and ancillary equipment divided by 8) and machine maintenance cost per year divided by production volume. The result is a machine cost per part that is constant over time, as seen in Figure 4.1. Also seen in the figure is a comparison to injection molding

The cost of additive manufactured parts is calculated by Ruffo et al. using an activity based cost model, where each cost is associated with a particular activity. They produce the same lever that Hopkinson and Dickens produced using selective laser sintering. In

\footnotetext{
${ }^{47}$ Ruffo, M, Christopher Tuck, Richard J.M. Hague. "Cost Estimation for Rapid Manufacturing - Laser Sintering Production for Low to Medium Volumes.” Proceedings of the Institution of Mechanical Engineers, Part B: Journal of Engineering Manufacture. 2006. 1417-1427. <https://dspace.lboro.ac.uk/dspace-jspui/handle/2134/4680>

${ }^{48}$ Hopkinson, Neil, and Phill M. Dickens. "Analysis of Rapid Manufacturing - Using Layer Manufacturing Processes for Production." Proceedings of the Institution of Mechanical Engineers, Part C : Journal of Mechanical Engineering Science. 2003. 217(C1): 31-39. <https://dspace.lboro.ac.uk/dspacejspui/handle/2134/3561>

49 Baumers, Martin. "Economic Aspects of Additive Manufacturing: Benefits, Costs, and Energy Consumption.” 2012. Doctoral Thesis. Loughborough University.
} 
Figure 4.1: Hopkinson and Dickens (2003) Cost Model Compared to Injection Molding

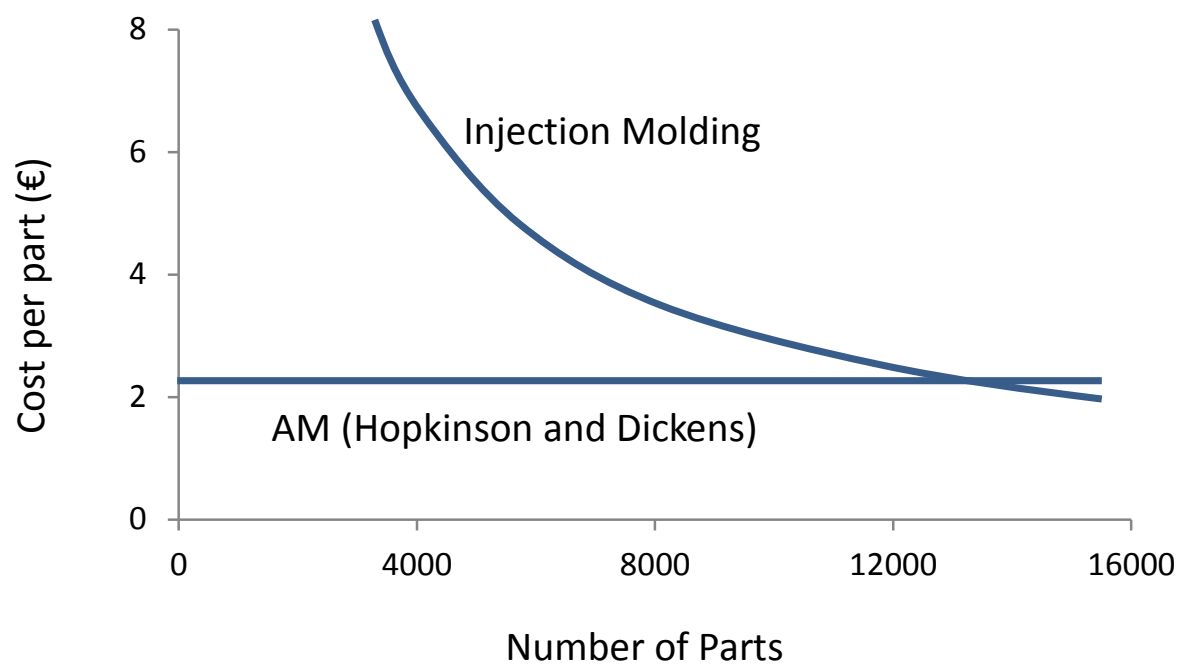

Adapted from Hopkinson and Dickens (2003)

their model, the total cost of a build $(\mathrm{C})$, is the sum of raw material costs and indirect costs. The raw material costs are the price $\left(\mathrm{P}_{\text {material }}\right)$, measured in euros per kilogram, multiplied by the mass in $\mathrm{kg}(\mathrm{M})$. The indirect costs are calculated as the total build time (T) multiplied by a cost rate $\left(\mathrm{P}_{\text {indirect }}\right)$. The total cost of a build is then represented as:

$$
C=P_{\text {material }} * M+P_{\text {indirect }} * T
$$

The cost per part is calculated as the total cost of a build (C) divided by the number of parts in the build. In contrast, Ruffo et al. indicate that the time and material used are the main variables in the costing model. It was assumed that the machine worked 100 hours/week for 50 weeks/year (57\% utilization). The estimated indirect cost per hour is shown in Table 4.1. Their cost model and the total costs are shown in Figure 4.2.

There are three different times that are calculated in Ruffo et al.'s model: 1) "time to laser scan the section and its border in order to sinter;" 2) "time to add layers of powder;" and 3) "time to heat the bed before scanning and to cool down slowly after scanning, adding layers of powder or just waiting time to reach the correct temperature." The sum of these times is the build time $(T)$ and the resulting cost model along with the Hopkinson and Dickens model is shown in Figure 4.3. The Ruffo et al. model has a jagged saw tooth shape to it, which is due to the impact of a new line, layer, or build. Each time one of these is added, average costs increase irregularly from raw material consumption and process time. At 1600 parts, the cost of the lever is estimated at $€ 2.76$ per part compared to Hopkinson and Dickens $€ 2.20$ for laser sintering. Ruffo et al. also conducted an examination where unused material was recycled. In this examination, the per-unit cost was $€$ 1.86. A comparison of the costs is made in Figure 3.6. 
Table 4.1: Indirect Cost Activities (Ruffo, Tuck, and Hague 2006a)

\begin{tabular}{lr} 
Activity & Cost/hr $(€)$ \\
\hline Production labor/machine hour & 7.99 \\
Machine costs & 14.78 \\
Production overhead & 5.90 \\
Administrative overhead & 0.41 \\
\hline
\end{tabular}

Figure 4.2: Ruffo, Tuck, and Hague Cost Model

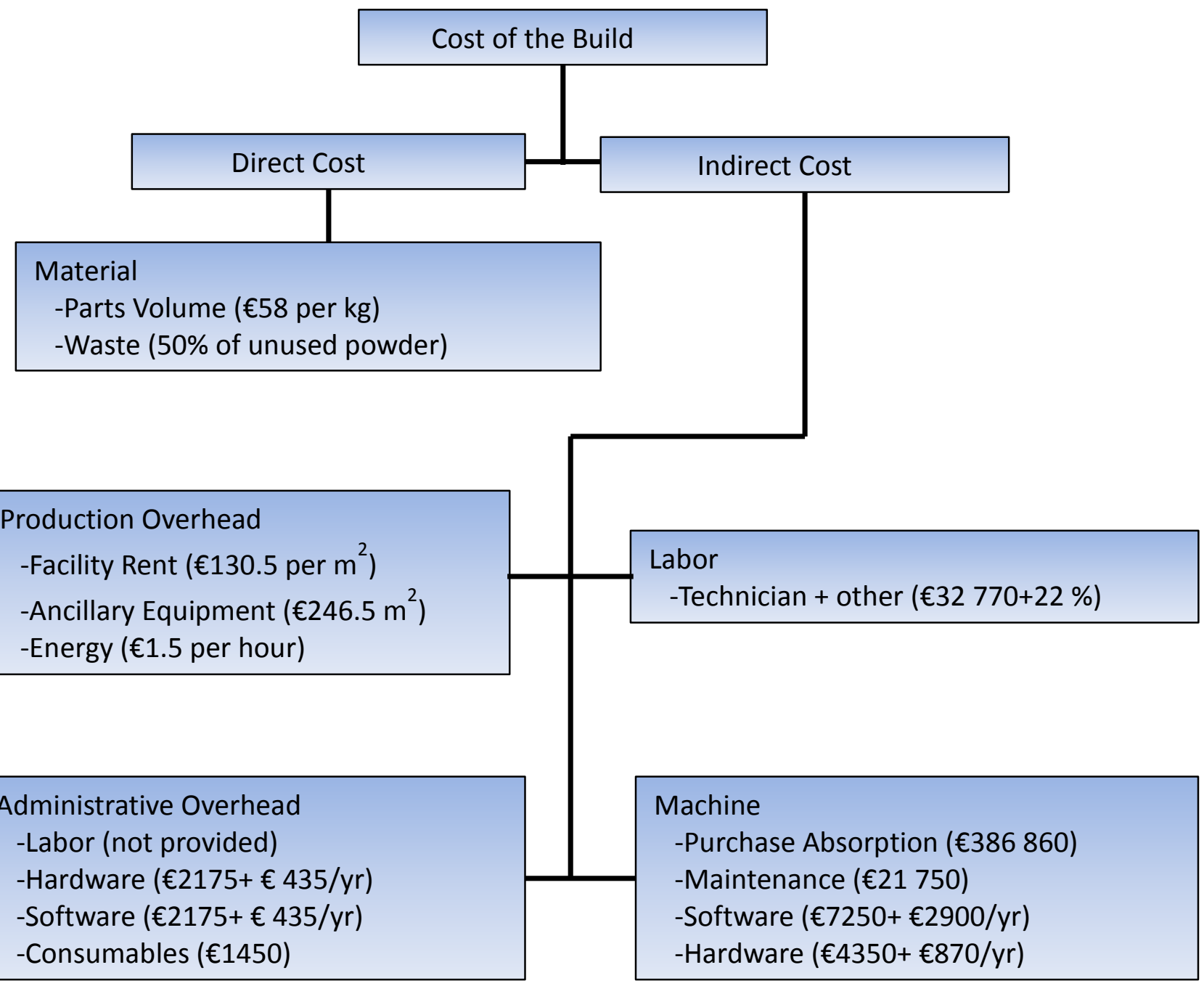


Figure 4.3: Cost Model Comparison (Ruffo, Tuck, and Hague vs. Hopkinson and Dickens)

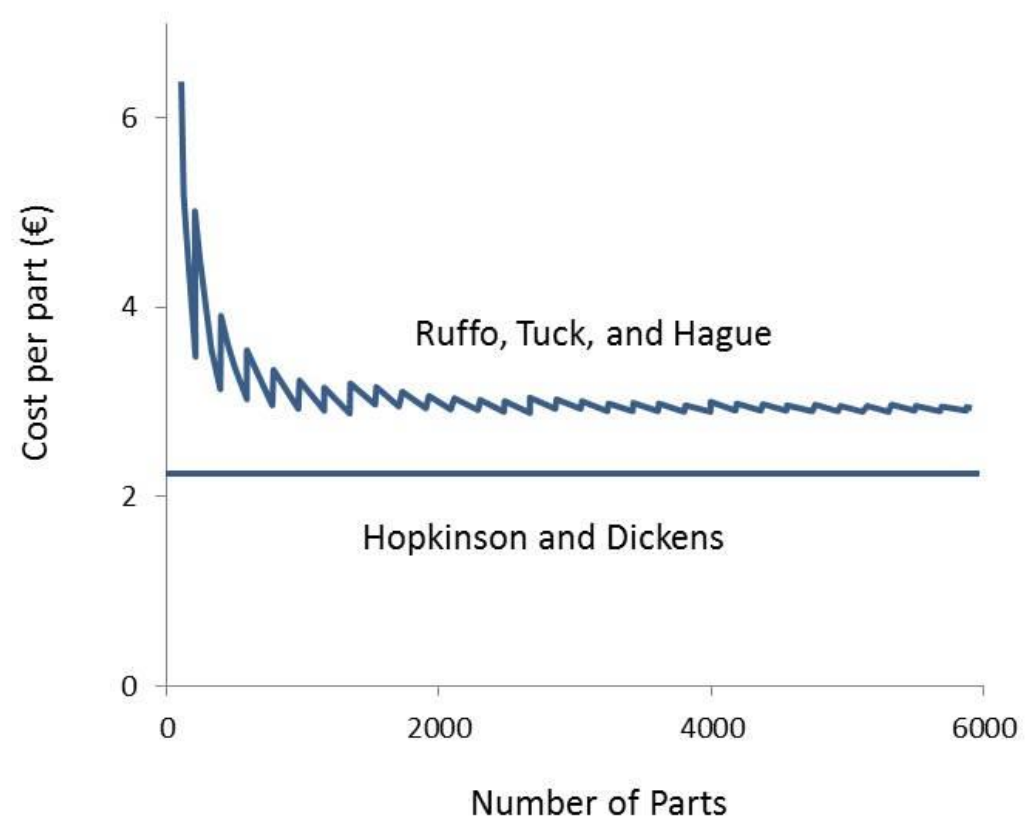

Adapted from Ruffo et al. and Hopkinson and Dickens

Many of the cost studies assume a scenario where one part is produced repeatedly; however, one of the benefits of additive manufacturing is the ability to produce different components simultaneously. Therefore, a "smart mix" of components in the same build might achieve reduced costs. In a single part production, the per part cost for a build is the total cost divided by the number of parts; however, the cost for different parts being built simultaneously is more complicated. Ruffo and Hague (2007) compare three costing methodologies for assessing this cost. The first method is based on parts volume where

$$
\operatorname{Cost}_{P_{i}}=\left(\frac{V_{P_{i}}}{V_{B}}\right) * \operatorname{Cost}_{B}
$$

Where

$\operatorname{Cost}_{P_{i}}=$ cost of part $\mathrm{i}$

$V_{P_{i}}=$ volume of part $\mathrm{i}$

$V_{B}=$ volume of the entire build

$\operatorname{Cost}_{B}=\sum \frac{\text { indirect_costs }}{\text { working_time }}\left(t_{x y}+t_{z}+t_{H C}\right)+\frac{\text { direct_cost }}{\text { mass_unit }} m_{B}$

$m_{B}=$ mass of the planned production proportional to the object volumes, and the time to manufacturing the entire build

$t_{x y}=$ time to laser-scan the section and its border to sinter powder

$t_{z}=$ time to add layers of powder

$t_{H C}=$ time to heat the bed before scanning and to cool down after scanning and adding layers of powder

$i=$ an index going from one to the number of parts in the build 
$\operatorname{Cost}_{B}$ also equals $\mathrm{C}$ from above, which is the total cost of a build. The second method is based on the cost of building a single part and is represented as the following:

$$
\operatorname{Cost}_{P_{i}}=\frac{\gamma_{i} * \operatorname{Cost}_{B}}{n_{i}}
$$

where

$$
\gamma_{i}=\frac{\operatorname{Cost}_{P_{i}}^{*}+n_{i}}{\sum_{j}\left(\operatorname{Cost}_{P_{j}}^{*} * n_{j}\right)}
$$

Also, $i$ is the index of the part being calculated, $j$ is the index for all parts manufactured in the same bed, $n_{i}$ is the number of parts identified with $i$, and $\operatorname{Cost}_{P_{i}}^{*}$ is the cost of a single part $i$ estimated using the earlier equation for $\mathrm{C}$. The third method is based on the cost of a part built in high-volume. It is similar to the second method, only the cost variables in $\gamma_{i}$ are calculated using a high number of parts rather than a single part. It is represented as the following:

$$
\operatorname{Cost}_{P_{i}}=\frac{\gamma_{i}^{\infty} * \operatorname{Cost}_{B}}{n_{i}}
$$

where

$$
\gamma_{i}^{\infty}=\frac{\operatorname{Cost}_{P_{i}}^{\infty}+n_{i}}{\sum_{j}\left(\operatorname{Cost}_{P_{j}}^{\infty} * n_{j}\right)}
$$

Where $\operatorname{Cost}_{P_{i}}^{\infty}$ is a hypothetical number, which approaches infinity, of manufactured parts $i$.

Ruffo and Hague use a case study to evaluate the validity of estimating the per part cost. The results suggest that only the third model provides a "fair assignment method." The other two were identified as being inappropriate due to the result drastically reducing the estimated cost of larger components at the expense of smaller parts.

\subsection{Other Comparisons to Traditional Manufacturing}

Atzeni and Salmi (2011) showed that the per assembly processing cost for a landing gear assembly for a 1:5 scale model of the P180 Avant II by Piaggio Aero Industries S.p.A. (i.e., the machine cost per assembly), with an estimated five years of useful life, was $€ 472.50$ for the additive manufacturing process of selective laser sintering (see Table 4.2). Compared to high-pressure die-casting, the mold cost and processing cost per part were $€ 0.26+€ 21000 / \mathrm{N}$, where $\mathrm{N}$ is the number of parts produced. For production runs of less than 42 , selective laser sintering was more cost effective than the traditional process of high-pressure die-casting (see Figure 4.4). 
Table 4.2: Production Costs Compared, Atzeni and Salmi (2011)

\begin{tabular}{lcc} 
& $\begin{array}{c}\text { High-Pressure Die- } \\
\text { Cast Part }(€)\end{array}$ & $\begin{array}{c}\text { Selective Laser } \\
\text { Sintering Part }(€)\end{array}$ \\
\hline Material cost per part & 2.59 & 25.81 \\
Pre-processing cost per part & - & 8.00 \\
Processing cost per part* & $0.26+21000 / \mathrm{N}$ & 472.50 \\
Post-processing cost per part & 17.90 & 20.00 \\
Assembly & 0.54 & - \\
\hline Total & $\mathbf{2 1 . 2 9 + 2 1 ~ 0 0 0 / N}$ & $\mathbf{5 2 6 . 3 1}$ \\
*Includes the mold for die-casting & &
\end{tabular}

Figure 4.4: Breakeven Point for High-Pressure Die-Casting and Selective Laser Sintering, Atzeni and Salmi (2011)

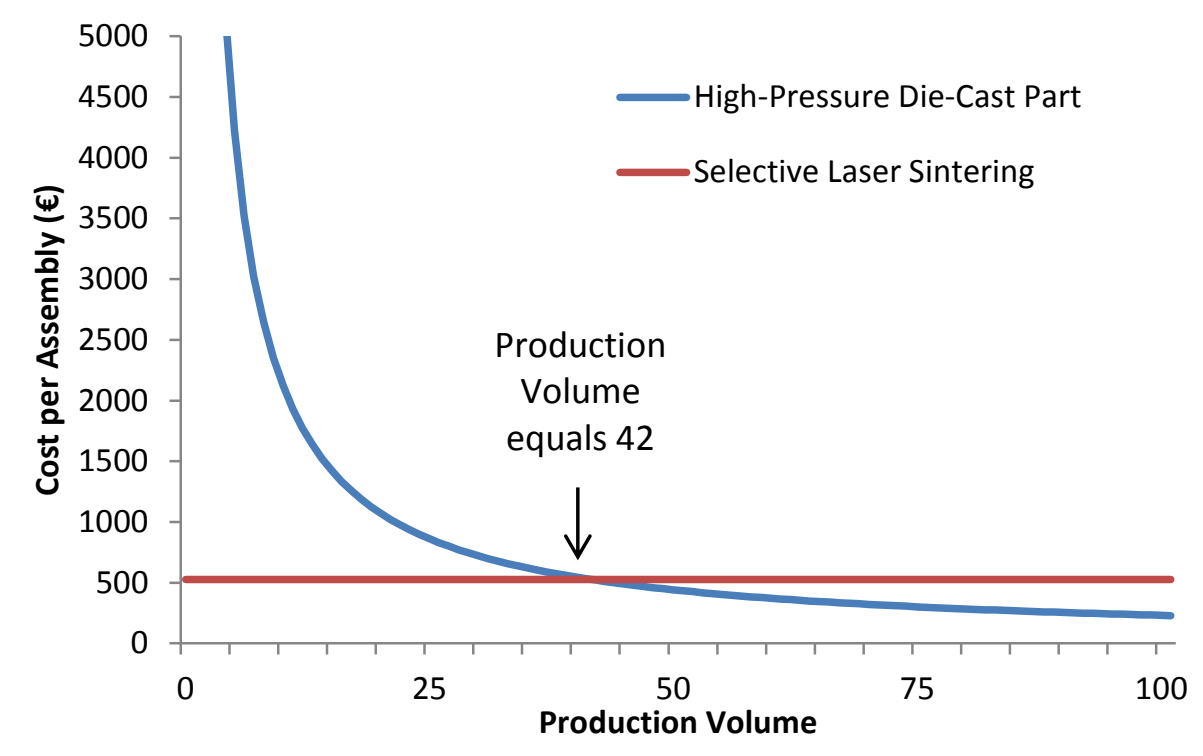

The aerospace industry often uses costly raw materials, which have high performance and low weight. These high performance materials are not only costly to purchase, but can also be costly to machine down using traditional manufacturing methods. Allen (2006) compares additive manufacturing to machining for aero engine parts. ${ }^{50}$ This work provides a more generic comparison of the two processes. The cost of providing a "near net shape" using machining was estimated as the following:

Where

$$
C_{s}=\left(V * \rho * C_{f}\right) *(V-v) * \rho * C_{m}
$$

\footnotetext{
${ }^{50}$ Allen, Jeff. 2006. "An Investigation into the Comparative Costs of Additive Manufacture vs. Machine from Solid for Aero Engine Parts.” In Cost Effective Manufacture via Net-Shape Processing, 17-1 - 17-10. Meeting Proceedings RTO-MP-AVT-139. Paper 17. DTIC Document.

$<$ http://www.rto.nato.int/abstracts.asp>
} 
$C_{S}=$ cost of providing a "near net shape" using machining

$V=$ volume of original billet

$\rho=$ density of titanium

$C_{f}=$ cost of ring rolled forged material

$v=$ volume of component

$C_{m}=$ cost of machining

The cost of producing a "near net shape" using additive manufacturing was estimated as the following:

Where

$$
C_{a}=v * \rho * C_{d}
$$

$C_{a}=$ cost of producing a "near net shape" using additive manufacturing

$v=$ volume of component

$\rho=$ density of titanium

$C_{d}=$ specific cost of deposited titanium

This work concluded that additive manufacturing is cost effective in instances where the buy/fly ratio is $12-1$ compared to more "conventional" ratios which tend to be lower. Note that the buy/fly ratio is calculated as the volume of the billet $(V)$ divided by the volume of the component $(v)$. It is a means for representing how much material must be machined away. Allen concludes that additive manufacturing techniques are attractive for components with a high buy/fly ratio, have a complex shape that requires significant machining, has a high material cost, and has slow machining rates.

\subsection{Additive Manufacturing Cost Advantage}

Many of the cost studies examine costs such as material and machine costs; however, many of the benefits may be hidden in inventory and supply chain costs. For instance, a dollar invested in automotive assembly takes 10.9 days to return in revenue. It spends 7.9 days in material inventory, waiting to be utilized. It spends 19.8 hours in production time and another 20.6 hours in down time when the factory is closed. Another 1.3 days is spent in finished goods inventory. ${ }^{51}$ Moreover, of the total time used, only $8 \%$ is spent in actual production. According to concepts from lean manufacturing, inventory and waiting, which constitute $92 \%$ of the automotive assembly time, are two of seven categories of waste. This is just the assembly of an automobile. The production of the engine parts, steering, suspension, power train, body, and others often occur separately and also have inventories of their own. Additionally, all of these parts are transported between locations. The average shipment of manufactured transportation equipment travels 801 miles. For the US, this amounts to 45.3 billion ton-miles of transportation equipment being moved annually. Because additive manufacturing can, in some instances now and possibly more in the future, build an entire assembly in one build, it reduces the need for some of the transportation and inventory costs, resulting in impacts throughout the supply chain. It is important to note that the ability to produce more complex

\footnotetext{
${ }^{51}$ Calculated from data in the Annual Survey of Manufactures and the Quarterly survey of plant capacity utilization.
} 
assemblies, such as those in an automobile, is still developing and involves some speculation about future capabilities. In addition to building complete or partial assemblies, there is also the potential of reducing the size of the supply chain through distributed manufacturing. Therefore, in order to understand the cost difference between additive manufacturing and other processes, it is necessary to examine the costs from raw material extraction to production and through the sale of the final product. This might be represented as:

$$
\begin{aligned}
C_{A M}=\left(M I_{R, A M}+M I_{M, A M}\right)+\left(P_{E, A M}+P_{R, A M}+P_{M, A M}\right) \\
+\left(F G I_{E, A M}+F G I_{R, A M}+F G I_{M, A M}\right)+W T_{A M}+R T_{A M}+T_{A M}
\end{aligned}
$$

Where

$C_{A M}=$ Cost of producing an additive manufactured product

$M I=$ Cost of material inventory for refining raw materials $(R)$ and for manufacturing $(M)$ for additive manufacturing $(A M)$

$P=$ Cost of the process of material extraction $(E)$, refining raw materials $(R)$, and manufacturing $(M)$, including administrative costs, machine costs, and other relevant costs for additive manufacturing $(A M)$

$F G I=$ Cost of finished goods inventory for material extraction $(E)$, refining raw materials $(R)$, and manufacturing $(M)$ for additive manufacturing $(A M)$

$W T_{A M}=$ Cost of wholesale trade for additive manufacturing $(A M)$

$R T_{A M}=$ Cost of retail trade for additive manufacturing $(A M)$

$T_{A M}=$ Transportation cost throughout the supply chain for an additive manufactured Product $(A M)$

This could be compared to the cost of traditional manufacturing, which could be represented as the following:

$$
\begin{gathered}
C_{\text {Trad }}=\left(M I_{R, \text { Trad }}+M I_{I, \text { Trad }}+M I_{A, \text { Trad }}\right)+\left(P_{E, \text { Trad }}+P_{R, \text { Trad }}+P_{I, \text { Trad }}+P_{A, \text { Trad }}\right) \\
+\left(F G I_{E, \text { Trad }}+F G I_{R, \text { Trad }}+F G I_{I, \text { Trad }}+F G I_{A, \text { Trad }}\right)+W T_{\text {Trad }}+R T_{\text {Trad }} \\
+T_{\text {Trad }}
\end{gathered}
$$

Where

$C_{\text {Trad }}=$ Cost of producing a product using traditional processes $($ Trad $)$

$M I=$ Cost of material inventory for refining raw materials $(R)$, producing intermediate goods $(I)$, and assembly $(A)$ for traditional manufacturing (Trad)

$P=$ Cost of the process of material extraction $(E)$, refining raw materials $(R)$, producing intermediate goods $(I)$, and assembly $(A)$, including administrative costs, machine costs, and other relevant costs for traditional manufacturing (Trad)

$F G I=$ Cost of finished goods inventory for material extraction $(E)$, refining raw materials $(R)$, producing intermediate goods $(I)$, and assembly $(A)$ for traditional manufacturing (Trad)

$W T_{\text {Trad }}=$ Cost of wholesale trade for traditional manufacturing (Trad) 
$R T_{\text {Trad }}=$ Cost of retail trade for traditional manufacturing $($ Trad $)$

$T_{\text {Trad }}=$ Transportation costs throughout the supply chain for a product made using traditional manufacturing (Trad)

Currently, there is a better understanding about the cost of the additive manufacturing process cost $\left(P_{A M}\right)$ than there is for the other costs of additive manufacturing. Additionally, most cost studies examine a single part or component; however, it is in the final product where additive manufacturing might have significant cost savings. Traditional manufacturing requires numerous intermediate products that are transported and assembled, whereas additive manufacturing can achieve the same final product with fewer component parts and multiple components built either simultaneously or in the same location. For example, consider the future possibility of an entire jet engine housing being made in one build using additive manufacturing compared to an engine housing that has parts made and shipped for assembly from different locations with each location having its own factory, material inventory, finished goods inventory, administrative staff, and transportation infrastructure among other things. Additionally, the jet engine housing might be made using less material, perform more efficiently, and last longer because the design is not limited to the methods used in traditional manufacturing; however, many of these benefits would not be captured in the previously mentioned cost model. To capture these benefits one would need to include a cradle to grave analysis.

\subsection{Additive Manufacturing Total Advantage}

At the company level, the goal is to maximize profit; however, at the societal level there are multiple stakeholders to consider and different costs and benefits. At this level, one might consider the goal to be to minimize resource use and maximize utility. Dollar values are affected by numerous factors such as scarcity, regulations, and education costs among other things that impact how resources are efficiently allocated. The allocation of resources is an important issue; however, understanding the societal impact of additive manufacturing requires separating resource allocation issues from resource utilization issues.

The factors of production are, typically, considered to be land (i.e., natural resources), labor, capital, and entrepreneurship; however, capital includes machinery and tools, which themselves are made of land and labor. Additionally, a major element in the production of all goods and services is time, as illustrated in many operations management discussions. Therefore, one might consider the most basic elements of production to be land, labor, human capital, entrepreneurship, and time. The human capital and entrepreneurship utilized in producing additive manufactured goods are important, but these are complex issues that are not a focus of this report. The remaining items land, labor, and time constitute the primary cost elements for production. It is important to note that there is a tradeoff between time and labor (measured in labor hours per hour), as illustrated in Figure 4.5. For example, it takes one hundred people less time to build a house than it takes for one person to build a house. It is also important to note that there is also a tradeoff between time/labor and land (i.e., natural resources), as illustrated in Figure 4.6. For example, a machine can reduce both the time and the 
Figure 4.5: Time and Labor Needed to Produce a Manufactured Product

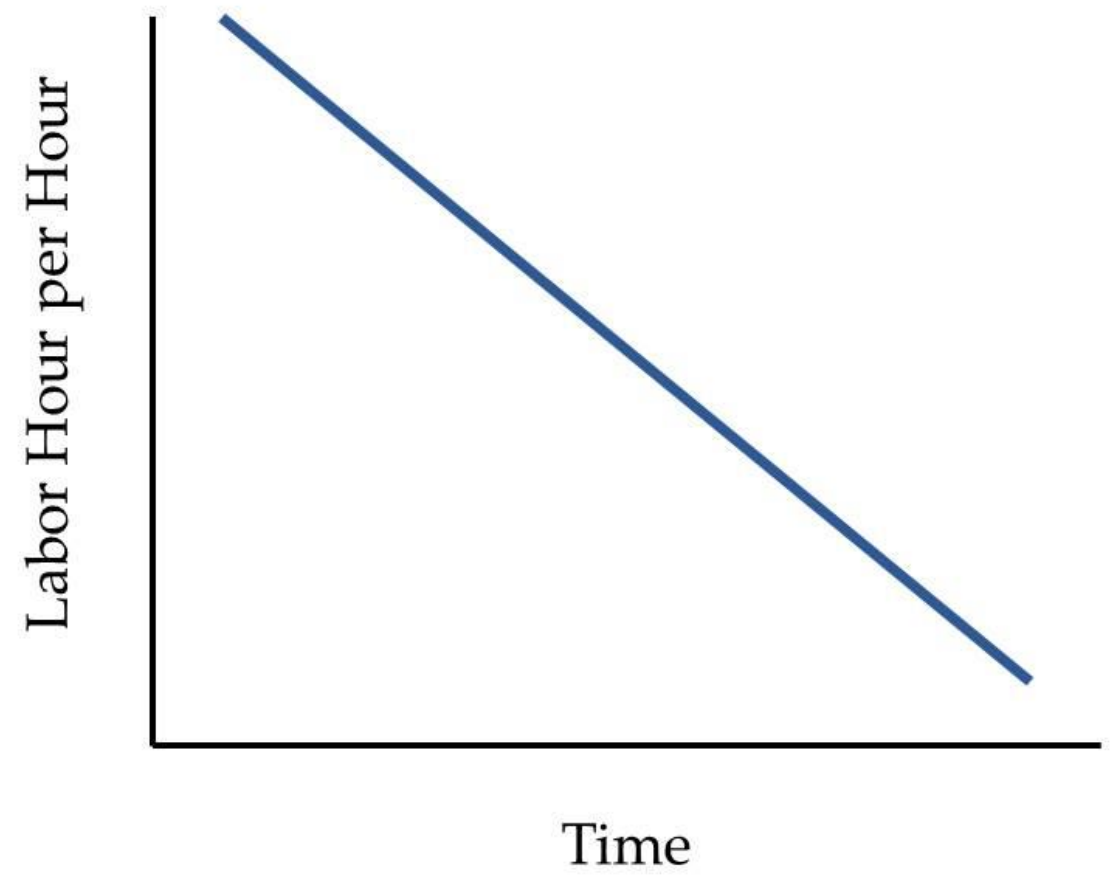

Figure 4.6: Time, Labor, and Natural Resources Needed to Produce a Manufactured Product

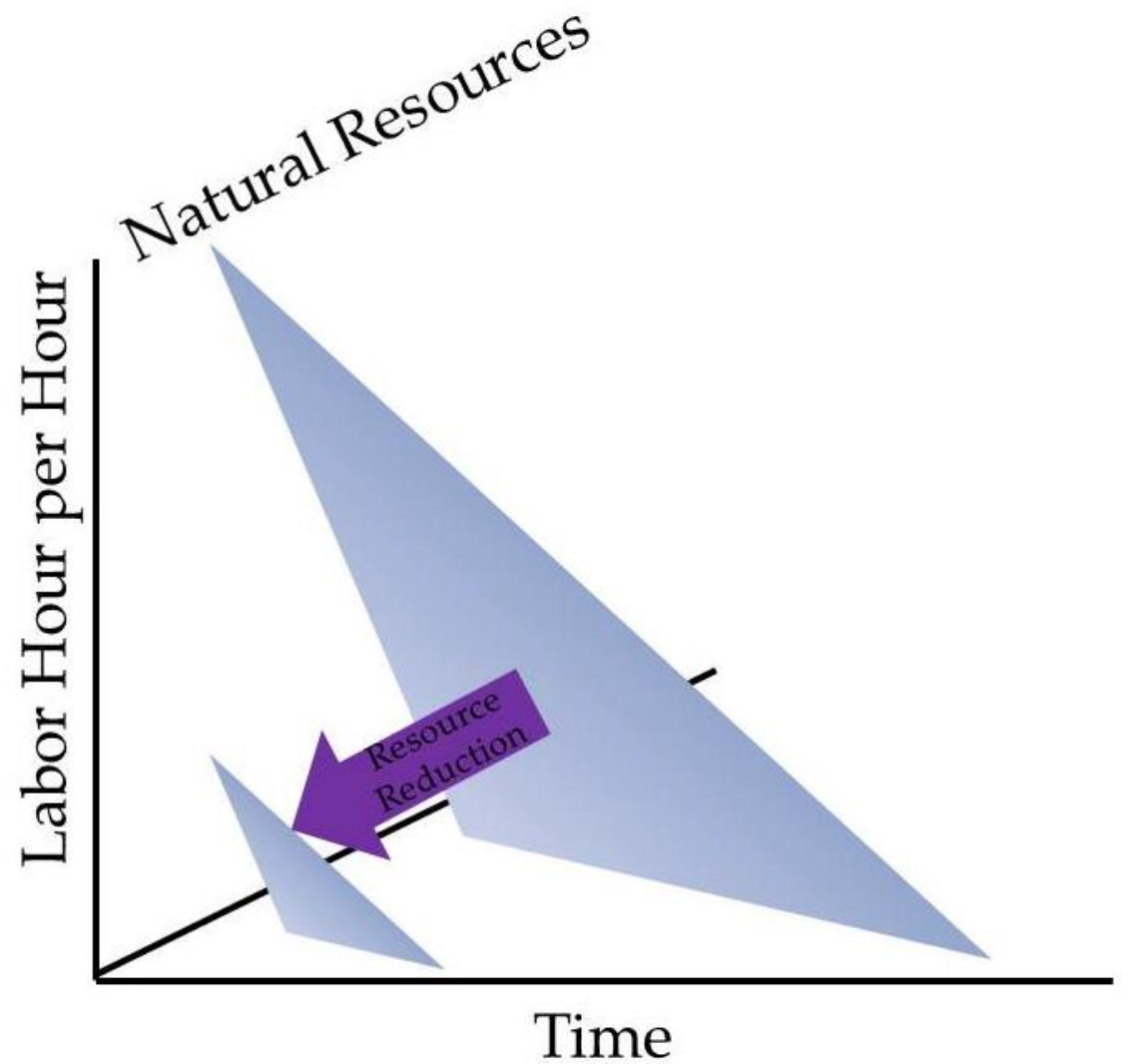


number of people needed for production, but utilizes more energy. The triangular plane in the figure represents possible combinations of land, labor, and time needed for producing a manufactured good. Moving anywhere along this plane is simply an alteration of resource use. A company can maximize profit by either altering resources or by reducing the resources needed for production. Moving along the plane in Figure 4.6 may result in a more efficient allocation of resources for a firm and for society; however, it does not reduce the combination of resources needed for production. Therefore, when examining the cost and benefits of a product or process from a societal perspective, it becomes apparent that one needs to measure land, labor, and time needed for production in order to understand whether there has been a reduction in the combination of resources needed to produce a manufactured good. If additive manufacturing results in a reduction in the resources needed for production, then that plane will move toward the origin as illustrated in Figure 4.6.

In addition to production, manufactured goods are produced to serve a designated purpose. For example, automobiles transport objects and people; cell phones facilitate communication; and monitors display information. Each item produced is designed for some purpose. In the process of fulfilling this purpose more resources are expended in the form of land, labor, and time. Additionally, a product with a short life span results in more resources being expended to reproduce the product. Additionally, the disposal of the old product may result in expending further resources. Additive manufactured products may provide product enhancements, new abilities, or an extended useful life. The total advantage of an additive manufactured good is the difference in the use of land, labor, and time expended on production, utilization, and disposal combined with the utility gained from the product compared to that of traditional manufacturing methods. This can be represented as the following:

$$
\begin{gathered}
T A_{L}=\left(L_{A M, P}+L_{A M, U}+L_{A M, D}\right)-\left(L_{T, P}+L_{T, U}+L_{T, D}\right) \\
T A_{L B}=\left(L B_{A M, P}+L B_{A M, U}+L B_{A M, D}\right)-\left(L B_{T, P}+L B_{T, U}+L B_{T, D}\right) \\
T A_{T}=\left(T_{A M, P}+T_{A M, U}+T_{A M, D}\right)-\left(T_{T, P}+T_{T, U}+T_{T, D}\right) \\
T A_{U}=U\left(P_{A M}\right)-U\left(P_{T}\right)
\end{gathered}
$$

$T A=$ The total advantage of additive manufacturing compared to traditional methods for Land $(L)$, labor $(L B)$, time $(T)$, and utility of the product $(U)$.

$L=$ The land or natural resources needed using additive manufacturing processes $(A M)$ or traditional methods $(T)$ for production $(P)$, utilization $(U)$, and disposal $(D)$ of the product

$L B=$ The labor hours per hour needed using additive manufacturing processes $(A M)$ or traditional methods $(T)$ for production $(P)$, utilization $(U)$, and disposal $(D)$ of the product 
$T=$ The time needed using additive manufacturing processes $(A M)$ or traditional methods $(T)$ for production $(P)$, utilization $(U)$, and disposal $(D)$ of the product

$U\left(P_{A M}\right)=$ The utility of a product manufactured using additive manufacturing processes, including the utility gained from increased abilities, enhancements, and useful life.

$U\left(P_{T}\right)=$ The utility of a product manufactured using traditional processes, including the utility gained from increased abilities, enhancements, and useful life.

In this case production includes material extraction, material refining, manufacturing, and transportation among other things. Unfortunately, our current abilities fall short of being able to measure all of these items for all products; however, it is important to remember that these items must be considered when measuring the total advantage of additive manufacturing. An additional challenge is that land, labor, time, and utility are measured in different units, making them difficult to compare. An additive manufactured product might require more labor but reduce the natural resources needed. In this instance, there is a tradeoff. 


\section{Implementation and Adoption of Additive Manufacturing}

Additive manufacturing is significantly different from traditional methods; thus, determining when and how to take advantage of the benefits of additive manufacturing is a challenge in and of itself. Additionally, the manufacturing industry is oriented toward optimizing production using traditional methods. Identifying products that benefit from increased complexity, or being produced in closer proximity to consumers, or understanding the impact on inventory is complex and difficult as it impacts factors that are difficult to measure.

\subsection{Additive Manufacturing and Firm Capabilities}

In order to create products and services, a firm needs resources, established processes, and capabilities. ${ }^{52}$ Resources include natural resources, labor, and other items needed for production. A firm must have access to resources in order to produce goods and services. The firm must also have processes in place that transform resources into products and services. Two firms may have the same resources and processes in place; however, their products may not be equivalent due to quality, performance, or cost of the product or service. This difference is due to the capabilities of the firm; that is, capabilities are the firm's ability to produce a good or service effectively. Kim and Park (2013) present three entities of capabilities (see Figure 5.1): controllability, flexibility, and integration. ${ }^{53}$

Figure 5.1: Necessities of a Firm

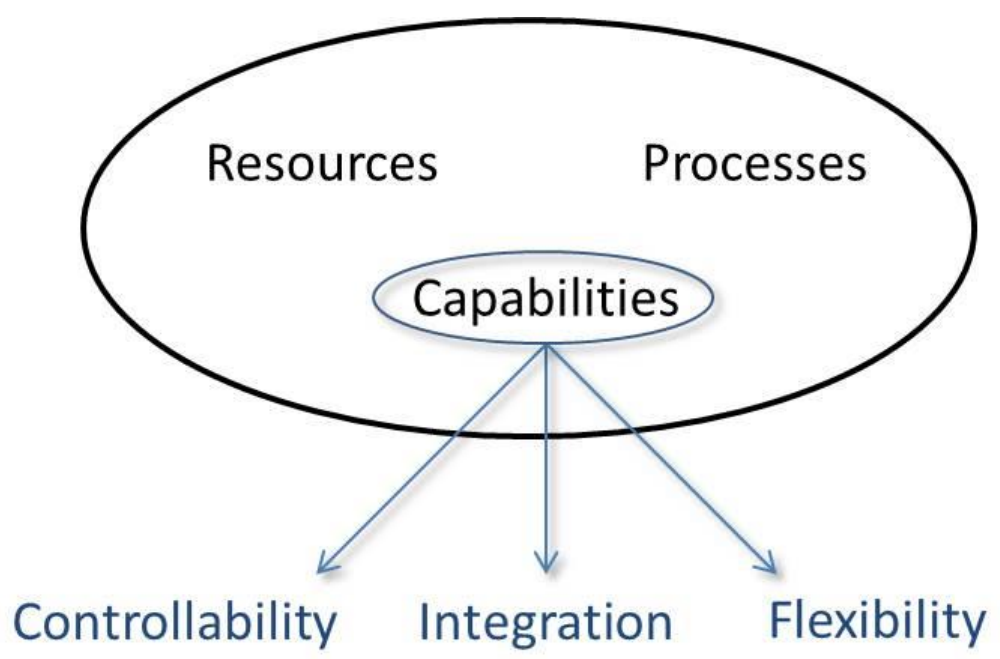

Adapted from Kim, Bowon and Chulsoon Park. (2013). "Firms' Integrating Efforts to Mitigate the Tradeoff Between Controllability and Flexibility.” International Journal of Production Research. 51(4): 1258-1278.

\footnotetext{
${ }^{52}$ Kim, Bowon. "Supply Chain Management: A Learning Perspective." Korea Advanced Institute of Science and Technology. Coursera Lecture 1-2.

${ }^{53}$ Kim, Bowon and Chulsoon Park. (2013). "Firms' Integrating Efforts to Mitigate the Tradeoff Between Controllability and Flexibility." International Journal of Production Research. 51(4): 1258-1278.
} 
Controllability is the firm's ability to control its processes. Its primary objective is to achieve efficiency that minimizes cost and maximizes accuracy and productivity. Flexibility is the firm's ability to deal with internal and external uncertainties. It includes reacting to changing circumstances while sustaining few impacts in time, cost, or performance. According to Kim and Park, there is a tradeoff between controllability and flexibility; that is, in the short term, a firm chooses combinations of flexibility and controllability, sacrificing one for the other as illustrated in Figure 5.2. Over time, a firm can integrate and increase both flexibility and controllability through technology or knowledge advancement among other things. In addition to the entities of capabilities, there are categories of capabilities or a chain of capabilities, which include basic capabilities, process-level capabilities, system-level capabilities, and performance. As seen in Figure 5.3, basic capabilities include overall knowledge and experience of a firm and its employees, including their engineering skills, safety skills, and work ethics among other things. Process-level capabilities include individual functions such as assembly, welding, and other individual activities. System-level capabilities include bringing capabilities together to transform resources into goods and services. The final item in the chain is performance, which is often measured in profit, revenue, or customer satisfaction among other things.

Figure 5.2: Flexibility and Controllability

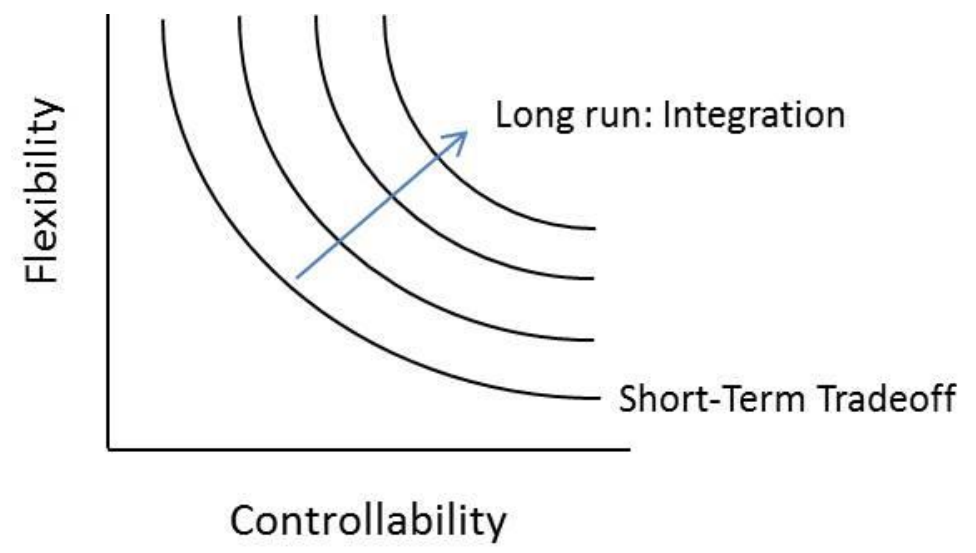

Adapted from Kim, Bowon and Chulsoon Park. (2013). "Firms' Integrating Efforts to Mitigate the Tradeoff Between Controllability and Flexibility." International Journal of Production Research. 51(4): 1258-1278.

Adopting a new technology, such as additive manufacturing, can have significant impacts on a firm's capabilities. As discussed in the previous sections, in some instances the per unit cost can be higher for additive manufacturing than for traditional methods. The result is that a firm sacrifices controllability for flexibility; thus, it makes sense for those firms that seek a high flexibility position to adopt additive manufacturing. In some instances, however, additive manufacturing can positively affect controllability. Additive manufacturing can reduce costs for products that have complex designs that are costly to manufacture using traditional methods. As the price of material and systems comes down 
for additive manufacturing, the controllability associated with this technology will increase, making it attractive to more firms.

In addition to the tradeoff between flexibility and controllability, additive manufacturing can also directly impact a firm's chain of capability, including the basic, process-level, and system-level capabilities. At the basic level, additive manufacturing requires new knowledge, approaches, and designs. These new knowledge areas can be costly and difficult to acquire. At the process-level, a firm that adopts additive manufacturing is abandoning many of its current individual functions to adopt a radically new production method. Former functions might have required significant investment in order to fully develop. Many firms may be apprehensive in abandoning these capabilities for a new process, which itself may require significant investment to fully develop. Finally, additive manufacturing can impact the system-level capability, as it is not only a process that affects the production of individual parts, but also the assembly of the parts. All of these changes can make it costly and risky for a business to adopt additive manufacturing technologies and can result in reducing the rate at which this technology is adopted.

Figure 5.3: Chain of Capability

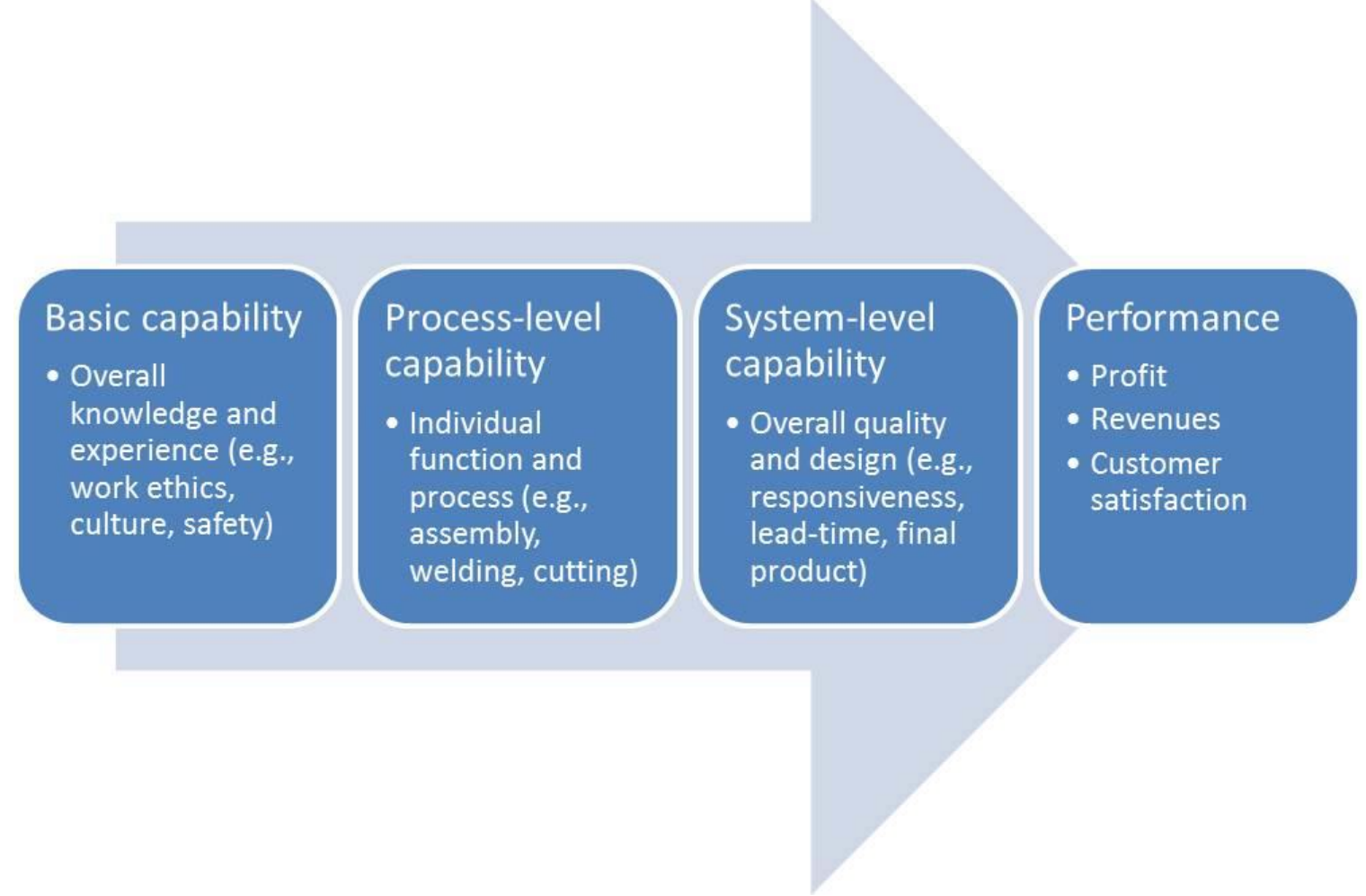

Adapted from Kim, Bowon and Chulsoon Park. (2013). "Firms' Integrating Efforts to Mitigate the Tradeoff Between Controllability and Flexibility." International Journal of Production Research. 51(4): 1258-1278. 


\subsection{Adoption of Additive Manufacturing}

Globally, 6494 industrial additive manufacturing systems were delivered in 2011 with a cumulative total of 49035 systems being delivered between 1988 and $2011 .{ }^{54}$ Of these, 18780 were deployed in the U.S. The growth in the cumulative number of additive manufacturing systems in the U.S. between 2010 and 2011 was $15.3 \%{ }^{55}$ It is difficult to predict the impact that additive manufacturing will have on future products. Currently, many believe that it may result in significant changes in how products are manufactured; however, there are often predictions from the past that have not come to fruition. Therefore, it is advantageous to attempt to better understand the potential future of additive manufacturing. Data from Wohlers provides some limited ability to examine past adoptions of additive manufacturing to conjecture about future adoptions. ${ }^{56}$

The status of some of the variables that affect the adoption of additive manufacturing technologies can be observed through existing articles and texts; however, many issues cannot be substantiated without gathering additional data. Surveys can often be used to assess a producer or user's opinion of a new technology, but this is often a resource intensive process. Thomas (2013) uses domestic unit sales to estimate future adoptions of additive manufacturing. ${ }^{57}$ Using the number of domestic unit sales ${ }^{58}$, the growth in sales can be fitted using least squares criterion to an exponential curve that represents the traditional logistic S-curve of technology diffusion. The most widely accepted model of technology diffusion was presented by Mansfield ${ }^{59}$ :

$$
p(t)=\frac{1}{1+e^{\alpha-\beta t}}
$$

where

$p(t)=$ the proportion of potential users who have adopted the new technology by time $t$; $\alpha=$ location parameter; and

$\beta=$ Shape parameter $(\beta>0)$.

In order to examine additive manufacturing, it is assumed that the proportion of potential units sold by time $t$ follows a similar path as the proportion of potential users who have adopted the new technology by time $t$. In order to examine shipments in the industry, it is assumed that an additive manufacturing unit represents a fixed proportion of the total

\footnotetext{
${ }^{54}$ Wohlers, Terry. "Wohlers Report 2012: Additive Manufacturing and 3D Printing State of the Industry." Wohlers Associates, Inc. 2012.

55 Ibid

56 Ibid.

57 Thomas, Douglas. 2013. Economics of the U.S. Additive Manufacturing Industry. NIST Special Publication 1163. Gaithersburg, MD: U.S. Dept. of Commerce, National Institute of Standards and Technology.

${ }^{58}$ Wohlers, Terry. "Wohlers Report 2012: Additive Manufacturing and 3D Printing State of the Industry." Wohlers Associates, Inc. 2012.

${ }^{59}$ Mansfield, Edwin. Innovation, Technology and the Economy: Selected Essays of Edwin Mansfield. Economists of the Twentieth Century Series (Brookfield, VT: 1995, E. Elgar).
} 
revenue; thus, revenue will grow similarly to unit sales. The proportion used was calculated from 2011 data. The parameters $\alpha$ and $\beta$ are estimated using regression on the cumulative annual sales of additive manufacturing systems in the U.S. between 1988 and 2011. United States system sales are estimated as a proportion of global sales. This method provides some insight into the current trend in the adoption of additive manufacturing technology. Unfortunately, there is little insight into the total market saturation level for additive manufacturing; that is, there is not a good sense of what percent of the relevant manufacturing industries (shown in Table 1.1) will produce parts using additive manufacturing technologies versus conventional technologies. In order to address this issue, a modified version of Mansfield's model is adopted from Chapman ${ }^{60}$ :

$$
p(t)=\frac{\eta}{1+e^{\alpha-\beta t}}
$$

where

$\eta=$ market saturation level in percent.

Because $\eta$ is unknown, it is varied between $0.15 \%$ and $100 \%$ of the relevant manufacturing shipments, as seen in Table 5.1. The $0.15 \%$ is derived from Wohlers estimate that the 2011 sales revenue represents $8 \%$ market penetration, which equates to $\$ 3.1$ billion in market opportunity and $0.15 \%$ market saturation. At this level, additive manufacturing is forecasted to reach $50 \%$ market potential in 2018 and $100 \%$ in 2045, as seen in the table. A more likely scenario seems to be that additive manufacturing would have between $5 \%$ and $35 \%$ market saturation. At these levels, additive manufacturing would reach $50 \%$ of market potential between 2031 and 2038 while reaching $100 \%$ between 2058 and 2065, as seen in Table 5.1. The industry would reach $\$ 50$ billion between 2029 and 2031 while reaching $\$ 100$ billion between 2031 and 2044 . As illustrated in Figure 5.4, it is likely that additive manufacturing is at the far left tail of the diffusion curve, making it difficult to forecast the future trends; thus, some caution should be used when interpreting this forecast. The figure illustrates the diffusion at each market saturation level presented in Table 5.1 with the exception of the $0.50 \%$ and $0.15 \%$ levels, as they are too small to be included in this graph.

\footnotetext{
${ }^{60}$ Chapman, Robert. "Benefits and Costs of Research: A Case Study of Construction Systems Integration and Automation Technologies in Commercial Buildings." NISTIR 6763. December 2001. National Institute of Standards and Technology.
} 
Table 5.1: Forecasts of U.S. Additive Manufacturing Shipments by Varying Market Potential

\begin{tabular}{|c|c|c|c|c|c|c|}
\hline $\begin{array}{l}\text { Market } \\
\text { Potential of } \\
\text { Relevant } \\
\text { Manufacturing } \\
\text { (percent of } \\
\text { shipments) }\end{array}$ & $\begin{array}{l}\text { Market } \\
\text { Potential, } \\
\text { Shipments } \\
\text { (\$billions } \\
\text { 2011) }\end{array}$ & $\begin{array}{l}\text { Approximate } \\
\text { Year } 100 \% \\
\text { of Market } \\
\text { Potential } \\
\text { Reached }\end{array}$ & $\begin{array}{c}\text { Approximate } \\
\text { Year } 50 \% \text { of } \\
\text { Market } \\
\text { Potential } \\
\text { Reached }\end{array}$ & $\begin{array}{l}\text { Approximate } \\
\text { Year } \$ 100 \\
\text { Billion in } \\
\text { Shipments is } \\
\text { Reached }\end{array}$ & $\begin{array}{l}\text { Approximate } \\
\text { Year } \$ 50 \\
\text { Billion in } \\
\text { Shipments is } \\
\text { Reached }\end{array}$ & $\mathrm{R}^{2}$ \\
\hline 100.00 & $\$ 2058.9$ & 2069 & 2042 & 2031 & 2028 & 0.948 \\
\hline 75.00 & $\$ 1544.2$ & 2068 & 2041 & 2031 & 2028 & 0.948 \\
\hline 50.00 & $\$ 1029.5$ & 2067 & 2039 & 2031 & 2029 & 0.948 \\
\hline 45.00 & $\$ 926.5$ & 2066 & 2039 & 2031 & 2029 & 0.948 \\
\hline 40.00 & $\$ 823.6$ & 2066 & 2038 & 2031 & 2029 & 0.948 \\
\hline 35.00 & $\$ 720.6$ & 2065 & 2038 & 2031 & 2029 & 0.948 \\
\hline 30.00 & $\$ 617.7$ & 2065 & 2037 & 2031 & 2029 & 0.948 \\
\hline 25.00 & $\$ 514.7$ & 2064 & 2037 & 2032 & 2029 & 0.948 \\
\hline 20.00 & $\$ 411.8$ & 2063 & 2036 & 2032 & 2029 & 0.948 \\
\hline 15.00 & $\$ 308.8$ & 2062 & 2035 & 2032 & 2029 & 0.948 \\
\hline 10.00 & $\$ 205.9$ & 2061 & 2033 & 2033 & 2029 & 0.948 \\
\hline 5.00 & $\$ 102.9$ & 2058 & 2031 & 2044 & 2031 & 0.948 \\
\hline 1.00 & $\$ 20.6$ & 2052 & 2025 & - & - & 0.949 \\
\hline 0.50 & $\$ 10.3$ & 2050 & 2023 & - & - & 0.949 \\
\hline 0.15 & $\$ 3.1$ & 2045 & 2018 & - & - & 0.950 \\
\hline
\end{tabular}

Thomas, Douglas. 2013. Economics of the U.S. Additive Manufacturing Industry. NIST Special Publication 1163. Gaithersburg, MD: U.S. Dept. of Commerce, National Institute of Standards and Technology. 
Figure 5.4: Forecasts of U.S. Additive Manufacturing Shipments, by Varying Market Saturation Levels

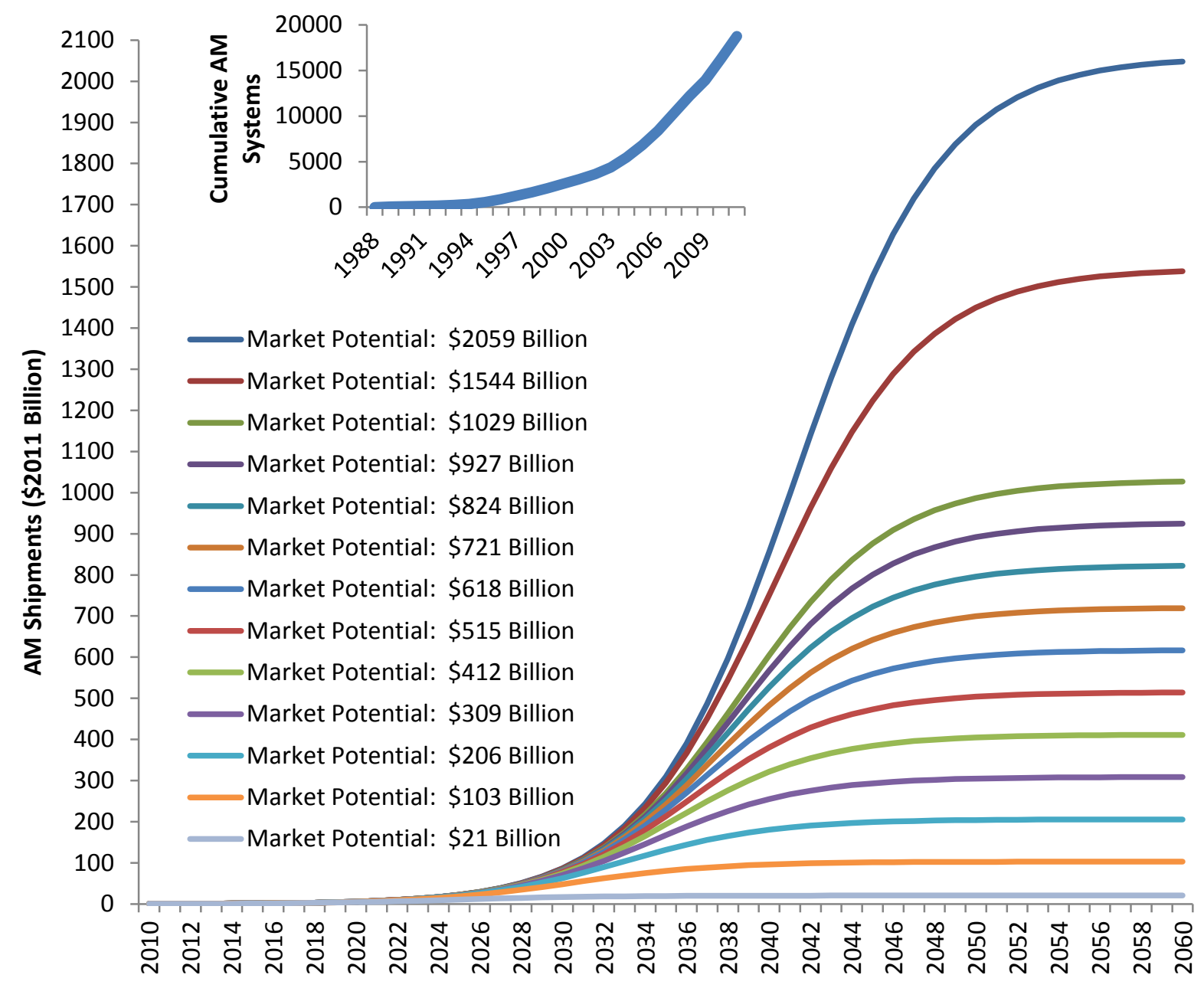

Thomas, Douglas. 2013. Economics of the U.S. Additive Manufacturing Industry. NIST Special Publication 1163. Gaithersburg, MD: U.S. Dept. of Commerce, National Institute of Standards and Technology. 


\section{Summary}

Current research on additive manufacturing costs reveals that this technology is cost effective for manufacturing small batches with continued centralized manufacturing; however, with increased automation distributed production may be cost effective. Due to the complexities of measuring additive manufacturing costs, current studies are limited in their scope. Many of the current studies examine the production of single parts and those that examine assemblies do not examine supply chain effects such as inventory and transportation costs along with decreased risk to supply disruption. Currently, research also reveals that material costs constitute a major proportion of the cost of a product produced using additive manufacturing. Technologies can often be complementary, where two technologies are adopted alongside each other and the benefits are greater than if they were adopted individually. Increasing adoption of additive manufacturing may lead to a reduction in raw material cost through economies of scale. The reduced cost in raw material might then propagate further adoption of additive manufacturing. There may also be economies of scale in raw material costs if particular materials become more common rather than a plethora of different materials. The additive manufacturing system is also a significant cost factor; however, this cost has continually decreased. Between 2001 and 2011 the average price decreased $51 \%$ after adjusting for inflation. ${ }^{61}$

A number of factors complicate minimizing the cost of additive manufacturing, including build orientation, envelope utilization, build time, energy consumption, product design, and labor. The simple orientation of the part in the build chamber can result in as much as $160 \%$ increase in the energy consumed. Additionally, fully utilizing the build chamber reduces the per-unit cost significantly. Each of these issues must be considered in the cost of additive manufacturing, making it difficult and complicated to minimize costs. These issues, likely, slow the adoption of this technology, as it requires advanced knowledge.

Additive manufacturing not only has implications for the costs of production, but also the utilization of the final product. This technology allows for the manufacture of products that might not have been possible using traditional methods. These products may have new abilities, extended useful life, or reduce the time, labor, or natural resources needed to use these products. For example, automobiles might be made lighter, reducing fuel costs or combustion engines might be designed to reduce cooling needs. For this reason, there is a need to track the land (i.e., natural resources), labor, and time expended on production, utilization, and disposal along with the utility gained from new designs. The difficulty in measuring these items, likely, slows the adoption of additive manufacturing.

\footnotetext{
${ }^{61}$ The price was adjusted using the Consumer Price Index for all consumers for all areas from the Bureau of Labor Statistics. This adjustment, likely, underestimates the degree of price deflation, as it does not account for quality and productivity improvements specific to these systems. Unfortunately, there is not a price index that accounts for these issues.
} 


\section{Bibliography with Abstracts}

Allen, Jeff. 2006. "An Investigation into the Comparative Costs of Additive Manufacture vs. Machine from Solid for Aero Engine Parts." In Cost Effective Manufacture via NetShape Processing, 17-1 - 17-10. Meeting Proceedings RTO-MP-AVT-139. Paper 17. DTIC Document. <http://www.rto.nato.int/abstracts.asp>

An overview of the relative economics of producing a near net shape by Additive Manufacturing (AM) processes compared with traditional machine from solid processes (MFS) is provided.

A relationship is developed to estimate the specific cost of AM material required to achieve a (typical) $30 \%$ saving over conventional MFS techniques. The use of AM techniques are shown to be advantageous for parts which have a high buy:fly ratio, have a complex shape, have a high cost of raw material used for machining from solid, have slow machining rates and are difficult and expensive to machine.

The specific cost of material deposited by additive manufacturing systems required to give a $30 \%$ saving over conventional Machine from solid techniques is estimated for a typical aerospace alloy over a range of buy:fly ratios.

The specific costs of a typical aerospace alloy deposited by present and future additive manufacturing systems are estimated and compared with the required specific costs estimated above.

It is concluded that additive manufacture is commercially viable using present additive manufacturing systems for components with a buy:fly ratio of about 12:1. For projected future additive manufacturing systems economic production of components with a buy:fly ratio of about 3 should be feasible.

Alexander, Paul, Seth Allen, and Debasish Dutta. 1998. "Part Orientation and Build Cost Determination in Layered Manufacturing." Computer-Aided Design 30 (5): 343-56. doi:10.1016/S0010-4485(97)00083-3.

As more choices of materials and build processes become available in layered manufacturing (LM), it is increasingly important to identify fundamental problems that underlie the entire field. Determination of best build orientation and minimizing build cost of a part are two such issues that must be considered in any LM process. By decoupling the solution to these problems from a specific LM technology, not only can the solution be applied to a variety of processes, but more realistic cost comparisons of parts built on different machines become possible.

Allen, Jeff. 2006. "An Investigation into the Comparative Costs of Additive Manufacture vs. Machine from Solid for Aero Engine Parts". DTIC Document.

An overview of the relative economics of producing a near net shape by Additive Manufacturing (AM) processes compared with traditional machine from solid processes (MFS) is provided.

A relationship is developed to estimate the specific cost of AM material required to achieve a (typical) $30 \%$ saving over conventional MFS techniques. The use of AM techniques are shown to be advantageous for parts which have a high buy:fly ratio, have a complex shape, have a high cost of raw material used for machining from solid, have slow machining rates and are difficult and expensive to machine.

The specific cost of material deposited by additive manufacturing systems required to give a $30 \%$ saving over conventional Machine from solid techniques is estimated for a typical aerospace alloy over a range of buy:fly ratios. 
The specific costs of a typical aerospace alloy deposited by present and future additive manufacturing systems are estimated and compared with the required specific costs estimated above.

It is concluded that additive manufacture is commercially viable using present additive manufacturing systems for components with a buy:fly ratio of about 12:1. For projected future additive manufacturing systems economic production of components with a buy:fly ratio of about 3 should be feasible.

\section{ATKINS Project. 2007. Manufacturing a Low Carbon Footprint: Zero Emission Enterprise Feasibility Study. Project No: N0012J. Loughborough University.}

Abstract unavailable.

Atzeni, Eleonora, Luca Iuliano, Paolo Minetola, and Alessandro Salmi. 2010. "Redesign and Cost Estimation of Rapid Manufactured Plastic Parts." Rapid Prototyping Journal 16 (5): 308-17.

Purpose - The purpose of this paper is to highlight how rapid manufacturing (RM) of plastic parts combined with part redesign could have positive repercussion on cost saving.

Design/methodology/approach - Comparison between two different technologies for plastic part production, the traditional injection molding (IM) and the emergent RM, is done with consideration of both the geometric possibilities of RM and the economic aspect. From an extended literature review, the redesign guidelines and the cost model are identified and then applied to a component selected for its shape complexity. It is an assembly that was redesigned for RM purpose, in order to take advantage of additive manufacturing potentialities. The geometric and economic differences between IM and RM are discussed.

Findings - This research evidences that currently in Western Europe RM combined with redesign can be economically convenient and competitive to IM for medium volume production of plastic parts. Consequently, this is a great opportunity to keep the production in Europe instead of moving it overseas.

Research limitations/implications - As regards manufacturing costs, results presented in this study are mainly based on cost estimation provided by Italian companies and it is assumed that the plant is located in Western Europe.

Practical implications - The research assesses the feasibility of making functional and operational plastic parts without the use of traditional manufacturing processes by redesign for RM.

Originality/value - Two different kinds of research papers comparing RM and IM exist in literature: on the one hand, the two techniques are evaluated from the economical point of view, on the other, the part redesign is analyzed. No paper considers the interrelation between redesign and cost estimation. In this work, these aspects are combined to point out that a remarkable cost reduction is obtained when the component shape is modified to exploit RM advantages.

Atzeni, Eleonora, and Alessandro Salmi. 2012. "Economics of Additive Manufacturing for End-Usable Metal Parts.” The International Journal of Advanced Manufacturing Technology 62 (9-12): 1147-55.

Additive manufacturing (AM) of metal parts combined with part redesign has a positive repercussion on cost saving. In fact, a remarkable cost reduction can be obtained if the component shape is modified to exploit AM potentialities. This paper deals with the evaluation of the production volume for which AM techniques result competitive with respect to conventional processes for the production of end-usable metal parts. For this purpose, a comparison between two different technologies for metal 
part fabrication, the traditional high-pressure die-casting and the direct metal laser sintering additive technique, is done with consideration of both the geometric possibilities of AM and the economic point of view. A design for additive manufacturing approach is adopted. Costs models of both processes are identified and then applied to an aeronautical component selected as case study. This research evidences that currently additive techniques can be economically convenient and competitive to traditional processes for small to medium batch production of metal parts.

Atzeni, Eleonora, Luca Iuliano, and Allessandro Salmi. 2011. "On the Competitiveness of Additive Manufacturing for the Production of Metal Parts." 9th International Conference on Advanced Manufacturing Systems and Technology.

\begin{abstract}
Additive Manufacturing (AM) of metal parts combined with part redesign has positive repercussion on cost saving. In fact a remarkable cost reduction can be obtained if the component shape is modified to exploit AM potentialities. This paper deals with the evaluation of the production volume for which AM techniques result competitive with respect to conventional processes. For this purpose a comparison between two different technologies for metal part production, the traditional high pressure die casting (HPDC) and the innovative AM, is done with consideration of both the geometric possibilities of AM and the economic point of view. Redesign guidelines and costs models are identified and then applied to an aeronautical component selected as case study. This research evidences that currently additive techniques can be economically convenient and competitive to traditional processes for low volume production of metal parts.
\end{abstract}

Baldinger, M., and A. Duchi. 2013. "Price Benchmark of Laser Sintering Service Providers." In High Value Manufacturing: Advanced Research in Virtual and Rapid Prototyping: Proceedings of the 6th International Conference on Advanced Research in Virtual and Rapid Prototyping, Leiria, Portugal, 1-5 October, 2013, 37. Leiria, Portugal: CRC Press.

Additive manufacturing is not only use for rapid prototyping in product development but increasingly for rapid manufacturing - meaning for production of final parts. Besides limitations around materials, quality and standards, cost is one of the major barriers to more widespread adoption. Due to the high investment for rapid manufacturing equipment and lack of knowledge, many companies choose to buy instead of make additively manufactured parts. Despite the importance of cost, there is limited insight into the price structure of additive manufacturing service providers. This study aims to narrow this gap through global price benchmark of labor sintering service providers.

Bartolo, Paulo Jorge da Silva, Mateus Artur Jorge, Fernando da Conceicao Batista, Henrique Amorim Almeida, Joao Manuel Matias, Joel Correia Vasco, Jorge Brites Gaspar, et al., eds. 2007. Virtual and Rapid Manufacturing: Advanced Research in Virtual and Rapid Prototyping. CRC Press.

Collection of 120 peer-reviewed papers that were presented at the 3rd International Conference on Advanced Research in Virtual and Rapid Prototyping, held in Leiria, Portugal in September 2007. Essential reading for all those working on V\&RP, focused on inducing increased collaboration between industry and academia. In addition to keynotes dealing with cutting-edge manufacturing engineering issues, contributions deal with topical research virtual and rapid prototyping (V\&RP), such as: 1. biomanufacturing, 2. CAD and 3D data acquistion technologies, 3. materials, 4. rapid tooling and manufacturing, 6. advanced rapid prototyping technologies and nanofabrication, 7. virtual environments, 8. collaborative design and engineering and 9. various applications. 
Baumers, Martin. 2012. "Economic Aspects of Additive Manufacturing: Benefits, Costs and Energy Consumption".

\begin{abstract}
Additive Manufacturing (AM) refers to the use of a group of technologies capable of combining material layer-by-layer to manufacture geometrically complex products in a single digitally controlled process step, entirely without moulds, dies or other tooling. AM is a parallel manufacturing approach, allowing the contemporaneous production of multiple, potentially unrelated, components or products. This thesis contributes to the understanding of the economic aspects of additive technology usage through an analysis of the effect of AM s parallel nature on economic and environmental performance measurement. Further, this work assesses AM s ability to efficiently create complex components or products. To do so, this thesis applies a methodology for the quantitative analysis of the shape complexity of AM output. Moreover, this thesis develops and applies a methodology for the combined estimation of build time, process energy flows and financial costs. A key challenge met by this estimation technique is that results are derived on the basis of technically efficient AM operation. Results indicate that, at least for the technology variant Electron Beam Melting, shape complexity may be realised at zero marginal energy consumption and cost. Further, the combined estimator of build time, energy consumption and cost suggests that AM process efficiency is independent of production volume. Rather, this thesis argues that the key to efficient AM operation lies in the user s ability to exhaust the available build space.
\end{abstract}

Baumers, M., C. Tuck, R. Hague, I. Ashcroft, and R. Wildman. 2010. “A Comparative Study of Metallic Additive Manufacturing Power Consumption." In 21 st Annual International Solid Freeform Fabrication Symposium-An Additive Manufacturing Conference, Austin/TX/USA, 9th-11th August. Austin, TX.

Efficient resource utilisation is seen as one of the advantages of Additive Manufacturing (AM). This paper presents a comparative assessment of electricity consumption of two major metallic AM processes, selective laser melting and electron beam melting. The experiments performed for this study are based on the production of a common power monitoring geometry. Due to the technology's parallel nature, the degree of build volume utilization will affect any power consumption metric. Therefore, this work explores energy consumption on the basis of whole builds - while compensating for discrepancies in packing efficiency. This provides insight not only into absolute levels of power consumption but also on comparative process efficiency.

Baumers, M., C. Tuck, R. Wildman, I. Ashcroft, and R. Hague. 2011. "Energy Inputs to Additive Manufacturing: Does Capacity Utilization Matter?" In 22nd Annual International Solid Freeform Fabrication Symposium-An Additive Manufacturing Conference, Austin/TX/USA, 8th-10th August.

The available additive manufacturing (AM) platforms differ in terms of their operating principle, but also with respect to energy input usage. This study presents an overview of electricity consumption across several major AM technology variants, reporting specific energy consumption during the production of dedicated test parts (ranging from 61 to $4849 \mathrm{MJ}$ per $\mathrm{kg}$ deposited). Applying a consistent methodology, energy consumption during single part builds is compared to the energy requirements of full build experiments with multiple parts (up to 240 units). It is shown empirically that the effect of capacity utilization on energy efficiency varies strongly across different platforms. 
Baumers, M., C. Tuck, R. Wildman, I. Ashcroft, E. Rosamond, and R. Hague. 2012. "Combined Buildtime, Energy Consumption and Cost Estimation for Direct Metal Laser Sintering." In 23rd Annual International Solid Freeform Fabrication Symposium-An Additive Manufacturing Conference, Austin/TX/USA, 6th-8th August.

As a single-step process, Additive Manufacturing (AM) affords full measurability with respect to process energy inputs and production cost. However, the parallel character of AM (allowing the contemporaneous production of multiple parts) poses a number of problems for the estimation of resource consumption. A novel combined estimator of build-time, energy consumption and production cost is presented for the EOSINT M270 Direct Metal Laser Sintering system. It is demonstrated that the quantity and variety of parts demanded and the resulting ability to utilize the available machine capacity impact process efficiency, both in energy and in financial terms.

Baumers, Martin, Chris Tuck, Ricky Wildman, Ian Ashcroft, Emma Rosamond, and Richard Hague. 2013. "Transparency Built-in Energy Consumption and Cost Estimation for Additive Manufacturing." Journal of Industrial Ecology 17 (3): 418-31. doi:10.1111/j.1530-9290.2012.00512.x.

The supply chains found in modern manufacturing are often complex and long. The resulting opacity poses a significant barrier to the measurement and minimization of energy consumption and therefore to the implementation of sustainable manufacturing. The current article investigates whether the adoption of additive manufacturing (AM) technology can be used to reach transparency in terms of energy and financial inputs to manufacturing operations. AM refers to the use of a group of electricitydriven technologies capable of combining materials to manufacture geometrically complex products in a single digitally controlled process step, entirely without molds, dies, or other tooling. The single-step nature affords full measurability with respect to process energy inputs and production costs. However, the parallel character of AM (allowing the contemporaneous production of multiple parts) poses previously unconsidered problems in the estimation of manufacturing resource consumption. This research discusses the implementation of a tool for the estimation of process energy flows and costs occurring in the AM technology variant direct metal laser sintering. It is demonstrated that accurate predictions can be made for the production of a basket of sample parts. Further, it is shown that, unlike conventional processes, the quantity and variety of parts demanded and the resulting ability to fully utilize the available machine capacity have an impact on process efficiency. It is also demonstrated that cost minimization in additive manufacturing may lead to the minimization of process energy consumption, thereby motivating sustainability improvements.

Behdani, Behzad, Zofia Lukszo, Arief Adhitya, and Rajagopalan Srinivasan. 2009. "Agent-Based Modeling to Support Operations Management in a Multi-Plant Enterprise." In Proceedings of the 2009 IEEE International Conference on Networking, Sensing and Control, Okayama, Japan, March 26-29, 2009, 323-28. Okayama, Japan: IEEE.

A global industrial enterprise is a complex network of different distributed production plants producing, handling, and distributing specific products. Agent-based modeling is a proven approach for modeling complex networks of intelligent and distributed actors. In this paper we will demonstrate how an agent-based model can be used to evaluate the dynamic behavior of a global enterprise, considering both the system-level performance as well as the components' behavior. Such quantitative model can be very useful for predicting the effects of local and operational activities on plant performance and improving the tactical and strategic decisionmaking at the enterprise level. 
Byun, Hong S., and Kwan H. Lee. 2006. "Determination of Optimal Build Direction in Rapid Prototyping with Variable Slicing." The International Journal of Advanced Manufacturing Technology 28 (3-4): 307-13. doi:10.1007/s00170-004-2355-5.

Several important factors must be taken into consideration in order to maximize the efficiency of rapid prototyping $(R P)$ processes. The ability to select the optimal orientation of the build direction is one of the most critical factors in using RP processes, since it affects part quality, build time, and part cost. This study aims to determine the optimal build-up direction when a part is built with the variable layer thickness for different RP systems. The average weighted surface roughness (AWSR) that is generated from the stair stepping effect, the build time, and the part cost using the variable layer thickness are all considered in the process. Using the multi-attribute decision-making method, the best orientation is determined among the orientation candidates chosen from the convex hull of a model. The validity of the algorithm is illustrated by an example. The algorithm can help RP users select the best build-up direction of the part and create an efficient process planning.

Campbell, I., J. Combrinck, D. De Beer, and L. Barnard. 2008. “Stereolithography Build Time Estimation Based on Volumetric Calculations. Rapid Prototyping Journal. 14(5): 271-279.

Purpose - Not all the inventors and designers have access to computer-aided design (CAD) software to transform their design or invention into a $3 D$ solid model. Therefore, they cannot submit an STL file to a rapid prototyping $(R P)$ service bureau for a quotation but perhaps only a $2 D$ sketch or drawing. This paper proposes an alternative approach to build time estimation that will enable cost quotations to be issued before $3 D C A D$ has been used.

Design/methodology/approach - The study presents a method of calculating build time estimations within a target error limit of 10 per cent of the actual build time of a prototype. This is achieved by using basic volumetric shapes, such as cylinders and cones, added together to represent the model in the $2 D$ sketch. By using this information the build time of the product is then calculated with the aid of models created in a mathematical solving software package.

Findings - The development of the build time estimator and its application to several build platforms are described together with an analysis of its performance in comparison with the benchmark software. The estimator was found to meet its target 10 per cent error limit in 80 per cent of the stereolithography builds that were analysed.

Research limitations/implications - The estimator method was not able to handle multicomponent complex parts builds in a timely manner. There is a trade-off between accuracy and processing time.

Practical implications - The output from the estimator can be fed directly into cost quotations to be sent to RP bureau customers at a very early stage in the design process.

Originality/value - Unlike all the other build estimators that were encountered, this method works directly from a $2 D$ sketch or drawing rather than a $3 D C A D$ file.

Chapman, Robert. "Benefits and Costs of Research: A Case Study of Construction Systems Integration and Automation Technologies in Commercial Buildings." NISTIR 6763. December 2001. National Institute of Standards and Technology.

This report focuses on a critical analysis of the economic impacts of past, ongoing, and planned research of the NIST Building and Fire Research Laboratory (BFRL) construction systems integration and automation technologies (CONSIAT) program. The CONSIAT program is an interdisciplinary 
research effort within BFRL - in collaboration with the Construction Industry Institute, the private sector, other federal agencies, and other laboratories within NIST - to develop key enabling technologies, standard communication protocols, and advanced measurement technologies needed to deliver fully-integrated and automated project process (FIAPP) products and services to the construction industry. The results of this analysis demonstrate that the use of FIAPP products and services will generate substantial cost savings to the owners and managers of commercial buildings and a contractors engaged in the construction of those buildings. The present value of savings nationwide expected from the use of FIAPP products and services is nearly $\$ 1.4$ billion (measured in 1997 dollars). Furthermore, because of BFRL's involvement, FIAPP products and services are expected to be commercially available in 2005. If BFRL had not participated in the development of FIAPP products and services, the commercial introduction of FIAPP products and services is expected to be delayed until 2009. Consequently, potential cost savings accruing to commercial building owners and managers and to contractors over the period 2005 through 2008 would have been foregone. The present value of these cost savings is approximately $\$ 120$ million. These cost savings measure the value of BFRL's contribution for its CONSIAT-related investment costs of approximately \$29.1 million. Stated in present value terms, every public dollar invested in BFRL'S CONSIAT-related research, development, and deployment effort is expected to generate $\$ 4.13$ in cost savings to the public.

Chen, Calvin C., and Paul A. Sullivan. 1996. "Predicting Total Build-Time and the Resultant Cure Depth of the 3D Stereolithography Process." Rapid Prototyping Journal 2 (4): 27-40. doi:10.1108/13552549610153389.

Accurate build-time prediction for making stereolithography parts not only benefits the service industry with information necessary for correct pricing and effective job scheduling, it also provides researchers with valuable information for various build parameter studies. Instead of the conventional methods of predicting build time based on the part's volume and surface, the present predictor uses the detailed scan and recoat information from the actual build files by incorporating the algorithms derived from a detailed study of the laser scan mechanism of the stereolithography machine. Finds that the scan velocity generated from the stereolithography machine depends primarily on the system's laser power, beam diameter, materials properties and the user's specification of cure depth. Proves that this velocity is independent of the direction the laser travels, and does not depend on the total number of segments of the scan path. In addition, the time required for the laser to jump from one spot to another without scan is linearly proportional to the total jump distance, and can be calculated by a proposed constant velocity. Most profoundly, the present investigation concludes that the machine uses a velocity factor which is only 68.5 per cent of the theoretical calculation. This much slower velocity results in an undesired amount of additional cure and proves to be the main cause of the $Z$ dimensional inaccuracy. The present build-time predictor was developed by taking into account all the factors stated above, and its accuracy was further verified by comparing the actual build-time observed for many jobs over a six month period.

Choi, S. H, and S Samavedam. 2002. "Modelling and Optimisation of Rapid Prototyping." Computers in Industry 47 (1): 39-53. doi:10.1016/S0166-3615(01)00140-

3.

This paper proposes a Virtual Reality (VR) system for modelling and optimisation of Rapid Prototyping (RP) processes. The system aims to reduce the manufacturing risks of prototypes early in a product development cycle, and hence, reduces the number of costly design-build-test cycles. It involves modelling and simulation of RP in a virtual system, which facilitates visualisation and testing the effects of process parameters on the part quality. Modelling of RP is based on quantifying the measures of part quality, which includes accuracy, build-time and efficiency with orientation, layer thickness and hatch distance. A mathematical model has been developed to estimate the build-time of the Selective Laser Sintering (SLS) process. The model incorporates various process parameters like layer thickness, hatch space, bed temperatures, laser power and sinter factor, etc. It has been integrated with the virtual simulation system to provide a test-bed to optimise the process parameters. 
Di Angelo, Luca, and Paolo Di Stefano. 2011. "A Neural Network-Based Build Time Estimator for Layer Manufactured Objects." International Journal of Advanced Manufacturing Technology 57 (1-4): 215-24. doi:10.1007/s00170-011-3284-8.

A correct prediction of build time is essential to calculate the accurate cost of a layer manufactured object. The methods presented in literature are of two types: detailed-analysis- and parametric-based approaches. The former require that a lot of data, related to the kinematic and dynamic performance of the machine, should be known. Parametric models, on the other hand, are of general use and relatively simple to implement; however, the parametric methods presented in literature only provide a few of the components of the total build time. Therefore, their performances are not properly suited in any case. In order to overcome these limitations, this paper proposes a parametric approach which uses a more complete set of build-time driving factors. Furthermore, considering the complexity of the parametric build time function, an artificial neural network is used so as to improve the method flexibility. The analysis of the test cases shows that the proposed approach provides a quite accurate estimation of build time even in critical cases and when supports are required.

Diegel, Olaf, Sarat Singamneni, Stephen Reay, and Andrew Withell. 2010. "Tools for Sustainable Product Design: Additive Manufacturing." Journal of Sustainable Development 3 (3).

The advent of additive manufacturing technologies presents a number of opportunities that have the potential to greatly benefit designers, and contribute to the sustainability of products. Additive manufacturing technologies have removed many of the manufacturing restrictions that may previously have compromised a designer's ability to make the product they imagined. Products can also be extensively customized to the user thus, once again, potentially increasing their desirability, pleasure and attachment and therefore their longevity. As additive manufacturing technologies evolve, and more new materials become available, and multiple material technologies are further developed, the field of product design has the potential to greatly change. This paper examines how aspects of additive manufacturing, from a sustainable design perspective, could become a useful tool in the arsenal to bring about the sustainable design of consumer products.

Dietrich, David M., and Elizabeth Cudney. 2011. "Impact of Integrative Design on Additive Manufacturing Quality." International Journal of Rapid Manufacturing 2 (3): 121-31.

To move additive manufacturing (AM) into a realm of credible manufacturing, quality evaluation techniques must be established to highlight the potential gains of AM technologies in the field of production quality in terms of dimensional control. This research aims to express the relationship among AM-enabled integrative design and quality evaluation techniques. The methodology proposed is backed by a comprehensive literature review that covers AM dimensional quality and conventional quality assessment techniques for production. The research proposes modelling the positive impact of integrating design using Taguchi's quality loss function $(Q L F)$ and tolerance stack-up models. In addition, the research provides a straightforward way to evaluate AM-enabled integrated designs that promotes the proliferation of AM technology as a sustainable and credible manufacturing method. A case study is presented that describes how to apply Taguchi?s QLF to AM integrated designs.

Direct Manufacturing Research Center. "Project CoA ${ }^{2}$ MPLy: Costing Analysis for Additive Manufacturing (AM) during Product Lifecycle."

Abstract unavailable.

Doubrovski, Zjenja, Jouke C. Verlinden, and Jo MP Geraedts. 2011. “Optimal Design for Additive Manufacturing: Opportunities and Challenges." In Proceedings of the ASME 
2011 International Design Engineering Technical Conferences \& Computers and Information in Engineering Conference IDETC/CIE 2011 August 29-31, 2011, Washington, DC, USA, 635-46. Washington, DC, USA: American Society of Mechanical Engineers.

Additive Manufacturing (AM) represents a maturing collection of production technologies also known as rapid prototyping, rapid manufacturing and three-dimensional printing. One of the most promising aspects of AM is the possibility to create highly complex geometries. Despite a growing body of knowledge concerning the technological challenges, there is a lack of methods that allow designers to effectively deal with the new possibilities.

This article presents a literature survey on the impact that AM can have on design. The survey was focused on the new opportunities of fabrication processes, the relationship between structure and performance, and optimization approaches. We applied Olsen's three-link chain model to relate product structure with performance, linked by strength, stiffness, compliance, dynamic, thermal, and visual properties. We also use this model to base our proposed Design for Additive Manufacturing (DfAM) method.

The findings show that there is a growing body of knowledge in the field of design for AM (DfAM), yet only considers a subset of properties. Furthermore, the knowledge on materials, computational optimization, computer aided design, and behavioral simulation embody separated domains and related software support. This is in contrast with design engineering, which requires a holistic approach to conceptualize new products.

Economist. Feb 18th 2010 "Printing Body Parts: Making a Bit of Me." <http://www.economist.com/node/15543683>

Abstract unavailable

Fogliatto, Flavio S, and Giovani J. C Da Silveira. 2011. Mass Customization Engineering and Managing Global Operations. London: Springer.

The analysis and implementation of mass customization (MC) systems has received growing consideration by researchers and practitioners since the late 1980s. In this paper we update the literature review on MC presented in a previous paper (Da Silveira, G., Borenstein, D., Fogliatto, F.S., 2001. Mass customization: literature review and research directions. International Journal of Production Economics, 72 (1), 1-13), and identify research gaps to be investigated in the future. Major areas of research in $M C$, and journals in which works have been published are explored through summary statistics. The result is a concise compendium of the relevant literature produced on the topic in the past decade.

Fogliatto, Flavio S., Giovani J. C. da Silveira, and Denis Borenstein. 2012. "The Mass Customization Decade: An Updated Review of the Literature." International Journal of Production Economics 138 (1): 14-25. doi:10.1016/j.ijpe.2012.03.002.

Mass customization (MC) has been hailed as a successful operations strategy across manufacturing and service industries for the past three decades. However, the wider implications of using MC approaches in the broader industrial and economic environment are not yet clearly understood. Mass Customization: Engineering and Managing Global Operations presents emerging research on the role of MC and personalization in today's international operations context. The chapters cover MC in the context of global industrial economics and operations. Moreover, the book discusses MC topics that are relevant. 
Giannatsis, J, V Dedoussis, and L Laios. 2001. "A Study of the Build-Time Estimation

Problem for Stereolithography Systems." Robotics and Computer-Integrated

Manufacturing 17 (4): 295-304. doi:10.1016/S0736-5845(01)00007-2.

In this paper the problem of build-time estimation for Stereolithography systems is examined. Experimental results from various case studies indicate that the accuracy of estimation greatly depends on the type of part geometry representation processed and the uncontrolled laser power fluctuations. It is shown that estimation based on sliced (CLI) representation can be extremely accurate, assuming that the average laser power during fabrication can be predicted. On the other hand, estimations based on tessellated (STL) representation, although not so accurate, satisfy the accuracy requirements imposed at early stages of the Stereolithography process, where no slice data are available. As part of this study, build-time itself is also analyzed and factors affecting it are identified and investigated experimentally. Results indicate that hatching time depends not only on the hatching distance and speed, as originally assumed, but also on the number of hatching vectors employed.

Gibson, Ian, David W. Rosen, and Brent Stucker. 2010. Additive Manufacturing Technologies. Springer.

\begin{abstract}
Additive Manufacturing Technologies: Rapid Prototyping to Direct Digital Manufacturing deals with various aspects of joining materials to form parts. Additive Manufacturing (AM) is an automated technique for direct conversion of $3 D$ CAD data into physical objects using a variety of approaches. Manufacturers have been using these technologies in order to reduce development cycle times and get their products to the market quicker, more cost effectively, and with added value due to the incorporation of customizable features. Realizing the potential of AM applications, a large number of processes have been developed allowing the use of various materials ranging from plastics to metals for product development. Authors Ian Gibson, David W. Rosen and Brent Stucker explain these issues, as well as:
\end{abstract}

-Providing a comprehensive overview of AM technologies plus descriptions of support technologies like software systems and post-processing approaches

-Discussing the wide variety of new and emerging applications like micro-scale AM, medical applications, direct write electronics and Direct Digital Manufacturing of end-use components

-Introducing systematic solutions for process selection and design for AM

Additive Manufacturing Technologies: Rapid Prototyping to Direct Digital Manufacturing is the perfect book for researchers, students, practicing engineers, entrepreneurs, and manufacturing industry professionals interested in additive manufacturing.

T. A. Grimm \& Associates, Inc. 2010. 3D Printer Benchmark: North American Edition. Edgewood, KY: T. A. Grimm \& Associates, Inc.

Abstract unavailable 
Hasan, S., and A.E.W. Rennie. 2008. "The Application of Rapid Manufacturing Technologies in the Spare Parts Industry." In 19th Annual International Solid Freeform Fabrication Symposium-An Additive Manufacturing Conference, Austin/TX/USA, 4th6th August. Austin, TX.

The advancement of Rapid Manufacturing (RM) has ushered the possibility of realising complex designs. This paper identifies the potential of possible applications of RM in the spare parts industry. It further underlines the need for a fully functional RM supply chain before proposing an e-business enabled business model for RM technologies.

Holmström, Jan, and Jouni Partanen. 2014. "Digital Manufacturing-Driven Transformations of Service Supply Chains for Complex Products.” Supply Chain Management: An International Journal 19 (4): 421 - 430.

\begin{abstract}
Purpose - The purpose of this paper is to explore the forms that combinations of digital manufacturing, logistics and equipment use are likely to take and how these novel combinations may affect the relationship among logistics service providers (LSPs), users and manufacturers of equipment.
\end{abstract}

Design/methodology/approach - Brian Arthur's theory of combinatorial technological evolution is applied to examine possible digital manufacturing-driven transformations. The F-18 Super Hornet is used as an illustrative example of a service supply chain for a complex product.

Findings - The introduction of digital manufacturing will likely result in hybrid solutions, combining conventional logistics, digital manufacturing and user operations. Direct benefits can be identified in the forms of life cycle extension and the increased availability of parts in challenging locations. Furthermore, there are also opportunities for both equipment manufacturers and LSPs to adopt new roles, thereby supporting the efficient and sustainable use of digital manufacturing.

Research limitations/implications - The phenomenon of digital manufacturing-driven transformations of service supply chains for complex product does not yet fully exist in the real world, and its study requires cross-disciplinary collaboration. Thus, the implication for research is to use a design science approach for early-stage explorative research on the form and function of novel combinations.

Practical implications - Digital manufacturing as a general-purpose technology gives LSPs an opportunity to consolidate demand from initial users and incrementally deploy capacity closer to new users. Reengineering the products that a manufacture currently uses is needed to increase the utilization of digital manufacturing.

Originality/value - The authors outline a typology of digital manufacturing-driven transformations and identify propositions to be explored in further research and practice.

Holmström, Jan, Jouni Partanen, Jukka Tuomi, and Manfred Walter. 2010. "Rapid Manufacturing in the Spare Parts Supply Chain: Alternative Approaches to Capacity Deployment." Journal of Manufacturing Technology Management 21 (6): 687-97. doi:10.1108/17410381011063996.

Purpose - The purpose of this paper is to describe and evaluate the potential approaches to introduce rapid manufacturing (RM) in the spare parts supply chain. 
Design/methodology/approach - Alternative conceptual designs for deploying RM technology in the spare parts supply chain were proposed. The potential benefits are illustrated for the aircraft industry. The general feasibility was discussed based on literature.

Findings - The potential supply chain benefits in terms of simultaneously improved service and reduced inventory makes the distributed deployment of RM very interesting for spare parts supply. However, considering the trade-offs affecting deployment it is proposed that most feasible is centralized deployment by original equipment manufacturers (OEMs), or deployment close to the point of use by generalist service providers of RM.

Research limitations/implications - The limited part range that is currently possible to produce using the technology means that a RM-based service supply chain is feasible only in very particular situations.

Practical implications - OEMs should include the consideration of RM in their long-term service supply chain development.

Originality/value - The paper identifies two distinct approaches for deploying RM in the spare parts supply chain.

Hopkinson, Neil. 2006. "Production Economics of Rapid Manufacture." In Rapid Manufacturing: An Industrial Revolution for the Digital Age, 147-57.

Abstract unavailable

Hopkinson, Neil, and P. Dickens. 2003. "Analysis of Rapid Manufacturing-using Layer Manufacturing Processes for Production.” Proceedings of the Institution of Mechanical Engineers, Part C: Journal of Mechanical Engineering Science 217 (1): 31-39.

Rapid prototyping $(R P)$ technologies that have emerged over the last 15 years are all based on the principle of creating three-dimensional geometries directly from computer aided design (CAD) by stacking two-dimensional profiles on top of each other. To date most RP parts are used for prototyping or tooling purposes; however, in future the majority may be produced as end-use products. The term 'rapid manufacturing' in this context uses RP technologies as processes for the production of end-use products.

This paper reports findings from a cost analysis that was performed to compare a traditional manufacturing route (injection moulding) with layer manufacturing processes (stereolithography, fused deposition modelling and laser sintering) in terms of the unit cost for parts made in various quantities. The results show that, for some geometries, it is more economical to use layer manufacturing methods than it is to use traditional approaches for production in the thousands.

Hopkinson, Neil, Richard Hague, and Philip Dickens, eds. 2006. Rapid Manufacturing: An Industrial Revolution for the Digital Age. John Wiley \& Sons.

Rapid Manufacturing is a new area of manufacturing developed from a family of technologies known as Rapid Prototyping. These processes have already had the effect of both improving products and reducing their development time; this in turn resulted in the development of the technology of Rapid Tooling, which implemented Rapid Prototyping techniques to improve its own processes. Rapid Manufacturing has developed as the next stage, in which the need for tooling is eliminated. It has been shown that it is economically feasible to use existing commercial Rapid Prototyping systems to manufacture series parts in quantities of up to 20,000 and customised parts in quantities of hundreds 
of thousands. This form of manufacturing can be incredibly cost-effective and the process is far more flexible than conventional manufacturing.

Rapid Manufacturing: An Industrial Revolution for the Digital Age addresses the academic fundamentals of Rapid Manufacturing as well as focussing on case studies and applications across a wide range of industry sectors. As a technology that allows manufacturers to create products without tools, it enables previously impossible geometries to be made. This book is abundant with images depicting the fantastic array of products that are now being commercially manufactured using these technologies.

-Includes contributions from leading researchers working at the forefront of industry.

-Features detailed illustrations throughout.

Rapid Manufacturing: An Industrial Revolution for the Digital Age is a groundbreaking text that provides excellent coverage of this fast emerging industry. It will interest manufacturing industry practitioners in research and development, product design and materials science, as well as having a theoretical appeal to researchers and post-graduate students in manufacturing engineering, product design, CAD/CAM and CIFM.

Huang, Samuel H., Peng Liu, Abhiram Mokasdar, and Liang Hou. 2013. "Additive Manufacturing and Its Societal Impact: A Literature Review." The International Journal of Advanced Manufacturing Technology 67 (5-8): 1191-1203. doi:10.1007/s00170-0124558-5.

Thirty years into its development, additive manufacturing has become a mainstream manufacturing process. Additive manufacturing build up parts by adding materials one layer at a time based on a computerized 3D solid model. It does not require the use of fixtures, cutting tools, coolants, and other auxiliary resources. It allows design optimization and the producing of customized parts on-demand. Its advantages over conventional manufacturing have captivated the imagination of the public, reflected in recent mainstream publications that call additive manufacturing "the third industrial revolution." This paper reviews the societal impact of additive manufacturing from a technical perspective. Abundance of evidences were found to support the promises of additive manufacturing in the following areas: (1) customized healthcare products to improve population health and quality of life, (2) reduced environmental impact for manufacturing sustainability, and (3) simplified supply chain to increase efficiency and responsiveness in demand fulfillment. In the mean time, the review also identified the need for further research in the areas of life-cycle energy consumption evaluation and potential occupation hazard assessment for additive manufacturing.

Igoe, Tom, and Catarina Mota. 2011. "A Strategist's Guide to Digital Fabrication." Strategy+Business, no. 64 (Autumn): 1-10.

Rapid advances in manufacturing technology point the way toward a decentralized, more customercentric "maker" culture. Here are the changes to consider before this innovation takes hold.

Kechagias, John, Stergios Maropoulos, and Stefanos Karagiannis. 2004. "Process BuildTime Estimator Algorithm for Laminated Object Manufacturing." Rapid Prototyping Journal 10 (5): 297-304. doi:10.1108/13552540410562331.

A method for estimating the build-time required by the laminated object manufacturing (LOM) process is presented in this paper. The proposed algorithm - taking into account the real process parameters and the information included in the part's STL-file-performs a minimum manipulation of the file, and calculates total volume, total surface area and flat areas involved in fine cross-hatching. A number of experiments performed verify the applicability of the algorithm in process build-time estimation. The 
time prediction estimates are within 7.6 per cent of the real build-times for the LOM process. It is believed that, through specific minor adjustments, the algorithm could well be employed in process build-time estimation for similar rapid prototyping processes.

Kellens, K., E. Yasa, Renaldi, W. Dewulf, JP Kruth, and J.R. Duflou. 2011. “Analyzing Product Lifecycle Costs for a Better Understanding of Cost Drivers in Additive Manufacturing." In 22nd Annual International Solid Freeform Fabrication SymposiumAn Additive Manufacturing Conference, Austin/TX/USA, 8th-10th August. Austin, TX.

\begin{abstract}
Manufacturing processes, as used for discrete part manufacturing, are responsible for a substantial part of the environmental impact of products, but are still poorly documented in terms of their environmental footprint. The lack of thorough analysis of manufacturing processes has as consequence that optimization opportunities are often not recognized and that improved machine tool design in terms of ecological footprint has only been targeted for a few common processes.
\end{abstract}

Additive manufacturing processes such as Selective Laser Sintering (SLS) and Selective Laser Melting (SLM) allow near-net shape manufacturing of complex work pieces. Consequently, they inherently offer opportunities for minimum-waste and sustainable manufacturing. Nevertheless, powder production, energy consumption as well as powder losses are important and not always optimized environmental impact drivers of SLS and SLM. This paper presents the results of a data collection effort, allowing to assess the overall environmental impact of these processes using the methodology of the CO2PE! (Cooperative Effort on Process Emissions in Manufacturing) initiative.

Based on the collected LCI data, a subsequent impact assessment analysis allows indentifying the most important contributors to the environmental impact of SLS/SLM. Next to the electricity consumption, the consumption of inert gasses proves to be an important cause of environmental impact. Finally, the paper sketches the improvement potential for SLS/SLM on machine tool as well as system level.

Kellens, Karel, Wim Dewulf, Wim Deprez, Evren Yasa, and Joost Duflou. 2010. "Environmental Analysis of SLM and SLS Manufacturing Processes." In Proceedings of LCE2010 Conference, 423-28. Hefei, China.

\footnotetext{
Manufacturing processes, as used for discrete part manufacturing, are responsible for a substantial part of the environmental impact of products, but are still poorly documented in terms of environmental footprint. In this paper, first a short description is offered about the CO2PE! - Initiative and the methodology used to analyse manufacturing unit processes. In a second part, the energy and resource flows inventorisation and impact assessment of some sample products made by Selective Laser Melting (SLM) and Selective Laser Sintering (SLS) processes are performed.
}

Kellens, Karel, Wim Dewulf, Michael Overcash, Michael Z. Hauschild, and Joost R. Duflou. 2012. "Methodology for Systematic Analysis and Improvement of Manufacturing Unit Process Life-Cycle Inventory (UPLCI) - CO2PE! Initiative (cooperative Effort on Process Emissions in Manufacturing). Part 1: Methodology Description." The International Journal of Life Cycle Assessment 17 (1): 69-78. doi:10.1007/s11367-011-0340-4.

Purpose This report proposes a life-cycle analysis (LCA)-oriented methodology for systematic inventory analysis of the use phase of manufacturing unit processes providing unit process datasets to be used in life-cycle inventory (LCI) databases and libraries. The methodology has been developed in the framework of the CO2PE! collaborative research programme (CO2PE! 2011a) and comprises two approaches with different levels of detail, respectively referred to as the screening approach and the in-depth approach. 
Methods The screening approach relies on representative, publicly available data and engineering calculations for energy use, material loss, and identification of variables for improvement, while the in-depth approach is subdivided into four modules, including a time study, a power consumption study, a consumables study and an emissions study, in which all relevant process in-and outputs are measured and analysed in detail. The screening approach provides the first insight in the unit process and results in a set of approximate LCI data, which also serve to guide the more detailed and complete in-depth approach leading to more accurate LCI data as well as the identification of potential for energy and resource efficiency improvements of the manufacturing unit process. To ensure optimal reproducibility and applicability, documentation guidelines for data and metadata are included in both approaches. Guidance on definition of functional unit and reference flow as well as on determination of system boundaries specifies the generic goal and scope definition requirements according to ISO 14040 (2006) and ISO 14044 (2006).

Results The proposed methodology aims at ensuring solid foundations for the provision of high-quality LCI data for the use phase of manufacturing unit processes. Envisaged usage encompasses the provision of high-quality data for LCA studies of products using these unit process datasets for the manufacturing processes, as well as the in-depth analysis of individual manufacturing unit processes.

Conclusions In addition, the accruing availability of data for a range of similar machines (same process, different suppliers and machine capacities) will allow the establishment of parametric emission and resource use estimation models for a more streamlined LCA of products including reliable manufacturing process data. Both approaches have already provided useful results in some initial case studies (Kellens et al. 2009; Duflou et al. (Int J Sustain Manufacturing 2:80-98, 2010); Santos et al. (J Clean Prod 19:356-364, 2011); UPLCI 2011; Kellens et al. 2011a) and the use will be illustrated by two case studies in Part 2 of this paper (Kellens et al. 2011b).

\section{Khajavi, Siavash H., Jouni Partanen, and Jan Holmström. 2014. "Additive Manufacturing in the Spare Parts Supply Chain." Computers in Industry 65 (1): 50-63.}

As additive manufacturing (AM) evolves to become a common method of producing final parts, further study of this computer integrated technology is necessary. The purpose of this research is to evaluate the potential impact of additive manufacturing improvements on the configuration of spare parts supply chains. This goal has been accomplished through scenario modeling of a real-life spare parts supply chain in the aeronautics industry. The spare parts supply chain of the F-18 Super Hornet fighter jet was selected as the case study because the air-cooling ducts of the environmental control system are produced using AM technology. In total, four scenarios are investigated that vary the supply chain configurations and additive manufacturing machine specifications. The reference scenario is based on the spare parts supplier's current practice and the possible future decentralization of production and likely improvements in AM technology. Total operating cost, including downtime cost, is used to compare the scenarios. We found that using current AM technology, centralized production is clearly the preferable supply chain configuration in the case example. However, distributed spare parts production becomes practical as AM machines become less capital intensive, more autonomous and offer shorter production cycles. This investigation provides guidance for the development of additive manufacturing machines and their possible deployment in spare parts supply chains. This study contributes to the emerging literature on AM deployment in supply chains with a real-world case setting and scenario model illustrating the cost trade-offs and critical requirements for technology development.

\section{Kim, Bowon. "Supply Chain Management: A Learning Perspective.” Korea Advanced Institute of Science and Technology. Coursera Lecture 1-2.}

As a human being, we all consume products and/or services all the time. This morning you got up and ate your breakfast, e.g., eggs, milk, bread, fresh fruits, and the like. After the breakfast, you drove your car to work or school. At your office, you used your computer, perhaps equipped with 27 " LCD monitor. During your break, you drank a cup of coffee and played with your iPhone. So on and so 
forth. You probably take it for granted that you can enjoy all of these products. But if you take a closer look at how each of these products can be made and eventually delivered to you, you will realize that each one of these is no short of miracle. For example, which fruit do you like? Consider fresh strawberries. In order for the strawberries to be on your breakfast table, there must be numerous functions, activities, transactions, and people involved in planting, cultivating, delivering, and consuming strawberries. Moreover, all of these functions, activities, transactions, and people are connected as an integral chain, through which physical products like strawberries themselves and virtual elements such as information and communication flow back and forth constantly. By grouping related functions or activities, we have a supply chain, comprised of four primary functions such as supplier, manufacturer, distributor, and finally consumer. A supply chain is essentially a value chain.

For the society or economy as a whole, the goal is to maximize value, i.e., to create satisfactory value without spending too much. In order to create the maximum value for the strawberry supply chain, every participant in the chain must carry out its function efficiently. In addition, all of the members must coordinate with each other effectively in order to ensure value maximization. We have to face the same issues for almost all the products and services we take for granted in our everyday life, e.g., cars, hamburgers, haircuts, surgeries, movies, banks, restaurants, and you name it!

In this course, we want to understand fundamental principles of value creation for the consumers or the market. We try to answer questions like how the product or service is made, how the value-creating activities or functions are coordinated, who should play what leadership roles in realizing all these, and so on. As our course title hints, we approach all of these issues from a learning perspective, which is dynamic in nature and emphasizes long-term capability building rather than short-term symptomatic problem solving.

Kim, Bowon and Chulsoon Park. (2013). "Firms' Integrating Efforts to Mitigate the Tradeoff Between Controllability and Flexibility." International Journal of Production Research. 51(4): 1258-1278.
We consider three manufacturing capabilities: controllability, flexibility, and integrating capability. Controllability is a firm's ability to control its process to enhance efficiency and accuracy and to better meet specifications. Flexibility is a firm's ability to cope with uncertainty and variation, both internal and external. Integrating capability is a firm's ability to integrate and coordinate diverse functions and parts of its supply chain, embodied in overall operations effectiveness and new product innovation. We put forth two hypotheses. First, there is an inherent tradeoff between controllability and flexibility. Second, a firm's integrating effort across its supply chain enables it to overcome such a tradeoff, making it possible to improve both controllability and flexibility simultaneously. Using data from 193 manufacturing companies, we test our hypotheses. It turns out that the relationship between controllability and flexibility is convex-shaped, indicating there are two distinct regions: one in which the relationship is negative and the other, positive. Further, the firms in the positive relationship region make significantly more effort to integrate, that is to say coordinate and communicate, across their supply chains, implying that as the firm strives to integrate its supply chain functions, it can mitigate the tradeoff between controllability and flexibility to a considerable extent.

Kruth, Jean-Pierre, Ben Vandenbroucke, van J. Vaerenbergh, and Peter Mercelis. 2005. "Benchmarking of Different SLS/SLM Processes as Rapid Manufacturing Techniques." In Int. Conf. Polymers and Moulds Innovations (PMI), Gent, Belgium, April 20-23, 2005. Gent, Belgium.

Recently, a shift of Rapid Prototyping (RP) to Rapid Manufacturing (RM) has come up because of technical improvements of Layer Manufacturing processes. Selective Laser Sintering (SLS) and Selective Laser Melting (SLM) techniques are no longer exclusively used for prototyping and the possibility to process all kind of metals yields opportunities to manufacture real functional parts, e.g., injection moulds (Rapid Tooling). 
This study examines different SLS/SLM processes with regard to conditions that become very important for manufacturing, speed and reliability. A benchmark model is developed facilitating to test these conditions and to check the process limitations. This benchmark is manufactured by five SLS/SLM machines which differ in process mechanism, powder material and optimal process parameters. To find out process accuracy, a dimensional analysis is performed and the surface roughness is measured. Besides, the benchmarks are tested for their mechanical properties such as density, hardness, strength and stiffness. Finally, speed and repeatability are discussed as important factors for manufacturing.

This paper presents the state of the art in SLS/SLM and aims at understanding the limitations of different SLS/SLM processes to form a picture of the potential manufacturing applications of these processes.

\section{Li, Fang. 2006. "Automated Cost Estimation for 3-Axis CNC Milling and Stereolithography Rapid Phototyping." http://mspace.lib.umanitoba.ca/jspui/handle/1993/8882.}

Rapid prototyping $(R P)$ is a supplementary additive manufacturing method to the traditional Computer Numerical Controlled (CNC) machining. The selection of the manufacturing method between RP and CNC machining is currently based on qualitative analysis and engineers' experience. There are situations when parts can be produced using either of the methods. In such cases, cost will be the decisive factor. However, lack of a quantitative cost estimation method to guide the selection between $R P$ and CNC machining makes the decision process difficult. This thesis proposes an automated cost estimator for CNC machining and Rapid Prototyping. Vertical CNC milling and Stereolithography Apparatus (SLA) RP technology are selected in specific, for cost modeling and process comparison. A binary questionnaire is designed to help estimate the CNC setup cost. An SLA build time estimator is implemented based on 3D systems' SLA3500 machine. SLA post processing cost is also investigated. Based on the developed methods, a prototype software tool was created with an output to Excel chart to facilitate the selection. Five cases have been studied with the software and the predicted results are found reasonable and effective.

Lindemann, C., U. Jahnke, M. Moi, and R. Koch. 2012. "Analyzing Product Lifecycle Costs for a Better Understanding of Cost Drivers in Additive Manufacturing." In 23rd Annual International Solid Freeform Fabrication Symposium-An Additive Manufacturing Conference, Austin/TX/USA, 6th-8th August. Austin, TX.

The costs of additive manufactured parts often seem too high in comparison to those of traditionally manufactured parts, as the information about major cost drivers, especially for additive manufactured metal parts, is weak. Therefore, a lifecycle analysis of additive manufactured parts is needed to understand and rate the cost drivers that act as the largest contributors to unit costs, and to provide a focus for future cost reduction activities for the Additive Manufacturing (AM) technology. A better understanding of the cost structure will help to compare the AM costs with the opportunity costs of the classical manufacturing technologies and will make it easier to justify the use of AM manufactured parts. This paper will present work in progress and methodology based on a sample investigated with business process analysis / simulation and activity based costing. In addition, cost drivers associated with metal AM process will be rated. 
Lindemann, C., U. Jahnke, M. Moi, and R. Koch. 2013. "Impact and Influence Factors of Additive Manufacturing on Product Lifecycle Costs." In 24th Annual International Solid Freeform Fabrication Symposium-An Additive Manufacturing Conference, Austin/TX/USA. Austin, TX.

At first sight the direct costs of Additive Manufacturing (AM) seem too high in comparison to traditional manufacturing. Considering the whole lifecycle costs of parts changes the point of view. Due to the modification of the new production process and new supply chains during a parts lifecycle, producing companies can strongly benefit from AM. Therefore, a costing model for assessing lifecycle costs with regard to specific applications and branches has been developed. The costing model represents the advantages of AM monetary. For the evaluation of this model and the influence factors, different case studies have been performed including different approaches in part redesign. Deeper research is and will be carried out with respect to the AM building rates and the comparability of various AM machines, as these facts are hardly comparable for end users. This paper will present the methodology as well as the results of the case studies conducted over the whole product lifecycle.

Luo, Yanchun, Zhiming Ji, M.C. Leu, and R. Caudill. 1999. "Environmental Performance Analysis of Solid Freedom Fabrication Processes." In Proceedings of the 1999 IEEE International Symposium on Electronics and the Environment, 1999. ISEE -1999, 1-6. doi:10.1109/ISEE.1999.765837.

This paper presents a method for analyzing the environmental performance of solid freeform fabrication $(S F F)$ processes. In this method, each process is divided into life phases. Environmental effects of every process phase are then analyzed and evaluated based on the environmental and resource management data. These effects are combined to obtain the environmental performance of the process. The analysis of the environmental performance of SFF processes considers the characteristics of SFF technology, includes material, energy consumption, processes wastes, and disposal. Case studies for three typical SFF processes: stereolithography (SL); selective laser sintering (SLS); and fused deposition modeling (FDM) are presented to illustrate this method

Munguia, Javier, Joaquim de Ciurana, and Carles Riba. 2009 "Neural-Network-Based Model for Build-Time Estimation in Selective Laser Sintering." Proceedings of the Institution of Mechanical Engineers. Part B, Journal of Engineering Manufacture. 223(8): 995-1003.

Cost assessment for rapid manufacturing (RM) is highly dependent on time estimation. Total build time dictates most indirect costs for a given part, such as labour, machine, costs, and overheads. A numberof parametric and empirical time estimators exist; however, they normally account for error rates between 20 and 35 per cent which are then translated to inaccurate final cost estimations. The estimator presented herein is based on the ability of artificial neural networds (ANNs) to learn and adapt to different cases, so that the developed model is capable of providing accurate estimates regardless of machine type or model. A simulation is performed with MATLAB to compare existing approaches for cost/time estimation for selective laser sintering (SLS). Error rates observed from the model range from 2 to 15 per cent, which shows the validity and robustness of the proposed method.

Mansfield, Edwin. Innovation, Technology and the Economy: Selected Essays of Edwin Mansfield. Economists of the Twentieth Century Series (Brookfield, VT: 1995, E. Elgar).

This text brings together selected essays of Edwin Mansfield, who has been engaged for almost 40 years in the economics of technical change, a field of importance for analysts and decision-makers. This text presents a quantitative analysis based largely on data collection from firms and other economic units. These essays, which include some of the most frequently cited studies in the field, are concerned with the process of industrial innovation, the nature, composition and effects of industrial 
research and development, the relationships between technical change, economic growth and inflation, the diffusion of innovations, international technology transfer, public policy toward civilian technology, and intellectual property protection. These topics are central to many current debates among both economic theorists and policy makers.

\title{
Mehrsai, Afshin, Hamid Reza Karimi, and Klaus-Dieter Thoben. 2013. "Integration of Supply Networks for Customization with Modularity in Cloud and Make-to-Upgrade Strategy." Systems Science \& Control Engineering 1 (1): 28-42. doi:10.1080/21642583.2013.817959.
}

\begin{abstract}
Today, integration of supply networks (SNs) out of heterogeneous entities is quite challenging for industries. Individualized demands are getting continuously higher values in the global business and this fact forces traditional businesses for restructuring their organizations. In order to contribute to new performances in manufacturing networks, in this paper a collaborative approach is recommended out of modularity structure, cloud computing, and make-to-upgrade concept for improving flexibility as well as coordination of entities in networks. A cloud-based framework for inbound and outbound manufacturing is introduced for complying with the production of individualized products in the turbulent global market, with local decision-makings and integrated performances. Additionally, the complementary aspects of these techniques with new features of products are conceptually highlighted. The compatibility of this wide range of theoretical concepts and practical techniques is explained here. A discrete-event simulation out of an exemplary cloud-based SN is set up to define the applicability of the cloud and the recommended strategy.
\end{abstract}

\section{Minetola, Paolo. 2012. "The Importance of a Correct Alignment in Contactless Inspection of Additive Manufactured Parts." International Journal of Precision Engineering and Manufacturing 13 (2): 211-18. doi:10.1007/s12541-012-0026-2.}

\begin{abstract}
Nowadays products having complex freeform custom-made shapes can he fabricated without any tool by means of additive manufacturing processes. Additive manufactured parts must be inspected for quality to verify, that they meet dimensional and geometrical specifications among other requirements just as any other product. Contactless inspection carried out with optical $3 D$ scanners is preferred to traditional pointwise measurements because of the higher amount of data retrieved in short times. A key step of the contactless inspection process is the definition of the part reference frame for the alignment of scan data. This paper considers different 3-2-1 alignments and analyze their influence on the inspection results, putting in evidence that an inattentive or inaccurate definition of the part reference frame can lead to incorrect evaluations of real part deviations.
\end{abstract}

\section{Mognol, Pascal, Denis Lepicart, and Nicolas Perry. 2006. "Rapid Prototyping: Energy and Environment in the Spotlight." Rapid Prototyping Journal 12 (1): 26-34. doi: $10.1108 / 13552540610637246$.}

Purpose - To discuss integration of the rapid prototyping environmental aspects with the primary focus on electrical energy consumption.

Design/methodology/approach - Various manufacturing parameters have been tested on three rapid prototyping systems: Thermojet (3DS), FDM 3000 (Stratasys) and EOSINT M250 Xtended (EOS). The objective is to select sets of parameters for reduction of electrical energy consumption. For this, a part is manufactured in several orientations and positions in the chamber of these RP systems. For each test, the electrical power is noted. Finally, certain rules are proposed to minimize this electrical energy consumption during a job.

Findings - It is important to minimize the manufacturing time but there is no general rule for optimization of electrical energy consumption. Each RP system must be tested with energy consumption considerations under the spotlight. 
Research limitations/implications - The work is only based on rapid prototyping processes. The objective is to take into consideration the complete life-cycle of a rapid prototyped part: manufacturing of raw material as far as reprocessing of waste.

Practical implications - Reduction of electrical energy consumption to complete a job.

Originality/value - Currently, environmental aspects are not well studied in rapid prototyping.

Morrow, W.R., H. Qi, I. Kim, J. Mazumder, and S.J. Skerlos. 2007. "Environmental Aspects of Laser-Based and Conventional Tool and Die Manufacturing." Journal of Cleaner Production 15 (10): 932-43. doi:10.1016/j.jclepro.2005.11.030.

Solid Freeform Fabrication (SFF) technologies such as Direct Metal Deposition (DMD) have made it possible to eliminate environmentally polluting supply chain activities in the tooling industry and to repair and remanufacture valuable tools and dies. In this article, we investigate three case studies to reveal the extent to which DMD-based manufacturing of molds and dies can currently achieve reduced environmental emissions and energy consumption relative to conventional manufacturing pathways. It is shown that DMD's greatest opportunity to reduce the environmental impact of tool and die manufacturing will come from its ability to enable remanufacturing. Laser-based remanufacturing of tooling is shown to reduce cost and environmental impact simultaneously, especially as the scale of the tool increases.

Moylan, Shawn, John Slotwinski, April Cooke, Kevin Jurrens, and M. Alkan Donmex. 2013. Lessons Learned in Establishing the NIST Metal Additive Manufacturing Laboratory. NIST Technical Note 1801. Gaithersburg, MD: U.S. Dept. of Commerce, National Institute of Standards and Technology.

This publication presents a summary of lessons learned by NIST staff during establishment of the NIST Metal Additive Manufacturing Laboratory and implementation of the metal additive manufacturing capability at NIST. These lessons learned resulted from the first implementation of a metal additive manufacturing system at NIST. While the NIST experiences were with a particular metal additive manufacturing system, we believe that these lessons are relevant and have common aspects for implementing other types of metal additive manufacturing systems. The intention is that this summary document will help others to implement metal additive manufacturing capabilities in their facilities. The NIST implementation spanned several months before the system was brought fully online, including facility preparation, system installation, operator training, standard procedure development, and initial experimental use. NIST staff members have been operating the machine for research purposes since early 2011. Parts have been built using metal powders of one stainless steel and one Cobalt-Chrome alloy. These lessons learned address room requirements, safety concerns, machine operation, materials and process parameters, build design file preparation and support structures, design guidelines, and post-processing of manufactured parts.

Munguía, J., J. Ciurana, and C. Riba. 2009. "Neural-Network-Based Model for BuildTime Estimation in Selective Laser Sintering." Proceedings of the Institution of Mechanical Engineers, Part B: Journal of Engineering Manufacture 223 (8): 995-1003.

Cost assessment for rapid manufacturing (RM) is highly dependent on time estimation. Total build time dictates most indirect costs for a given part, such as labour, machine costs, and overheads. A number of parametric and empirical time estimators exist; however, they normally account for error rates between 20 and 35 per cent which are then translated to inaccurate final cost estimations. The estimator presented herein is based on the ability of artificial neural networks (ANNs) to learn and adapt to different cases, so that the developed model is capable of providing accurate estimates regardless of machine type or model. A simulation is performed with MATLAB to compare existing 
approaches for cost/time estimation for selective laser sintering (SLS). Error rates observed from the model range from 2 to 15 per cent, which shows the validity and robustness of the proposed method.

Neef, Andreas, Klaus Burmeister, Stefan Krempl. 2005. Vom Personal Computer zum Personal Fabricator (From Personal Computer to Personal Fabricator). Hamburg: Murmann Verlag.

Abstract unavailable

Paul, Ratnadeep, and Sam Anand. 2012. "Process Energy Analysis and Optimization in Selective Laser Sintering." Journal of Manufacturing Systems 31 (4): 429-37. doi:10.1016/j.jmsy.2012.07.004.

Additive manufacturing (AM) processes are increasingly being used to manufacture complex precision parts for the automotive, aerospace and medical industries. One of the popular AM processes is the selective laser sintering (SLS) process which manufactures parts by sintering metallic, polymeric and ceramic powder under the effect of laser power. The laser energy expenditure of SLS process and its correlation to the geometry of the manufactured part and the SLS process parameters, however, have not received much attention from AM/SLS researchers. This paper presents a mathematical analysis of the laser energy required for manufacturing simple parts using the SLS process. The total energy expended is calculated as a function of the total area of sintering (TAS) using a convex hull based approach and is correlated to the part geometry, slice thickness and the build orientation. The TAS and laser energy are calculated for three sample parts and the results are provided in the paper. Finally, an optimization model is presented which computes the minimal TAS and energy required for manufacturing a part using the SLS process.

Quick, Darren. 2009. “3D Bio-Printer to Create Arteries and Organs.” Gizmag. http://www.gizmag.com/3d-bio-printer/13609/.

Abstract unavailable

\section{Reeves, Philip. 2007. "Rapid manufacturing-Business Implementation \& Global Economic Value”. Econolyst Ltd, UK.}

Much has been written about the benefits of additive layer manufacturing for the production of end use part otherwise known as Rapid Manufacturing (RM), as an alternative to moulding or machining or in the manufacture of increasing complex geometries. Other additive manufacturing benefits have also been discussed in the fields of materials science and mass personalisation. This paper looks beyond the scientific and physical benefits of additive manufacturing into the more practical implications of implementing RM into the main stream production environment.

The paper starts by discussing the current position of RM within the global manufacturing economy. The paper then discusses the development of a simple iterative stage methodology for RM, which can be implemented by businesses based on a six step approach. It is suggested that this could then accelerate companies through the technology selection, justification and implementation of RM, either through technology purchase or the establishment of dedicated RM supply chains.

The paper is the result of the author's engagement in both academic research projects as an industrial partner, and through experience implementing RM technologies into both end use companies and European regional technology centres. 
Reeves Philip. (2008) "How the Socioeconomic Benefits of Rapid Manufacturing can Offset Technological Limitations.” RAPID 2008 Conference and Exposition. Lake Buena Vista, FL: 1-12.

Abstract unavailable

Reeves, Philip. 2009. “Additive Manufacturing-A Supply Chain Wide Response to Economic Uncertainty and Environmental Sustainability." Econolyst Limited, The Silversmiths, Crown Yard, Wirksworth, Derbyshire, DE4 4ET, UK.

In this paper the author will review some of the current commercial applications of Additive Layer Manufacturing (ALM) and the business benefits associated with technology adoption. The paper will review applications such as Rapid Tooling, where ALM processes are being used to make fully dense tool cavity inserts with highly efficient heating and cooling channels. This approach has been proven to have clear down-stream economic benefits within the supply chain, resulting in reduced cycle times, improved moulding quality and a lower carbon footprint.

The paper will also address how ALM is being used as a sustainable alternative to subtractive machining in the production of high buy-to-fly ratio parts, and how different Design-ForManufacturing (DFM) rules associated with ALM, are being exploited to manufacture lighter weight, energy efficient products with less raw material. The paper concludes with a look into the future, possibly into a 'tool-less' society, where consumer products are printed to order, using the consumers own design data as-and-when they are needed, using either a globally distributed just-in-time supply chain or inversely manufacture within the consumers own home.

Rickenbacher, L., A. Spierings, and K. Wegener. 2013. "An Integrated Cost-Model for Selective Laser Melting (SLM).” Rapid Prototyping Journal 19 (3): 208-14.

\footnotetext{
Purpose - The integration of additive manufacturing (AM) processes into a production environment requires a cost-model that allows the precise estimation of the total cost per part, although the part might be produced in the same build job together with other parts of different sizes, complexities and quantities. Several cost-models have been proposed in the past, but most of them are not able to calculate the costs for each single part in a mixed build job or are not suitable for Selective Laser Melting (SLM). The purpose of this paper is to develop a cost model, including all pre-and postprocessing steps linked to SLM.
}

Design/methodology/approach - Based on collected data and the generic cost model of Alexander et al., an adapted model was developed for the SLM process including all required pre-and postprocesses. Each process was analysed and modelled in detail, allowing an evaluation of the influences of the different geometries on the cost of each part.

Findings - By simultaneously building up multiple parts, the manufacturing as well as the set-up time and therefore the total cost per part can be significantly reduced. In the presented case study a cost reduction of 41 per cent can be achieved in average.

Originality/value - Using different cost allocation algorithms, the developed cost model enables a precise determination of total cost per part avoiding that any geometry is preferred in simultaneous manufacture. This helps to optimize build jobs and to manufacture SLM parts more economically by pooling parts from different projects, whereas the cost per part can still be precisely determined.

Ruffo, M., and R. Hague. 2007. “Cost Estimation for Rapid Manufacturing-Simultaneous Production of Mixed Components Using Laser Sintering." Proceedings of the Institution 
of Mechanical Engineers, Part B: Journal of Engineering Manufacture 221 (11): 158591.

Rapid manufacturing (RM) is a production method able to build components by adding material layer by layer, and it thus allows the elimination of tooling from the production chain. For this reason, RM enables a cost-efficient production of low-volume components favouring the customization strategy. Previous work has been developed on costing methodologies applicable to RM, but it was limited to the scenario of the production of copies of the same part. In reality, RM enables the production of different components simultaneously, and thus a smart mix of components in the same machine can achieve an enhanced cost reduction. This paper details this concept by proposing mathematical models for the assignment of the full production cost into each single product and by validating through a case study. This paper extends previous work on RM costing by adding the scenario of simultaneous production of different parts.

Ruffo, M., C. Tuck, and R. Hague. 2006a. "Cost Estimation for Rapid ManufacturingLaser Sintering Production for Low to Medium Volumes.” Proceedings of the Institution of Mechanical Engineers, Part B: Journal of Engineering Manufacture 220 (9): 1417-27.

Rapid manufacturing (RM) is a modern production method based on layer by layer manufacturing directly from a three-dimensional computer-aided design model. The lack of tooling makes RM economically suitable for low and medium production volumes. A comparison with traditional manufacturing processes is important; in particular, cost comparison. Cost is usually the key point for decision making, with break-even points for different manufacturing technologies being the dominant information for decision makers. Cost models used for traditional production methodologies focus on material and labour costs, while modern automated manufacturing processes need cost models that are able to consider the high impact of investments and overheads. Previous work on laser sintering costing was developed in 2003. This current work presents advances and discussions on the limits of the previous work through direct comparison. A new cost model for laser sintering is then proposed. The model leads to graph profiles that are typical for layer-manufacturing processes. The evolution of cost models and the indirect cost significance in modern costing representation is shown finally.

Ruffo, M., C. Tuck, and R. Hague. 2006b. "Empirical Laser Sintering Time Estimator for Duraform PA.” International Journal of Production Research 44 (23): 5131-46.

The paper presents work on the development of a build-time estimator for rapid manufacturing. A time estimator is required to develop a comprehensive costing tool for rapid manufacturing. An empirical method was used to estimate build times using both simulated and actual builds for a laser sintering machine. The estimator presented herein is based upon object geometry and, therefore, the fundamental data driving the model are obtainable from current three-dimensional computer-aided design models. The aim is to define a model describing the build times for a laser sintering machine either for single or multiple objects.

Ruffo, M., C. Tuck, and R. Hague. 2007. "Make or Buy Analysis for Rapid Manufacturing." Rapid Prototyping Journal 13 (1): 23-29.

Purpose - The purpose of this paper is to outline how rapid manufacturing $(R M)$ could influence the decision-making process for managers involved in make or buy decisions.

Design/methodology/approach - A literature review on make or buy issues has been carried out and the results of which have been distilled into a number of qualitative considerations. These considerations have been formed into three possible make or buy scenarios: the firm has no experience of rapid prototyping (RP) or RM; the firm already has an RP department; and the firm already has an $R M$ function. In order to analyse the decision further a quantitative approach has been taken, mainly adapted to the last scenario but applicable also to the second scenario. Here, manufacturing cost data 
has been directly compared with price information from two current RP bureaus. The differences between RM cost and RP price have been studied.

Findings - Strategically, the points analysed were in favour of the make option. Economically, the lack of dedicated RM bureaus and the consequent use of RP costing has further pushed the make or buy decision in favour of make.

Originality/value - There is a lack of work on the implementation of RM as a mainstream manufacturing process. Existing knowledge has begun to look at the use and costs of RM, however, this paper highlights the lack of dedicated RM providers.

\title{
Senyana, Lionel Nduwayezu. 2011. "Environmental Impact Comparison of Distributed and Centralized Manufacturing Scenarios". Rochester Institute of Technology.
}

\begin{abstract}
Centralized manufacturing and distributed manufacturing are two fundamentally different methods for producing components. This work describes a centralized manufacturing scenario in which parts are produced via forging and finish machining at one central location and are then shipped to the end user. The distributed manufacturing model involves a scenario in which an additive manufacturing process (Electron Beam Melting) is used to produce parts to near net shape with minimal finish machining. Because the process doesn't require molds or dies, production can take place in small production quantities "on demand" at job shops located close to the end user with little transportation. In other words, parts are not produced until they are needed. This is in stark contrast to the centralized model where large quantities of parts are produced and then distributed at a later date when needed from warehouses. The aim of this thesis is to compare the environmental impact of these two different production approaches under a variety of conditions. The SimaPro software package has been used to model both approaches with input from the user involving part size, amount of finish machining, transportation distances, mode of transportation, production quantities, etc. Results from simulation models indicate that at small production quantities, the environmental impact of forging die production dominates the centralized manufacturing model. As production quantity increases, finish machining begins to dominate the environmental impact. Despite the large transportation distances involved, the transportation distance and mode of transportation actually have relatively little impact on overall environmental impact compared with other factors. Regardless of the production scenario being evaluated, the distributed manufacturing approach had less environmental impact. The production of titanium powder as the raw material contributed the majority of environmental impact for this approach. Although this work examines environmental impact, it does not consider the cost of producing a part. It should be pointed out, however, that the distributed manufacturing approach could someday have a profound effect on supply chain management for replacement parts by reducing or eliminating the need for warehouses along with associated inventory carrying costs, product obsolescence costs, heating and cooling energy, etc.
\end{abstract}

Sreenivasan, R., and D.L. Bourell. 2009. "Sustainability Study in Selective Laser Sintering - An Energy Perspective." In 20th Annual International Solid Freeform Fabrication Symposium-An Additive Manufacturing Conference, Austin/TX/USA, 3rd5th August. Austin, TX.

This paper presents a sustainability analysis of Selective Laser Sintering (SLS) from an energy standpoint. Data of electrical power consumed by the system over an entire build were acquired using a LabVIEW 8.6 circuit. The power drawn by individual subsystems were also measured, and an energy balance was performed. These data were then used to arrive at a Total Energy Indicator of the process with the help of a specific type of Environmental and Resource Management Data (ERMD) known as Eco-Indicators, which indicates the level of sustainability of the process. 
Sreenivasan, R., A. Goel, and D.L. Bourell. 2010. "Sustainability Issues in Laser-Based Additive Manufacturing." Physics Procedia 5 (January): 81-90.

doi:10.1016/j.phpro.2010.08.124.

Sustainability is a consideration of resource utilization without depletion or adverse environmental impact. In manufacturing, important sustainability issues include energy consumption, waste generation, water usage and the environmental impact of the manufactured part in service. This paper deals with three aspects of sustainability as it applies to additive manufacturing. First is a review of the research needs for energy and sustainability as applied to additive manufacturing based on the 2009 Roadmap for Additive Manufacturing Workshop. The second part is an energy assessment for selective laser sintering (SLS) of polymers. Using polyamide powder in a $3 D$ Systems Vanguard HiQ Sinterstation, energy loss during a build was measured due to the chamber heaters, the roller mechanism, the piston elevators and the laser. This accounted for $95 \%$ of the total energy consumption. An overall energy assessment was accomplished using eco-indicators. The last topic is electrochemical deposition of porous SLS non-polymeric preforms. The goal is to reduce energy consumption in SLS of non-polymeric materials. The approach was to mix a transient binder with the material, to create an SLS green part, to convert the binder, and then to remove the open, connected porosity and to densify the part by chemical deposition at room temperature within the pore network. The model system was silicon carbide powder mixed with a phenolic transient binder coupled with electrolytic deposition of nickel. Deposition was facilitated by inserting a conductive graphite cathode in the part center to draw the positive nickel ions through the interconnected porous network and to deposit them on the pore walls.

Stoneman, Paul. The Economics of Technological Diffusion. 2002. Oxford: Blackwell.

This book presents a detailed overview of the economics of technological diffusion in all its various dimensions. Topics covered include:

- Game-theoretic approaches to the modelling of technological change

- Finance and technological change

- Technological change in international trade.

Telenko, Cassandra, and Carolyn Conner Seepersad. 2010. "Assessing Energy Requirements and Material Flows of Selective Laser Sintering of Nylon Parts." In 21st Annual International Solid Freeform Fabrication Symposium-An Additive Manufacturing Conference, Austin/TX/USA, 6th-8th August, 8-10. Austin, TX.

Selective laser sintering (SLS) is a prominent technology for rapid manufacturing (RM) of functional parts. SLS and competitive RM technologies are generally assumed to be more environmentally sustainable than conventional manufacturing methods because the additive process minimizes tooling, material waste, and chemical fluids. A thorough life cycle analysis (LCA) of the environmental impacts of SLS has yet to be published. This study focuses on a section of the SLS part life-cycle. It tracks the nylon powder material flows from the extraction and synthesis of the material to SLS part production. Basic material properties and environmental effects are reported. Estimates of material waste and energy use are also reported and compared with those of injection molding.

Telenko, Cassandra, and Carolyn Conner Seepersad. 2011. “A Comparative Evaluation of Energy Consumption of Selective Laser Sintering and Injection Molding of Nylon Parts." Rapid Prototyping J 18: 472-81.

Additive manufacturing is often advocated as a sustainable alternative to competing manufacturing technologies. This research study focuses on estimating and comparing the energy consumption required for different production volumes of nylon parts using either selective laser sintering (SLS) or injection molding (IM). For IM \& SLS, energy consumption is estimated for nylon material refinement 
and part fabrication. For IM, energy consumption is also estimated for manufacturing the injection molds and refining their metal feedstock. A paintball gun handle serves as a representative part for calculating and normalizing material flows and processing times. For different sets of assumptions, cross-over production volumes are calculated, at which the per-part energy consumption of the two processes is equivalent. These energy-based cross-over production volumes are compared to similar economic cross-over production volumes available in the literature.

Telenko, Cassandra, and Carolyn Conner Seepersad. 2012. "A Comparison of the Energy Efficiency of Selective Laser Sintering and Injection Molding of Nylon Parts." Rapid Prototyping Journal 18 (6): 472-81.

Purpose - The purpose of this paper is to evaluate the energy consumed to fabricate nylon parts using selective laser sintering (SLS) and to compare it with the energy consumed for injection molding (IM) the same parts.

Design/methodology/approach - Estimates of energy consumption include the energy consumed for nylon material refinement, adjusted for SLS and IM process yields. Estimates also include the energy consumed by the SLS and IM equipment for part fabrication and the energy consumed to machine the injection mold and refine the metal feedstock required to fabricate it. A representative part is used to size the injection mold and to quantify throughput for the SLS machine per build.

Findings - Although SLS uses significantly more energy than IM during part fabrication, this energy consumption is partially offset by the energy consumption associated with production of the injection mold. As a result, the energy consumed per part for IM decreases with the number of parts fabricated while the energy consumed per part for SLS remains relatively constant as long as builds are packed efficiently. The crossover production volume, at which IM and SLS consume equivalent amounts of energy per part, ranges from 50 to 300 representative parts, depending on the choice of mold plate material.

Research limitations/implications - The research is limited to material refinement and part fabrication and does not consider other aspects of the life cycle, such as waste disposal, distributed 2 manufacturing, transportation, recycling or use. Also, the crossover volumes are specific to the representative part and are expected to vary with part geometry.

Originality/value - The results of this comparative study of SLS and IM energy consumption indicate that manufacturers can save energy using SLS for parts with small production volumes. The comparatively large amounts of nylon material waste and energy consumption during fabrication make it inefficient, from an energy perspective, to use SLS for higher production volumes. The crossover production volume depends on the geometry of the part and the choice of material for the mold.

\section{Thomas, Douglas. 2013. Economics of the U.S. Additive Manufacturing Industry. NIST Special Publication 1163. Gaithersburg, MD: U.S. Dept. of Commerce, National Institute of Standards and Technology.}

There is a general concern that the U.S. manufacturing industry has lost competitiveness with other nations. Additive manufacturing may provide an important opportunity for advancing U.S. manufacturing while maintaining and advancing U.S. innovation. Additive manufacturing is a relatively new process where material is joined together layer by layer to make objects from threedimensional models as opposed to conventional methods where material is removed. The U.S. is currently a major user of additive manufacturing technology and the primary producer of additive manufacturing systems. Globally, an estimated $\$ 642.6$ million in revenue was collected for additive manufactured goods, with the U.S. accounting for an estimated $\$ 246.1$ million or $38.3 \%$ of global production in 2011. Change agents for the additive manufacturing industry can focus their efforts on 
three primary areas to advance this technology: cost reduction, accelerating the realization of benefits, and increasing the benefits of additive manufacturing. Significant impact on these areas may be achieved through reduction in the cost of additive manufacturing system utilization, material costs, and facilitating the production of large products. There is also a need for a standardized model for cost categorization and product quality and reliability testing.

Tuck, Christopher, Richard Hague, and Neil Burns. 2007. "Rapid Manufacturing: Impact on Supply Chain Methodologies and Practice." International Journal of Services and Operations Management 3 (1): 1-22.

This paper demonstrates the use of Rapid Manufacturing (RM) as the enabling technology for flexible manufacturing in a number of industrial sectors. This paper discusses the evolution of Rapid Prototyping $(R P)$ to $R M$ and the current issues that require further research for the successful integration of this technology within manufacturing companies. The use of RM will have particular impact on supply chain management paradigms such as lean and agile and has particular strategic fit with mass customisation. The effect of RM will have on these paradigms is discussed and confirmed with example cases from automotive production, motor sport and medical devices industries. In conclusion, RM has already been shown in the three cases to offer benefits, particularly where fast reconfiguration of the manufacturing process is required and with the production of customised components.

University of San Francisco. Walmart: Keys to Successful Supply Chain Management. $<$ http://www.usanfranonline.com/resources/supply-chain-management/walmart-keys-tosuccessful-supply-chain-management/\#.U5IDQfldXzg>

Abstract unavailable

Vasquez, Mike. 2009. "Economic and Technological Advantages of Using High Speed Sintering as a Rapid Manufacturing Alternative in Footwear Applications". Massachusetts Institute of Technology.

Rapid manufacturing is a family of technologies that employ additive layer deposition techniques to construct parts from computer based design models.[2] These parts can then be used as prototypes or finished goods. One type of rapid manufacturing technology, Selective Laser Sintering, only allows for a point-by-point sintering process to construct the $3 D$ representations of CAD models. This makes for long processing periods and is ineffective for high volume manufacturing. However, a new process called high-speed sintering uses infrared energy to 'flash' the polymer powder at multiple points making the layer deposition process much more time efficient. In effect each infusion of energy results in an entire layer being constructed rather than a single point. One of the first industrial applications for this technique is in performance footwear manufacturing. New Balance, a Boston based shoe and apparel company, in collaboration with Loughborough University has an interest in exploring the technology for low volume parts manufacturing as well as personalized footwear. High speed sintering has the potential to replace injection molding for specific footwear and non-footwear applications. This technology has several key advantages over injection molding including the ability to build complex geometries that would be impossible with injection molding. Also as the technology continues to evolve new materials could improve the mechanical performance of finished parts. Nevertheless, as with commercializing any new technology identifying a cost effective implementation route is a pivotal step.(cont.) This project addressed this concern by thoroughly investigating the current and potential state of high speed sintering. The manufacture of a New Balance shoe part using both high speed sintering and injection molding was directly compared. Several factors including time to manufacture and cost were investigated. 
Verma, Anoop, and Rahul Rai. 2013. "Energy Efficient Modeling and Optimization of Additive Manufacturing Processes." In 24th Annual International Solid Freeform Fabrication Symposium-An Additive Manufacturing Conference, Austin/TX/USA. Austin, TX.
Additive manufacturing (AM) is a leading technology in various industries including medical and aerospace for prototype and functional part fabrication. Despite being environmentally conscious, avenues pertaining to further reducing the impact of AM on the environment exist. Material wastage and energy consumption are two major concerns of the process that requires immediate attention. In this research, a multi-step optimization enabling additive manufacturing process towards energy efficiency is developed. Process objectives such as material waste and energy consumption are minimized both in part and layer domain. Numerous examples are presented to demonstrate the applicability of the developed approach. The models formulated here for selective laser sintering (SLS) process can be easily extended to other additive manufacturing technologies.

Walter, Manfred, Jan Holmström, H. Tuomi, and H. Yrjölä. 2004. "Rapid Manufacturing and Its Impact on Supply Chain Management." In Proceedings of the Logistics Research Network Annual Conference, 9-10.

\begin{abstract}
Suppliers of spare parts suffer from high inventory and distribution costs in many industries. Original Equipment Manufacturers (OEMs) have attempted to reduce these supply chain costs by cutting production lead-times, batch constraints and delivery lead-times. The emphasis in supply chain management has been towards increased inventory turnover.
\end{abstract}

Today, rapid manufacturing technologies - the ability to produce parts on demand without the need for tooling and setup - has the potential to become the basis for new solutions in supply chain management. This paper presents new supply chain solutions made possible by both the centralised and decentralised applications of rapid manufacturing. A decision-support model is outlined to help supply chain managers better capture emergent business opportunities arising from rapid manufacturing technology.

The logistical problems of the spare parts business in the aircraft industry are used as an example due to the high technical and logistical requirements involved. The applications and benefits of rapid manufacturing technologies in the supply chain for aircraft spare parts are presented.

Wohlers, Terry. "Wohlers Report 2012: Additive Manufacturing and 3D Printing State of the Industry." Wohlers Associates, Inc. 2012.

Abstract unavailable.

Wohlers, Terry. "Wohlers Report 2014: Additive Manufacturing and 3D Printing State of the Industry." Wohlers Associates, Inc. 2014.

Abstract unavailable.

Young, Son K. “A Cost Estimation Model for Advanced Manufacturing Systems.” International Journal of Production Research. 1991. 29(3): 441-452.

As manufacturers continue to automate their factories, they discover that existing cost measures should be updated. Much of the existing literature has discussed the 'why's' but there is little about the 'how's'. This paper expands the cost concept to include quality and flexibility because they are critical factors for performance evaluation and project justification of advanced manufacturing systems. Then, 
a quantitative method of estimating the cost elements is illustrated. Finally, various approaches to collecting parametric values of the cost model and applications of the cost model are presented.

\title{
Zhai, Yun. 2012. "Early Cost Estimation for Additive Manufacture". Cranfield University.
}

\begin{abstract}
Additive Manufacture (AM) is a novel manufacturing method; it is a process of forming components by adding materials. Owing to material saving and manufacturing cost saving, more and more research has been focused on metal AM technologies. WAAM is one AM technology, using arc as the heat sources and wire as the material to create parts with weld beads on a layer-by-layer basis. The process can produce components in a wide range of materials, including aluminum, titanium and steel. High deposition rate, material saving and elimination of tooling cost are critical characteristics of the process. Cost estimation is important for all companies. The estimated results can be used as a datum to create a quote for customers or evaluate a quote from suppliers, an important consideration for the application of WAAM is its cost effectiveness compared with traditional manufacture methods. The aim of this research is to find a way to develop a cost estimating method capable of providing manufacturing cost comparison of WAAM with CNC. A cost estimation model for CNC machining has been developed. A process planning approach for WAAM was also defined as part of this research. An Excel calculation spreadsheet was also built and it can be easily used to estimate and compare manufacture cost of WAAM with CNC. Using the method developed in this research, the cost driver analysis of WAAM has been made. The result shows that reduced material cost is the biggest cost driver in WAAM. The cost comparison of WAAM and CNC also has been made and the results show that with the increase of buy-to-fly ratio WAAM is more economical than CNC machining.
\end{abstract}

\section{Zhang, Y, and A Bernard. 2014. "Generic Build Time Estimation Model for Parts Produced by SLS." In High Value Manufacturing: Advanced Research in Virtual and Rapid Prototyping: Proceedings of the 6th International Conference on Advanced Research in Virtual and Rapid Prototyping, Leiria, Portugal, 1-5 October, 2013.}

\footnotetext{
Rapid Prototyping (RP) has evolved into Additive Manufacturing (AM) and plays an important role in numerous application domains. Cost and lead time of AM become significant factors affecting the comparison between AM and other traditional processes. The accuracy of build time estimation directly affects the cost estimation for AM production. This paper introduces an analytical method to build time estimation for parts, which takes real AM production context that was usually neglected by former models into consideration. To illustrate the proposed method, an analytical generic build time estimation model is constructed for SLS process with a simple calculation example. The results reflect the importance of production context for the build time estimation.
} 